\title{
5. UNDERWAY GEOPHYSICAL MEASUREMENTS: GLOMAR CHALLENGER LEGS 45 AND 46
}

\author{
Philip D. Rabinowitz, ${ }^{1}$ James R. Heirtzler, ${ }^{2}$ Thomas D. Aitken, ${ }^{1}$ and G. M. Purdy ${ }^{2}$
}

We present here the navigation and underway geophysical measurements (magnetics, bathymetry, and seismic profiling) obtained aboard Glomar Challenger during Legs 45 and 46 . On both legs the ship left San Juan, Puerto Rico, and proceeded to sites on either side of the Mid-Atlantic Ridge crest on an approximate flow line near $23^{\circ} \mathrm{N}$. The ship's track for Leg 45, which began at San Juan on 30 November 1975 and ended at San Juan on 20 January 1976, is shown in Figure 1. The ship's tracks for Leg 46, which began at San Juan on 28 January 1976 and ended at Las Palmas, Canary Islands, on 9 March 1976, are given in Figures 2 and 3. Dates and times for the first navigational fix of the day, progressive distance in hundreds of nautical miles along the ship's track, and site numbers are noted. Tables 1 and 2 list the positioning information for Legs 45 and 46, respectively, acquired underway by the satellite navigation system and used to plot the ship's tracks. Errors are generally less than 1 nautical mile (Talwani et al., 1966). Also listed in Tables 1 and 2 are the regional magnetic field values, computed at each navigation point using the reference field of Fabiano and Peddie (1969), and used to determine the magnetic anomaly profiles in Figures $4,5,6 \mathrm{a}$ to $6 \mathrm{~d}$, and $7 \mathrm{a}$ to $7 \mathrm{~d}$.

Magnetic anomalies, plotted normal to the ship's tracks from San Juan to Site 396, are given for Legs 45 and 46 in Figure 4. The zero level for the magnetic anomalies has been arbitrarily adjusted to avoid confusion and also to clarify the shorter wavelength positivenegative anomaly trends. Magnetic anomalies, plotted normal to the ship's track from Site 396 to Las Palmas for Leg 46, are given in Figure 5. In this diagram, the ship's track is the zero magnetic anomaly level. It has not been adjusted as in Figure 4 . The three closely spaced tracks in Figure 4 allow us to identify some key sea-floor-spreading magnetic anomalies. The anomalies are identified according to the numbering system of Heirtzler et al. (1968) and LaBrecque et al. (1977). The anomaly identifications are aided by the larger data base given in Pitman and Talwani (1972). Since we have only one ship track line from Site 396 to Las Palmas, we feel it may be misleading to place anomaly identifications on the magnetic profile. The reader is referred to Pitman and Talwani (1972), Hayes and

\footnotetext{
'Lamont-Doherty Geological Observatory of Columbia University.

${ }^{2}$ Woods Hole Oceanographic Institution, Woods Hole, Massachusetts.
}

Rabinowitz (1975), and Uchupi et al. (1976) for anomaly identifications in the eastern central Atlantic Ocean. Note the long wavelength (1000 to $1500 \mathrm{~km})$ magnetic high observed east of $28^{\circ} \mathrm{W}$ and long wavelength magnetic low observed west of $28^{\circ} \mathrm{W}$ in Figure 5 . These long wavelength anomalies are discussed in Uchupi et al. (1976).

Figures $6 \mathrm{a}$ to $6 \mathrm{~d}$ and $7 \mathrm{a}$ to $7 \mathrm{~d}$ show magnetic anomaly and bathymetric data plotted as functions of time, distance, latitude, and longitude, with the distance plotted as a linear function. The data processing procedure, including program listings, is given in Talwani (1969). The vertical scales show depth in uncorrected fathoms (assuming a sound speed of $800 \mathrm{fm} /$ $\mathrm{sec}$ ) under " $\mathrm{D}$ " and magnetic anomaly values in gammas under "M." On the lowermost scale at the bottom of the figure, distances are shown at intervals of 200 nautical miles. In addition, tick marks shown above the distance scale indicate the distance at which any change in course or speed occurred. The corresponding course and speed between changes and the coordinates at the points of change are noted above the distance scale listings. Navigational changes, which occur too frequently to be shown in the space available, or minor adjustments in course or speed, are indicated only by tick marks. At the top of the figures, from top to bottom, are shown time in days, time in hours, latitude in degrees, and longitude in degrees.

Seismic reflection profile records for Legs 45 and 46 are given in Figures 8-1 to 8-18 and 9-1 to 9-27, respectively. These data were recorded on dry-paper EDO recorders and in general were obtained using two airguns ( 20 and $40 \mathrm{in}^{3}$ firing chambers) as a sound source. Depths are labeled on the sides of the records in two-way reflection time ( $1 \mathrm{sec}=400 \mathrm{fm}$ water depth). Times and dates are listed on the bottom of the records to key into the navigation plots (Figures 1 to 3 ) and listings (Tables 1 and 2).

For detailed descriptions of the geophysical measurements in the vicinity of Sites 395 and 396, the reader is referred to Hussong, Fryer, et al.; Purdy, Rabinowitz, and Schouten; Purdy, Schouten, et al.; and Purdy and Rabinowitz all in this volume.

\section{ACKNOWLEDGMENTS}

The efforts of the laboratory technicians aboard D/V Glomar Challenger, under the direction of laboratory officers Michael Lehman (Leg 45) and Gerald Bode (Leg 46), is greatly appreciated. Two of us (P.D.R. and T.D.A.) were partially supported by IPOD Site Survey Management under Grant UC-NSF-C-482-2. 


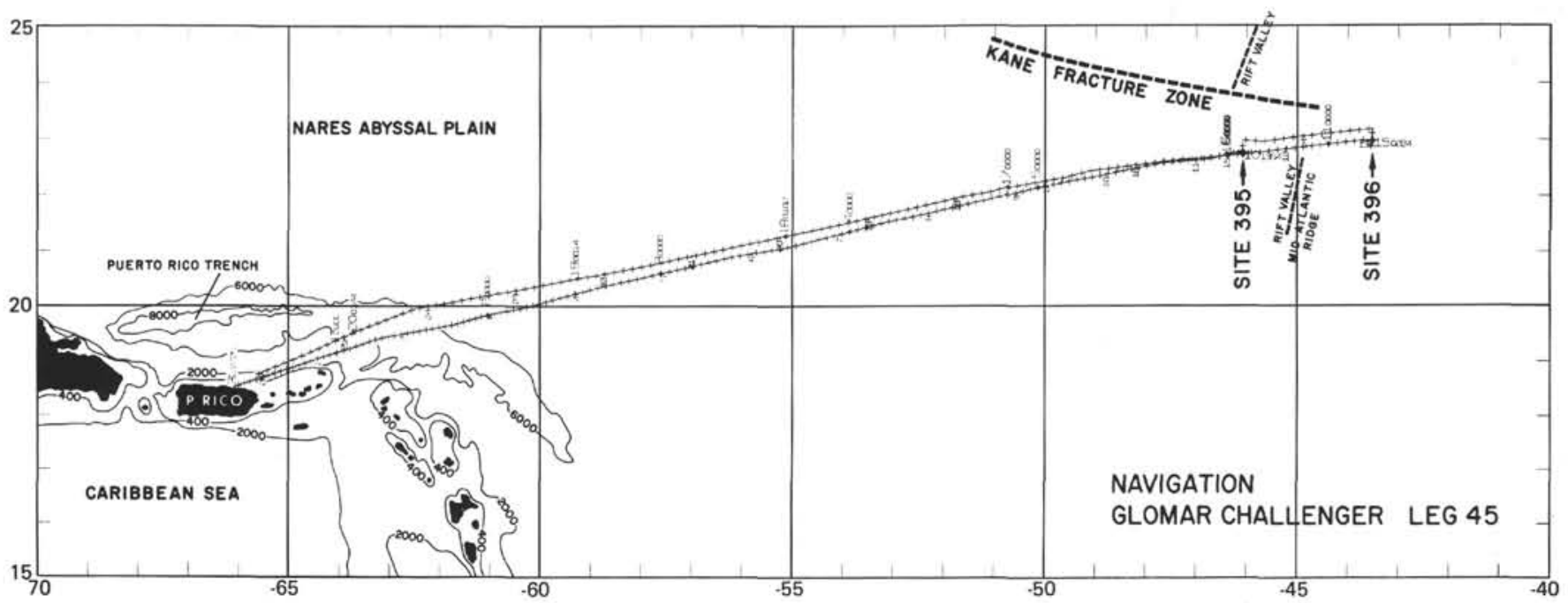

Figure 1. Track chart for Leg 45 of Glomar Challenger from San Juan, Puerto Rico, to San Juan, Puerto Rico. First navigation fix of every day and distance in hundreds of nautical miles along track are shown. Hour marks along track designated by "plus" marks. Generalized bathymetry after Uchupi (1971). Location of ridge axes and Kane fracture zone after Rabinowitz and Purdy (1976).

\section{REFERENCES}

Fabiano, E. G. and Peddie, N. U., 1969. Grid values of total magnetic intensity I.G.R.F., 1965: U.S. ESSA Tech. Rept., v. 38 , p. 55 .

Hayes, D. E. and Rabinowitz, P. D., 1975. Mesozoic magnetic lineations and the magnetic quiet zone of the eastern North Atlantic: Earth Planet. Sci. Lett., v. 28, p. 105-115.

Heirtzler, J. R., Dickson, G. O., Herron, E. M., Pitman, W. C., III, and LePichon, X., 1968. Marine magnetic anomalies, geomagnetic field reversals, and motions of the ocean floor and continents: J. Geophys. Res., v. 73, p. 2119-2136.

LaBrecque, J. L., Kent, D. V., and Cande, S. C., 1977. Revised magnetic polarity time scale for the Late Cretaceous and Cenozoic: Geology, v. 5, no. 6, p. 330-335.

Pitman, W. C., III, and Talwani, M., 1972. Sea floor spreading in the North Atlantic: Geol. Soc. Am. Bull., v. 83, no. 3, p. 619-646.
Rabinowitz, P. D. and Purdy, G. M., 1976. The Kane fracture zone in the central western Atlantic ocean: Earth Planet. Sci. Lett., v. 33, p. 21-26.

Talwani, M., 1969. A computer system for the reduction, storage, and display of underway data acquired at sea: Lamont-Doherty Geological Observatory of Columbia University Tech. Rept. 1, CU-1-69 N00014-67-A-01080004 , p. 348.

Talwani, M., Dorman, J., Worzel, J. L., and Bryan, G. M., 1966. Navigation at sea by satellite: J. Geophys. Res., v. 71, p. 5891-5902.

Uchupi, E., 1971. Bathymetric atlas of the Atlantic, Caribbean, and Gulf of Mexico: Woods Hole Oceanographic Institution Ref. No. 71-72, Woods Hole, Mass.

Uchupi, E., Emery, K. O., Bowin, C. O., and Phillips, J. D., 1976. Continental margin off western Africa: Senegal to Portugal: Am. Assoc. Petrol. Geol. Bull., p. 809-878. 


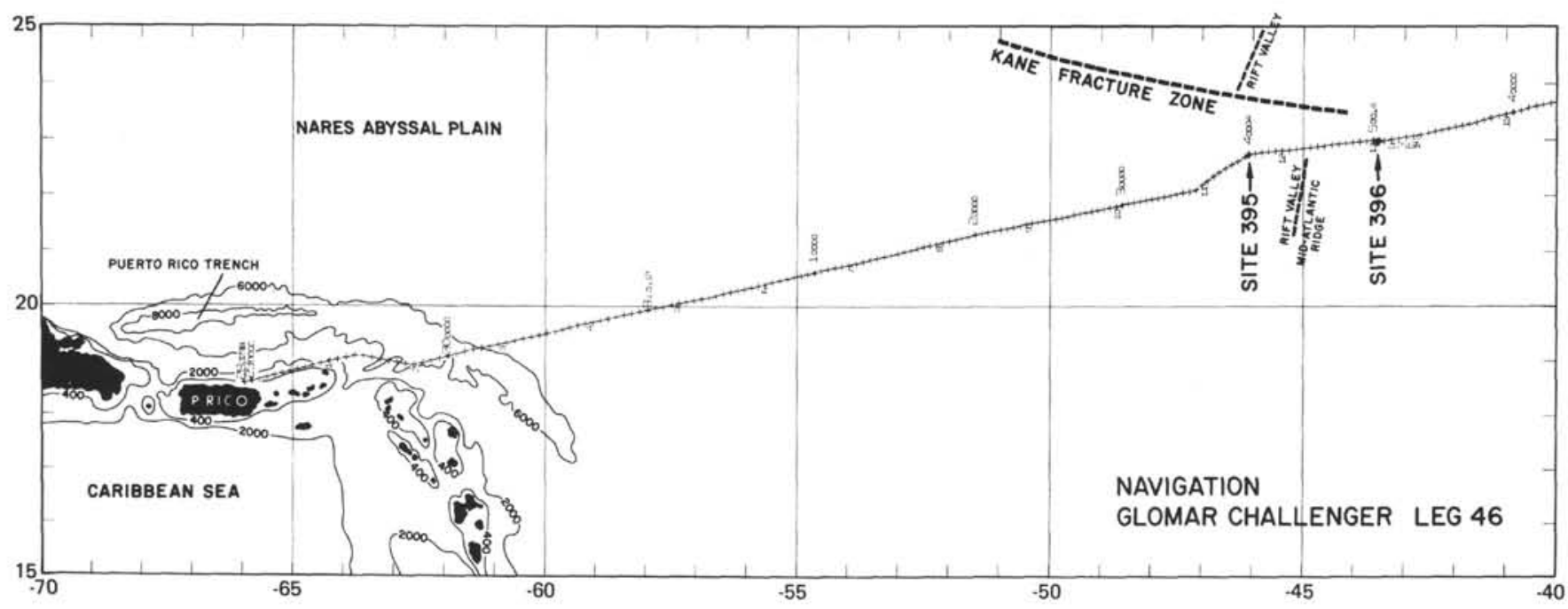

Figure 2. Track chart for Leg 46 of Glomar Challenger from San Juan, Puerto Rico, to Site 396. First navigation fix of every day and distance along track are noted. Hour mark along track designated by "plus" marks. Generalized bathymetry after Uchupi (1971). Location of ridge axes and Kane fracture zone after Rabinowitz and Purdy (1976).

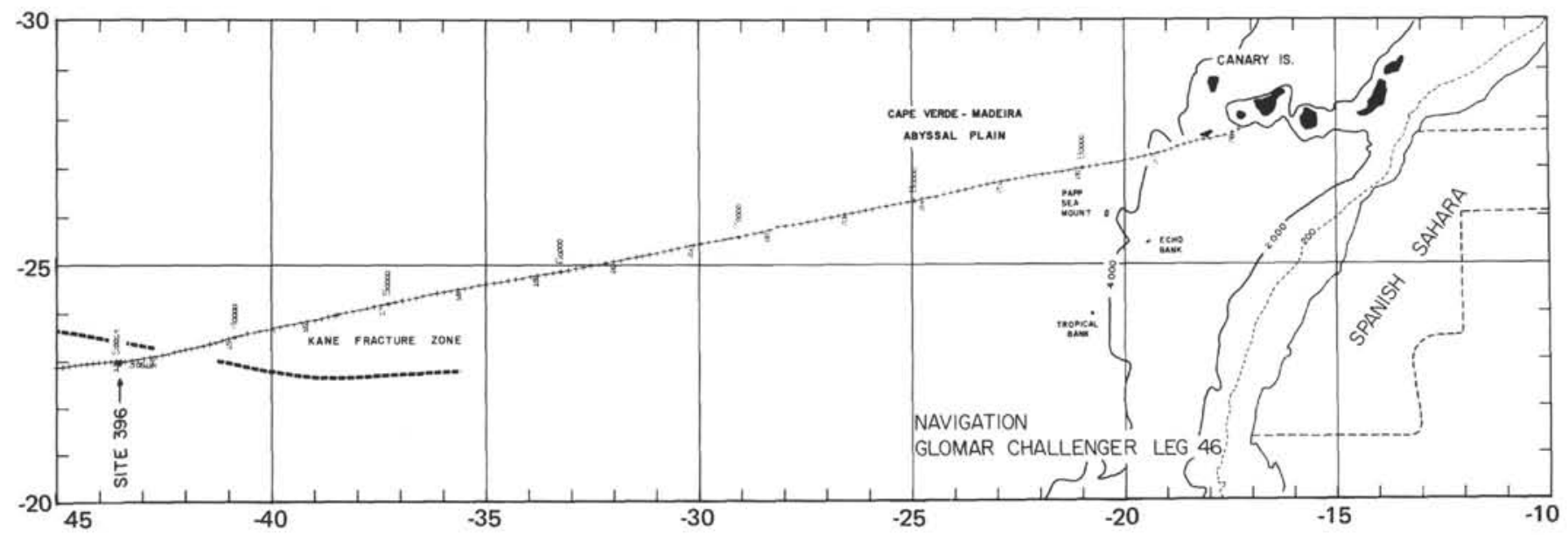

Figure 3. Track chart for Leg 46 of Glomar Challenger from Site 396 to Las Palmas, Canary Islands. First navigation fix of every day and distance along track are noted. Hour mark along track designated by "plus" marks. Generalized bathymetry after Uchupi (1971). 
P. D. RABINOWITZ, J. R. HEIRTZLER, T. D. AITKEN, G. M. PURDY

TABLE 1

Positioning Information (from satellite navigation system) and Magnetic Field Values, Leg 45

\begin{tabular}{|c|c|c|c|c|c|c|c|c|c|c|}
\hline Day & Mon & Year & $\begin{array}{l}\text { Time } \\
\text { Zone }\end{array}$ & Time & Latitude & Longitude & Distance & Speed & Course & $\begin{array}{c}\text { Regional Magnetic } \\
\text { Field Value (Gammas) }\end{array}$ \\
\hline 30 & 11 & 1975 & 0.0 & 705 & $18^{\circ} 30.0^{\prime}$ & $-66^{\circ} 05.5^{\prime}$ & 0.0 & 5.8 & 71 & 42610. \\
\hline 30 & 11 & 1975 & 0.0 & 727 & $18^{\circ} 30.7^{\prime}$ & $-66^{\circ} 03.4^{\prime}$ & 2.1 & 6.1 & 68 & 42612. \\
\hline 30 & 11 & 1975 & 0.0 & 740 & $18^{\circ} 31.2^{\prime}$ & $-66^{\circ} 02.1^{\prime}$ & 3.4 & 6.5 & 68 & 42613. \\
\hline 30 & 11 & 1975 & 0.0 & 830 & $18^{\circ} 33.2^{\prime}$ & $-65^{\circ} 56.8^{\prime}$ & 8.8 & 7.1 & 72 & 42619. \\
\hline 30 & 11 & 1975 & 0.0 & 912 & $18^{\circ} 34.7^{\prime}$ & $-65^{\circ} 51.8^{\prime}$ & 13.8 & 7.4 & 72 & 42621. \\
\hline 30 & 11 & 1975 & 0.0 & 954 & $18^{\circ} 36.3^{\prime}$ & $-65^{\circ} 46.6^{\prime}$ & 19.0 & 7.4 & 71 & 42622. \\
\hline 30 & 11 & 1975 & 0.0 & 1154 & $18^{\circ} 41.2^{\prime}$ & $-65^{\circ} 31.8^{\prime}$ & 33.9 & 7.3 & 72 & 42631. \\
\hline 30 & 11 & 1975 & 0.0 & 1340 & $18^{\circ} 45.1^{\prime}$ & $-65^{\circ} 18.8^{\prime}$ & 46.8 & 6.3 & 71 & 42633 . \\
\hline 30 & 11 & 1975 & 0.0 & 1400 & $18^{\circ} 45.8^{\prime}$ & $-65^{\circ} 16.7^{\prime}$ & 48.9 & 7.3 & 72 & 42634. \\
\hline 30 & 11 & 1975 & 0.0 & 1654 & $18^{\circ} 52.2^{\prime}$ & $-64^{\circ} 55.3^{\prime}$ & 70.1 & 7.1 & 71 & 42637. \\
\hline 30 & 11 & 1975 & 0.0 & 2002 & $18^{\circ} 59.3^{\prime}$ & $-64^{\circ} 32.9^{\prime}$ & 92.5 & 7.5 & 70 & 42642 . \\
\hline 30 & 11 & 1975 & 0.0 & 2030 & $19^{\circ} 00.5^{\prime}$ & $-64^{\circ} 29.4^{\prime}$ & 96.0 & 7.5 & 73 & 42644. \\
\hline 30 & 11 & 1975 & 0.0 & 2340 & $19^{\circ} 07.5^{\prime}$ & $-64^{\circ} 05.4^{\prime}$ & 119.7 & 7.9 & 75 & 42641 . \\
\hline 1 & 12 & 1975 & 0.0 & 000 & $19^{\circ} 08.2^{\prime}$ & $-64^{\circ} 02.7^{\prime}$ & 112.4 & 7.9 & 75 & 42640. \\
\hline 1 & 12 & 1975 & 0.0 & 124 & $19^{\circ} 11.1^{\prime}$ & $-63^{\circ} 51.4^{\prime}$ & 133.4 & 7.7 & 71 & 42633. \\
\hline 1 & 12 & 1975 & 0.0 & 520 & $19^{\circ} 21.0^{\prime}$ & $-63^{\circ} 20.9^{\prime}$ & 163.9 & 7.2 & 72 & 42637. \\
\hline 1 & 12 & 1975 & 0.0 & 600 & $19^{\circ} 22.5^{\prime}$ & $-63^{\circ} 16.1^{\prime}$ & 168.7 & 7.2 & 76 & 42636. \\
\hline 1 & 12 & 1975 & 0.0 & 706 & $19^{\circ} 24.4^{\prime}$ & $-63^{\circ} 07.9^{\prime}$ & 176.6 & 7.4 & 73 & 42629. \\
\hline 1 & 12 & 1975 & 0.0 & 726 & $19^{\circ} 25.1^{\prime}$ & $-63^{\circ} 05.4^{\prime}$ & 179.1 & 7.3 & 81 & 42627. \\
\hline 1 & 12 & 1975 & 0.0 & 752 & $19^{\circ} 25.6^{\prime}$ & $-63^{\circ} 02.1^{\prime}$ & 182.2 & 7.1 & 80 & 42621. \\
\hline 1 & 12 & 1975 & 0.0 & 902 & $19^{\circ} 27.0^{\prime}$ & $-62^{\circ} 53.5^{\prime}$ & 190.5 & 7.3 & 80 & 42607. \\
\hline 1 & 12 & 1975 & 0.0 & 1244 & $19^{\circ} 31.7^{\prime}$ & $-62^{\circ} 25.4^{\prime}$ & 217.4 & 7.3 & 80 & 42558. \\
\hline 1 & 12 & 1975 & 0.0 & 1708 & $19^{\circ} 37.1^{\prime}$ & $-61^{\circ} 52.0^{\prime}$ & 249.3 & 7.4 & 80 & 42497. \\
\hline 1 & 12 & 1975 & 0.0 & 1800 & $19^{\circ} 38.2^{\prime}$ & $-61^{\circ} 45.3^{\prime}$ & 255.7 & 7.3 & 76 & 42484. \\
\hline 1 & 12 & 1975 & 0.0 & 1856 & $19^{\circ} 39.9^{\prime}$ & $-61^{\circ} 38.3^{\prime}$ & 262.5 & 6.8 & 74 & 42477. \\
\hline 1 & 12 & 1975 & 0.0 & 2048 & $19^{\circ} 43.4^{\prime}$ & $-61^{\circ} 25.3^{\prime}$ & 275.2 & 7.0 & 74 & 42466. \\
\hline 1 & 12 & 1975 & 0.0 & 2305 & $19^{\circ} 47.9^{\prime}$ & $-61^{\circ} 08.9^{\prime}$ & 291.3 & 6.9 & 78 & 42453. \\
\hline 2 & 12 & 1975 & 0.0 & 000 & $19^{\circ} 49.2^{\prime}$ & $-61^{\circ} 02.3^{\prime}$ & 297.7 & 7.0 & 78 & 42442. \\
\hline 2 & 12 & 1975 & 0.0 & 028 & $19^{\circ} 49.9^{\prime}$ & $-60^{\circ} 58.9^{\prime}$ & 300.9 & 7.4 & 77 & 42437. \\
\hline 2 & 12 & 1975 & 0.0 & 330 & $19^{\circ} 54.8^{\prime}$ & $-60^{\circ} 35.6^{\prime}$ & 323.4 & 7.5 & 81 & 42401. \\
\hline 2 & 12 & 1975 & 0.0 & 430 & $19^{\circ} 56.0^{\prime}$ & $-60^{\circ} 27.7^{\prime}$ & 330.9 & 7.4 & 81 & 42384. \\
\hline 2 & 12 & 1975 & 0.0 & 500 & $19^{\circ} 56.6^{\prime}$ & $-60^{\circ} 23.8^{\prime}$ & 334.6 & 7.7 & 78 & 42375 . \\
\hline 2 & 12 & 1975 & 0.0 & 518 & $19^{\circ} 57.1^{\prime}$ & $-60^{\circ} 21.4^{\prime}$ & 336.9 & 7.4 & 75 & 42372 \\
\hline 2 & 12 & 1975 & 0.0 & 616 & $19^{\circ} 58.9^{\prime}$ & $-60^{\circ} 14.0^{\prime}$ & 344.1 & 7.5 & 76 & 42362. \\
\hline 2 & 12 & 1975 & 0.0 & 812 & $20^{\circ} 02.4^{\prime}$ & $-59^{\circ} 59.1^{\prime}$ & 358.5 & 7.5 & 76 & 42342 . \\
\hline 2 & 12 & 1975 & 0.0 & 832 & $20^{\circ} 03.0^{\prime}$ & $-59^{\circ} 56.5^{\prime}$ & 361.1 & 7.7 & 73 & 42338. \\
\hline 2 & 12 & 1975 & 0.0 & 912 & $20^{\circ} 04.5^{\prime}$ & $-59^{\circ} 51.3^{\prime}$ & 366.2 & 8.1 & 74 & 42334. \\
\hline 2 & 12 & 1975 & 0.0 & 958 & $20^{\circ} 06.2^{\prime}$ & $-59^{\circ} 44.9^{\prime}$ & 372.4 & 8.5 & 75 & 42327. \\
\hline 2 & 12 & 1975 & 0.0 & 1150 & $20^{\circ} 10.3^{\prime}$ & $-59^{\circ} 28.6^{\prime}$ & 388.3 & 8.6 & 75 & 42306. \\
\hline 2 & 12 & 1975 & 0.0 & 1336 & $20^{\circ} 14.2^{\prime}$ & $-59^{\circ} 13.0^{\prime}$ & 403.4 & 8.8 & 75 & 42285 . \\
\hline 2 & 12 & 1975 & 0.0 & 1516 & $20^{\circ} 17.9^{\prime}$ & $-58^{\circ} 57.9^{\prime}$ & 418.1 & 9.0 & 76 & 42264. \\
\hline 2 & 12 & 1975 & 0.0 & 1700 & $20^{\circ} 21.8^{\prime}$ & $-58^{\circ} 41.7^{\prime}$ & 433.7 & 8.6 & 80 & 42240 . \\
\hline 2 & 12 & 1975 & 0.0 & 1704 & $20^{\circ} 21.9^{\prime}$ & $-58^{\circ} 41.1^{\prime}$ & 434.3 & 8.8 & 78 & 42239. \\
\hline 2 & 12 & 1975 & 0.0 & 1804 & $20^{\circ} 23.7^{\prime}$ & $-58^{\circ} 31.9^{\prime}$ & 443.1 & 9.0 & 79 & 42220 . \\
\hline 2 & 12 & 1975 & 0.0 & 1948 & $20^{\circ} 26.7^{\prime}$ & $-58^{\circ} 15.5^{\prime}$ & 458.8 & 8.9 & 78 & 42186. \\
\hline 2 & 12 & 1975 & 0.0 & 2035 & $20^{\circ} 28.2^{\prime}$ & $-58^{\circ} 08.2^{\prime}$ & 465.8 & 9.2 & 78 & 42172. \\
\hline 2 & 12 & 1975 & 0.0 & 2144 & $20^{\circ} 30.4^{\prime}$ & $-57^{\circ} 57.2^{\prime}$ & 476.3 & 8.9 & 76 & 42150. \\
\hline 2 & 12 & 1975 & 0.0 & 2334 & $20^{\circ} 34.2^{\prime}$ & $-57^{\circ} 40.3^{\prime}$ & 492.6 & 9.5 & 77 & 42120. \\
\hline 3 & 12 & 1975 & 0.0 & 000 & $20^{\circ} 35.1^{\prime}$ & $-57^{\circ} 36.0^{\prime}$ & 496.7 & 9.5 & 78 & 42112. \\
\hline 3 & 12 & 1975 & 0.0 & 120 & $20^{\circ} 37.8^{\prime}$ & $-57^{\circ} 22.8^{\prime}$ & 509.4 & 9.2 & 77 & 42085. \\
\hline 3 & 12 & 1975 & 0.0 & 242 & $20^{\circ} 40.6^{\prime}$ & $-57^{\circ} 09.7^{\prime}$ & 521.9 & 9.0 & 76 & 42060 . \\
\hline 3 & 12 & 1975 & 0.0 & 428 & $20^{\circ} 44.4^{\prime}$ & $-56^{\circ} 53.2^{\prime}$ & 537.8 & 8.9 & 77 & 42031. \\
\hline 3 & 12 & 1975 & 0.0 & 906 & $20^{\circ} 53.5^{\prime}$ & $-56^{\circ} 10.3^{\prime}$ & 579.0 & 8.9 & 80 & 41944. \\
\hline 3 & 12 & 1975 & 0.0 & 1240 & $20^{\circ} 59.0^{\prime}$ & $-55^{\circ} 36.7^{\prime}$ & 610.8 & 8.9 & 81 & 41858. \\
\hline 3 & 12 & 1975 & 0.0 & 1430 & $21^{\circ} 01.6^{\prime}$ & $-55^{\circ} 19.5^{\prime}$ & 627.1 & 9.3 & 81 & 41811. \\
\hline 3 & 12 & 1975 & 0.0 & 1455 & $21^{\circ} 02.2^{\prime}$ & $-55^{\circ} 15.4^{\prime}$ & 631.0 & 9.1 & 81 & 41800 \\
\hline 3 & 12 & 1975 & 0.0 & 1616 & $21^{\circ} 04.2^{\prime}$ & $-55^{\circ} 02.4^{\prime}$ & 643.2 & 8.9 & 76 & 41765 \\
\hline 3 & 12 & 1975 & 0.0 & 1700 & $21^{\circ} 05.8^{\prime}$ & $-54^{\circ} 55.6^{\prime}$ & 649.8 & 8.9 & 75 & 41752. \\
\hline 3 & 12 & 1975 & 0.0 & 1840 & $21^{\circ} 09.7^{\prime}$ & $-54^{\circ} 40.3^{\prime}$ & 664.6 & 8.9 & 77 & 41725 . \\
\hline 3 & 12 & 1975 & 0.0 & 2052 & $21^{\circ} 14.2^{\prime}$ & $-54^{\circ} 19.9^{\prime}$ & 684.1 & 8.5 & 81 & 41683. \\
\hline 3 & 12 & 1975 & 0.0 & 2114 & $21^{\circ} 14.7^{\prime}$ & $-54^{\circ} 16.6^{\prime}$ & 687.2 & 8.9 & 70 & 41673 . \\
\hline 3 & 12 & 1975 & 0.0 & 2120 & $21^{\circ} 15.0^{\prime}$ & $-54^{\circ} 15.7^{\prime}$ & 688.1 & 7.8 & 77 & 41673. \\
\hline 3 & 12 & 1975 & 0.0 & 2140 & $21^{\circ} 15.6^{\prime}$ & $-54^{\circ} 13.0^{\prime}$ & 690.7 & 8.8 & 75 & 41667. \\
\hline 4 & 12 & 1975 & 0.0 & 000 & $21^{\circ} 20.9^{\prime}$ & $-53^{\circ} 51.7^{\prime}$ & 711.3 & 8.8 & 75 & 41627. \\
\hline 4 & 12 & 1975 & 0.0 & 415 & $21^{\circ} 30.5^{\prime}$ & $-53^{\circ} 13.0^{\prime}$ & 748.5 & 8.7 & 78 & 41554. \\
\hline 4 & 12 & 1975 & 0.0 & 438 & $21^{\circ} 31.2^{\prime}$ & $-53^{\circ} 09.5^{\prime}$ & 751.9 & 8.9 & 79 & 41546. \\
\hline 4 & 12 & 1975 & 0.0 & 618 & $21^{\circ} 34.0^{\prime}$ & $-52^{\circ} 53.8^{\prime}$ & 766.7 & 9.1 & 81 & 41505 . \\
\hline 4 & 12 & 1975 & 0.0 & 646 & $21^{\circ} 34.7^{\prime}$ & $-52^{\circ} 49.3^{\prime}$ & 771.0 & 9.1 & 78 & 41492. \\
\hline 4 & 12 & 1975 & 0.0 & 806 & $21^{\circ} 37.2^{\prime}$ & $-52^{\circ} 36.5^{\prime}$ & 783.1 & 8.6 & 76 & 41461. \\
\hline
\end{tabular}


TABLE 1 - Continued

\begin{tabular}{|c|c|c|c|c|c|c|c|c|c|c|}
\hline Day & Mon & Year & $\begin{array}{l}\text { Time } \\
\text { Zone }\end{array}$ & Time & Latitude & Longitude & Distance & Speed & Course & $\begin{array}{c}\text { Regional Magnetic } \\
\text { Field Value (Gammas) }\end{array}$ \\
\hline 4 & 12 & 1975 & 0.0 & 832 & $21^{\circ} 38.1^{\prime}$ & $-52^{\circ} 32.6^{\prime}$ & 786.9 & 9.0 & 77 & 41453. \\
\hline 4 & 12 & 1975 & 0.0 & 1144 & $21^{\circ} 44.5^{\prime}$ & $-52^{\circ} 02.3^{\prime}$ & 815.8 & 8.9 & 78 & 41383. \\
\hline 4 & 12 & 1975 & 0.0 & 1628 & $21^{\circ} 53.6^{\prime}$ & $-51^{\circ} 18.0^{\prime}$ & 857.9 & 8.9 & 79 & 41277. \\
\hline 4 & 12 & 1975 & 0.0 & 1736 & $21^{\circ} 55.5^{\prime}$ & $-51^{\circ} 07.3^{\prime}$ & 868.0 & 8.7 & 76 & 41249. \\
\hline 4 & 12 & 1975 & 0.0 & 1834 & $21^{\circ} 57.5^{\prime}$ & $-50^{\circ} 58.5^{\prime}$ & 876.4 & 9.0 & 77 & 41230. \\
\hline 4 & 12 & 1975 & 0.0 & 1918 & $21^{\circ} 59.0^{\prime}$ & $-50^{\circ} 51.6^{\prime}$ & 883.0 & 9.0 & 77 & 41214. \\
\hline 4 & 12 & 1975 & 0.0 & 2022 & $22^{\circ} 01.1^{\prime}$ & $-50^{\circ} 41.5^{\prime}$ & 892.6 & 8.6 & 76 & 41190. \\
\hline 4 & 12 & 1975 & 0.0 & 2330 & $22^{\circ} 07.5^{\prime}$ & $-50^{\circ} 13.3^{\prime}$ & 919.5 & 8.7 & 78 & 41128. \\
\hline 5 & 12 & 1975 & 0.0 & 000 & $22^{\circ} 08.4^{\prime}$ & $-50^{\circ} 08.7^{\prime}$ & 923.8 & 8.9 & 79 & 41116. \\
\hline 5 & 12 & 1975 & 0.0 & 118 & $22^{\circ} 10.6^{\prime}$ & $-49^{\circ} 56.5^{\prime}$ & 935.3 & 8.7 & 79 & 41084. \\
\hline 5 & 12 & 1975 & 0.0 & 250 & $22^{\circ} 13.1^{\prime}$ & $-49^{\circ} 42.4^{\prime}$ & 948.6 & 8.8 & 78 & 41046. \\
\hline 5 & 12 & 1975 & 0.0 & 350 & $22^{\circ} 14.9^{\prime}$ & $-49^{\circ} 33.1^{\prime}$ & 957.4 & 8.8 & 80 & 41022. \\
\hline 5 & 12 & 1975 & 0.0 & 514 & $22^{\circ} 17.1^{\prime}$ & $-49^{\circ} 20.0^{\prime}$ & 969.7 & 8.7 & 81 & 40986. \\
\hline 5 & 12 & 1975 & 0.0 & 656 & $22^{\circ} 19.4^{\prime}$ & $-49^{\circ} 04.3^{\prime}$ & 984.4 & 8.4 & 81 & 40939. \\
\hline 5 & 12 & 1975 & 0.0 & 722 & $22^{\circ} 20.0^{\prime}$ & $-49^{\circ} 00.4^{\prime}$ & 988.1 & 8.8 & 78 & 40927. \\
\hline 5 & 12 & 1975 & 0.0 & 910 & $22^{\circ} 23.4^{\prime}$ & $-48^{\circ} 43.6^{\prime}$ & 1004.0 & 8.8 & 79 & 40886. \\
\hline 5 & 12 & 1975 & 0.0 & 1050 & $22^{\circ} 26.3^{\prime}$ & $-48^{\circ} 28.1^{\prime}$ & 1018.6 & 8.8 & 78 & 40846. \\
\hline 5 & 12 & 1975 & 0.0 & 1215 & $22^{\circ} 28.8^{\prime}$ & $-48^{\circ} 14.9^{\prime}$ & 1031.1 & 8.8 & 81 & 40812. \\
\hline 5 & 12 & 1975 & 0.0 & 1236 & $22^{\circ} 29.3^{\prime}$ & $-48^{\circ} 11.6^{\prime}$ & 1034.2 & 8.9 & 80 & 40802. \\
\hline 5 & 12 & 1975 & 0.0 & 1538 & $22^{\circ} 34.2^{\prime}$ & $-47^{\circ} 42.9^{\prime}$ & 1061.1 & 9.4 & 82 & 40724. \\
\hline 5 & 12 & 1975 & 0.0 & 1600 & $22^{\circ} 34.7^{\prime}$ & $-47^{\circ} 39.2^{\prime}$ & 1064.6 & 9.3 & 86 & 40712. \\
\hline 5 & 12 & 1975 & 0.0 & 1724 & $22^{\circ} 35.7^{\prime}$ & $-47^{\circ} 25.1^{\prime}$ & 1077.6 & 8.9 & 85 & 40660 . \\
\hline 5 & 12 & 1975 & 0.0 & 1910 & $22^{\circ} 37.1^{\prime}$ & $-47^{\circ} 08.2^{\prime}$ & 1093.3 & 9.0 & 85 & 40600 . \\
\hline 5 & 12 & 1975 & 0.0 & 2058 & $22^{\circ} 38.4^{\prime}$ & $-46^{\circ} 50.7^{\prime}$ & 1109.5 & 8.9 & 85 & 40537. \\
\hline 5 & 12 & 1975 & 0.0 & 2130 & $22^{\circ} 38.8^{\prime}$ & $-46^{\circ} 45.6^{\prime}$ & 1114.2 & 8.3 & 77 & 40519. \\
\hline 5 & 12 & 1975 & 0.0 & 2236 & $22^{\circ} 40.8^{\prime}$ & $-46^{\circ} 35.9^{\prime}$ & 1123.4 & 8.6 & 75 & 40496. \\
\hline 5 & 12 & 1975 & 0.0 & 2300 & $22^{\circ} 41.7^{\prime}$ & $-46^{\circ} 32.3^{\prime}$ & 1126.8 & 8.1 & 75 & 40489. \\
\hline 6 & 12 & 1975 & 0.0 & 000 & $22^{\circ} 43.8^{\prime}$ & $-46^{\circ} 23.8^{\prime}$ & 1135.0 & 8.1 & 74 & 40472. \\
\hline 6 & 12 & 1975 & 0.0 & 022 & $22^{\circ} 44.6^{\prime}$ & $-46^{\circ} 20.7^{\prime}$ & 1137.9 & 7.9 & 74 & 40466. \\
\hline 6 & 12 & 1975 & 0.0 & 044 & $22^{\circ} 45.4^{\prime}$ & $-46^{\circ} 17.7^{\prime}$ & 1140.8 & 7.0 & 84 & 40461. \\
\hline 6 & 12 & 1975 & 0.0 & 052 & $22^{\circ} 45.5^{\prime}$ & $-46^{\circ} 16.7^{\prime}$ & 1141.7 & 5.4 & 84 & 40457. \\
\hline 6 & 12 & 1975 & 0.0 & 202 & $22^{\circ} 46.2^{\prime}$ & $-46^{\circ} 09.9^{\prime}$ & 1148.0 & 5.8 & 87 & 40435 . \\
\hline 6 & 12 & 1975 & 0.0 & 221 & $22^{\circ} 46.3^{\prime}$ & $-46^{\circ} 07.9^{\prime}$ & 1149.9 & 5.9 & 110 & 40427. \\
\hline 6 & 12 & 1975 & 0.0 & 251 & $22^{\circ} 45.3^{\prime}$ & $-46^{\circ} 04.9^{\prime}$ & 1152.8 & 0.0 & 90 & 40405 . \\
\hline 10 & 1 & 1976 & 0.0 & 1354 & $22^{\circ} 45.3^{\prime}$ & $-46^{\circ} 04.9^{\prime}$ & 1152.8 & 8.5 & 88 & 40398. \\
\hline 10 & 1 & 1976 & 0.0 & 1500 & $22^{\circ} 45.7^{\prime}$ & $-45^{\circ} 54.8^{\prime}$ & 1162.2 & 9.7 & 83 & 40358. \\
\hline 10 & 1 & 1976 & 0.0 & 1830 & $22^{\circ} 49.7^{\prime}$ & $-45^{\circ} 18.2^{\prime}$ & 1196.1 & 9.5 & 84 & 40240 . \\
\hline 10 & 1 & 1976 & 0.0 & 2126 & $22^{\circ} 52.8^{\prime}$ & $-44^{\circ} 48.3^{\prime}$ & 1223.9 & 9.2 & 84 & 40142. \\
\hline 10 & 1 & 1976 & 0.0 & 2334 & $22^{\circ} 54.9^{\prime}$ & $-44^{\circ} 27.2^{\prime}$ & 1243.4 & 9.4 & 83 & 40073. \\
\hline 11 & 1 & 1976 & 0.0 & 000 & $22^{\circ} 55.4^{\prime}$ & $-44^{\circ} 22.8^{\prime}$ & 1247.5 & 9.4 & 84 & 40060 . \\
\hline 11 & 1 & 1976 & 0.0 & 403 & $22^{\circ} 59.5^{\prime}$ & $-43^{\circ} 41.6^{\prime}$ & 1285.6 & 5.5 & 90 & 39926. \\
\hline 11 & 1 & 1976 & 0.0 & 404 & $22^{\circ} 59.5^{\prime}$ & $-43^{\circ} 41.5^{\prime}$ & 1285.7 & 9.7 & 90 & 39926. \\
\hline 11 & 1 & 1976 & 0.0 & 420 & $22^{\circ} 59.5^{\prime}$ & $-43^{\circ} 38.7^{\prime}$ & 1288.3 & 9.6 & 95 & 39914. \\
\hline 11 & 1 & 1976 & 0.0 & 449 & $22^{\circ} 59.1^{\prime}$ & $-43^{\circ} 33.7^{\prime}$ & 1292.9 & 6.7 & 94 & 39890. \\
\hline 11 & 1 & 1976 & 0.0 & 512 & $22^{\circ} 58.9^{\prime}$ & $-43^{\circ} 30.9^{\prime}$ & 1295.5 & 0.0 & 90 & 39876. \\
\hline 15 & 1 & 1976 & 0.0 & 224 & $22^{\circ} 58.9^{\prime}$ & $-43^{\circ} 30.9^{\prime}$ & 1295.5 & 10.6 & 196 & 39876. \\
\hline 15 & 1 & 1976 & 0.0 & 250 & $22^{\circ} 54.5^{\prime}$ & $-43^{\circ} 32.3^{\prime}$ & 1300.1 & 10.7 & 192 & 39840. \\
\hline 15 & 1 & 1976 & 0.0 & 310 & $22^{\circ} 51.0^{\prime}$ & $-43^{\circ} 33.1^{\prime}$ & 1303.7 & 8.5 & 6 & 39811. \\
\hline 15 & 1 & 1976 & 0.0 & 436 & $23^{\circ} 03.1^{\prime}$ & $-43^{\circ} 31.7^{\prime}$ & 1315.9 & 9.3 & 7 & 39918. \\
\hline 15 & 1 & 1976 & 0.0 & 500 & $23^{\circ} 06.8^{\prime}$ & $-43^{\circ} 31.2^{\prime}$ & 1319.6 & 9.4 & 11 & 39950 . \\
\hline 15 & 1 & 1976 & 0.0 & 530 & $23^{\circ} 11.4^{\prime}$ & $-43^{\circ} 30.2^{\prime}$ & 1324.3 & 10.0 & 266 & 39989. \\
\hline 15 & 1 & 1976 & 0.0 & 556 & $23^{\circ} 11.1^{\prime}$ & $-43^{\circ} 34.9^{\prime}$ & 1328.6 & 10.4 & 264 & 40005. \\
\hline 15 & 1 & 1976 & 0.0 & 715 & $23^{\circ} 09.7^{\prime}$ & $-43^{\circ} 49.7^{\prime}$ & 1342.3 & 7.7 & 266 & 40054. \\
\hline 15 & 1 & 1976 & 0.0 & 725 & $23^{\circ} 09.6^{\prime}$ & $-43^{\circ} 51.1^{\prime}$ & 1343.6 & 10.5 & 264 & 40059. \\
\hline 15 & 1 & 1976 & 0.0 & 836 & $23^{\circ} 08.4^{\prime}$ & $-44^{\circ} 04.6^{\prime}$ & 1356.0 & 10.3 & 264 & 40104. \\
\hline 15 & 1 & 1976 & 0.0 & 1144 & $23^{\circ} 04.8^{\prime}$ & $-44^{\circ} 39.3^{\prime}$ & 1388.2 & 10.5 & 264 & 40216. \\
\hline 15 & 1 & 1976 & 0.0 & 1400 & $23^{\circ} 02.4^{\prime}$ & $-45^{\circ} 05.1^{\prime}$ & 1412.0 & 10.3 & 262 & 40302. \\
\hline 15 & 1 & 1976 & 0.0 & 1602 & $22^{\circ} 59.5^{\prime}$ & $-45^{\circ} 27.6^{\prime}$ & 1432.9 & 9.8 & 261 & 40371. \\
\hline 15 & 1 & 1976 & 0.0 & 1606 & $22^{\circ} 59.4^{\prime}$ & $-45^{\circ} 28.3^{\prime}$ & 1433.6 & 10.4 & 263 & 40373. \\
\hline 15 & 1 & 1976 & 0.0 & 1630 & $22^{\circ} 58.9^{\prime}$ & $-45^{\circ} 32.8^{\prime}$ & 1437.8 & 10.5 & 265 & 40387. \\
\hline 15 & 1 & 1976 & 0.0 & 1730 & $22^{\circ} 57.9^{\prime}$ & $-45^{\circ} 44.1^{\prime}$ & 1448.2 & 10.7 & 272 & 40426 . \\
\hline 15 & 1 & 1976 & 0.0 & 1744 & $22^{\circ} 58.0^{\prime}$ & $-45^{\circ} 46.8^{\prime}$ & 1450.7 & 10.3 & 275 & 40439. \\
\hline 15 & 1 & 1976 & 0.0 & 1920 & $22^{\circ} 59.4^{\prime}$ & $-46^{\circ} 04.6^{\prime}$ & 1467.1 & 9.8 & 183 & 40528. \\
\hline 15 & 1 & 1976 & 0.0 & 2007 & $22^{\circ} 51.7^{\prime}$ & $-46^{\circ} 05.0^{\prime}$ & 1474.9 & 10.0 & 188 & 40458. \\
\hline 15 & 1 & 1976 & 0.0 & 2024 & $22^{\circ} 48.9^{\prime}$ & $-46^{\circ} 05.4^{\prime}$ & 1477.7 & 9.9 & 186 & 40433. \\
\hline 15 & 1 & 1976 & 0.0 & 2035 & $22^{\circ} 47.1^{\prime}$ & $-46^{\circ} 05.6^{\prime}$ & 1479.5 & 7.3 & 189 & 40417. \\
\hline 15 & 1 & 1976 & 0.0 & 2040 & $22^{\circ} 46.5^{\prime}$ & $-46^{\circ} 05.7^{\prime}$ & 1480.1 & 6.3 & 163 & 40412. \\
\hline 15 & 1 & 1976 & 0.0 & 2043 & $22^{\circ} 46.2^{\prime}$ & $-46^{\circ} 05.6^{\prime}$ & 1480.4 & 7.0 & 148 & 40409. \\
\hline 15 & 1 & 1976 & 0.0 & 2055 & $22^{\circ} 45.0^{\prime}$ & $-46^{\circ} 04.8^{\prime}$ & 1481.8 & 8.2 & 137 & 40394. \\
\hline
\end{tabular}


TABLE 1 - Continued

\begin{tabular}{|c|c|c|c|c|c|c|c|c|c|c|}
\hline Day & Mon & Year & $\begin{array}{l}\text { Time } \\
\text { Zone }\end{array}$ & Time & Latitude & Longitude & Distance & Speed & Course & $\begin{array}{l}\text { Regional Magnetic } \\
\text { Field Value (Gammas) }\end{array}$ \\
\hline 15 & 1 & 1976 & 0.0 & 2057 & $22^{\circ} 44.8^{\prime}$ & $-46^{\circ} 04.6^{\prime}$ & 1482.1 & 0.3 & 231 & 40391. \\
\hline 15 & 1 & 1976 & 0.0 & 2220 & $22^{\circ} 44.5^{\prime}$ & $-46^{\circ} 05.0^{\prime}$ & 1482.6 & 7.3 & 263 & 40390. \\
\hline 15 & 1 & 1976 & 0.0 & 2240 & $22^{\circ} 44.2^{\prime}$ & $-46^{\circ} 07.6^{\prime}$ & 1485.0 & 9.9 & 263 & 40398. \\
\hline 16 & 1 & 1976 & 0.0 & 000 & $22^{\circ} 42.7^{\prime}$ & $-46^{\circ} 21.8^{\prime}$ & 1498.2 & 9.9 & 263 & 40445 . \\
\hline 16 & 1 & 1976 & 0.0 & 120 & $22^{\circ} 41.2^{\prime}$ & $-46^{\circ} 36.0^{\prime}$ & 1511.3 & 9.9 & 265 & 40492. \\
\hline 16 & 1 & 1976 & 0.0 & 300 & $22^{\circ} 39.9^{\prime}$ & $-46^{\circ} 53.8^{\prime}$ & 1527.8 & 9.7 & 267 & 40557. \\
\hline 16 & 1 & 1976 & 0.0 & 312 & $22^{\circ} 39.8^{\prime}$ & $-46^{\circ} 55.9^{\prime}$ & 1529.8 & 10.4 & 267 & 40565 . \\
\hline 16 & 1 & 1976 & 0.0 & 346 & $22^{\circ} 39.5^{\prime}$ & $-47^{\circ} 02.3^{\prime}$ & 1535.7 & 10.1 & 264 & 40590. \\
\hline 16 & 1 & 1976 & 0.0 & 408 & $22^{\circ} 39.1^{\prime}$ & $-47^{\circ} 06.3^{\prime}$ & 1539.4 & 10.1 & 266 & 40603. \\
\hline 16 & 1 & 1976 & 0.0 & 534 & $22^{\circ} 38.1^{\prime}$ & $-47^{\circ} 21.9^{\prime}$ & 1553.8 & 11.5 & 255 & 40662 . \\
\hline 16 & 1 & 1976 & 0.0 & 536 & $22^{\circ} 38.0^{\prime}$ & $-47^{\circ} 22.3^{\prime}$ & 1554.2 & 10.3 & 263 & 40662. \\
\hline 16 & 1 & 1976 & 0.0 & 928 & $22^{\circ} 33.4^{\prime}$ & $-48^{\circ} 05.3^{\prime}$ & 1594.2 & 10.3 & 263 & 40806. \\
\hline 16 & 1 & 1976 & 0.0 & 1244 & $22^{\circ} 29.4^{\prime}$ & $-48^{\circ} 41.3^{\prime}$ & 1627.7 & 9.8 & 262 & 40926. \\
\hline 16 & 1 & 1976 & 0.0 & 1312 & $22^{\circ} 28.8^{\prime}$ & $-48^{\circ} 46.2^{\prime}$ & 1632.2 & 10.0 & 263 & 40941. \\
\hline 16 & 1 & 1976 & 0.0 & 1500 & $22^{\circ} 26.6^{\prime}$ & $-49^{\circ} 05.5^{\prime}$ & 1650.2 & 10.7 & 259 & 41005 . \\
\hline 16 & 1 & 1976 & 0.0 & 1520 & $22^{\circ} 25.9^{\prime}$ & $-49^{\circ} 09.3^{\prime}$ & 1653.8 & 10.3 & 255 & 41015. \\
\hline 16 & 1 & 1976 & 0.0 & 1540 & $22^{\circ} 25.0^{\prime}$ & $-49^{\circ} 12.9^{\prime}$ & 1657.2 & 10.7 & 256 & 41022. \\
\hline 16 & 1 & 1976 & 0.0 & 1652 & $22^{\circ} 21.8^{\prime}$ & $-49^{\circ} 26.3^{\prime}$ & 1670.0 & 11.0 & 254 & 41050 . \\
\hline 16 & 1 & 1976 & 0.0 & 1722 & $22^{\circ} 20.3^{\prime}$ & $-49^{\circ} 32.0^{\prime}$ & 1675.5 & 10.2 & 257 & 41061. \\
\hline 16 & 1 & 1976 & 0.0 & 1745 & $22^{\circ} 19.4^{\prime}$ & $-49^{\circ} 36.1^{\prime}$ & 1679.4 & 10.1 & 260 & 41070 . \\
\hline 17 & 1 & 1976 & 0.0 & 000 & $22^{\circ} 08.7^{\prime}$ & $-50^{\circ} 43.5^{\prime}$ & 1742.7 & 10.2 & 261 & 41264 . \\
\hline 17 & 1 & 1976 & 0.0 & 036 & $22^{\circ} 07.7^{\prime}$ & $-50^{\circ} 50.0^{\prime}$ & 1748.8 & 9.5 & 254 & 41283. \\
\hline 17 & 1 & 1976 & 0.0 & 150 & $22^{\circ} 04.4^{\prime}$ & $-51^{\circ} 02.2^{\prime}$ & 1760.6 & 10.3 & 259 & 41304. \\
\hline 17 & 1 & 1976 & 0.0 & 222 & $22^{\circ} 03.4^{\prime}$ & $-51^{\circ} 08.0^{\prime}$ & 1766.0 & 10.3 & 260 & 41320. \\
\hline 17 & 1 & 1976 & 0.0 & 412 & $22^{\circ} 00.2^{\prime}$ & $-51^{\circ} 28.1^{\prime}$ & 1785.0 & 10.3 & 260 & 41377. \\
\hline 17 & 1 & 1976 & 0.0 & 500 & $21^{\circ} 58.8^{\prime}$ & $-51^{\circ} 36.9^{\prime}$ & 1793.2 & 10.2 & 259 & 41402 . \\
\hline 17 & 1 & 1976 & 0.0 & 600 & $21^{\circ} 56.8^{\prime}$ & $-51^{\circ} 47.7^{\prime}$ & 1803.4 & 10.5 & 257 & 41430. \\
\hline 17 & 1 & 1976 & 0.0 & 834 & $21^{\circ} 50.8^{\prime}$ & $-52^{\circ} 15.9^{\prime}$ & 1830.3 & 10.3 & 257 & 41495 . \\
\hline 17 & 1 & 1976 & 0.0 & 1020 & $21^{\circ} 46.8^{\prime}$ & $-52^{\circ} 35.1^{\prime}$ & 1848.6 & 10.6 & 258 & 41540 . \\
\hline 17 & 1 & 1976 & 0.0 & 1154 & $21^{\circ} 43.4^{\prime}$ & $-52^{\circ} 52.6^{\prime}$ & 1865.2 & 8.9 & 250 & 41583 \\
\hline 17 & 1 & 1976 & 0.0 & 1156 & $21^{\circ} 43.3^{\prime}$ & $-52^{\circ} 52.9^{\prime}$ & 1865.5 & 9.3 & 257 & 41584. \\
\hline 17 & 1 & 1976 & 0.0 & 1340 & $21^{\circ} 39.7^{\prime}$ & $-53^{\circ} 09.8^{\prime}$ & 1881.6 & 9.2 & 257 & 41622. \\
\hline 17 & 1 & 1976 & 0.0 & 1550 & $21^{\circ} 35.3^{\prime}$ & $-53^{\circ} 30.8^{\prime}$ & 1901.6 & 9.9 & 258 & 41670 . \\
\hline 17 & 1 & 1976 & 0.0 & 1746 & $21^{\circ} 31.2^{\prime}$ & $-53^{\circ} 50.8^{\prime}$ & 1920.6 & 10.1 & 258 & 41716. \\
\hline 17 & 1 & 1976 & 0.0 & 2022 & $21^{\circ} 25.6^{\prime}$ & $-54^{\circ} 18.4^{\prime}$ & 1946.9 & 9.8 & 258 & 41780. \\
\hline 17 & 1 & 1976 & 0.0 & 2206 & $21^{\circ} 22.1^{\prime}$ & $-54^{\circ} 36.3^{\prime}$ & 1963.9 & 10.0 & 259 & 41822 \\
\hline 18 & 1 & 1976 & 0.0 & 102 & $21^{\circ} 16.4^{\prime}$ & $-55^{\circ} 07.3^{\prime}$ & 1993.4 & 9.9 & 258 & 41898. \\
\hline 18 & 1 & 1976 & 0.0 & 132 & $21^{\circ} 15.4^{\prime}$ & $-55^{\circ} 12.5^{\prime}$ & 1998.3 & 10.3 & 258 & 41910. \\
\hline 18 & 1 & 1976 & 0.0 & 340 & $21^{\circ} 10.8^{\prime}$ & $-55^{\circ} 35.5^{\prime}$ & 2020.3 & 10.0 & 260 & 41961 . \\
\hline 18 & 1 & 1976 & 0.0 & 400 & $21^{\circ} 10.2^{\prime}$ & $-55^{\circ} 39.0^{\prime}$ & 2023.6 & 10.3 & 258 & 41970. \\
\hline 18 & 1 & 1976 & 0.0 & 508 & $21^{\circ} 07.7^{\prime}$ & $-55^{\circ} 51.2^{\prime}$ & 2035.2 & 10.1 & 258 & 41997. \\
\hline 18 & 1 & 1976 & 0.0 & 546 & $21^{\circ} 06.4^{\prime}$ & $-55^{\circ} 57.9^{\prime}$ & 2041.6 & 10.2 & 258 & 42012. \\
\hline 18 & 1 & 1976 & 0.0 & 1322 & $20^{\circ} 50.7^{\prime}$ & $-57^{\circ} 18.8^{\prime}$ & 2118.8 & 10.3 & 257 & 42190. \\
\hline 18 & 1 & 1976 & 0.0 & 1454 & $20^{\circ} 47.2^{\prime}$ & $-57^{\circ} 35.3^{\prime}$ & 2134.6 & 10.5 & 258 & 42222. \\
\hline 18 & 1 & 1976 & 0.0 & 1546 & $20^{\circ} 45.3^{\prime}$ & $-57^{\circ} 44.8^{\prime}$ & 2143.7 & 10.4 & 259 & 42241. \\
\hline 18 & 1 & 1976 & 0.0 & 1638 & $20^{\circ} 43.6^{\prime}$ & $-57^{\circ} 54.3^{\prime}$ & 2152.7 & 10.9 & 259 & 42262. \\
\hline 18 & 1 & 1976 & 0.0 & 1658 & $20^{\circ} 42.9^{\prime}$ & $-57^{\circ} 58.1^{\prime}$ & 2156.3 & 10.5 & 260 & 42271. \\
\hline 18 & 1 & 1976 & 0.0 & 1730 & $20^{\circ} 41.9^{\prime}$ & $-58^{\circ} 04.0^{\prime}$ & 2161.9 & 10.4 & 259 & 42284. \\
\hline 18 & 1 & 1976 & 0.0 & 1844 & $20^{\circ} 39.4^{\prime}$ & $-58^{\circ} 17.4^{\prime}$ & 2174.7 & 10.5 & 260 & 42312. \\
\hline 18 & 1 & 1976 & 0.0 & 2112 & $20^{\circ} 34.8^{\prime}$ & $-58^{\circ} 44.5^{\prime}$ & 2200.5 & 9.9 & 260 & 42373. \\
\hline 18 & 1 & 1976 & 0.0 & 2258 & $20^{\circ} 31.8^{\prime}$ & $-59^{\circ} 02.9^{\prime}$ & 2218.0 & 10.0 & 261 & 42415. \\
\hline 19 & 1 & 1976 & 0.0 & 014 & $20^{\circ} 29.9^{\prime}$ & $-59^{\circ} 16.3^{\prime}$ & 2230.7 & 9.9 & 258 & 42449. \\
\hline 19 & 1 & 1976 & 0.0 & 202 & $20^{\circ} 26.3^{\prime}$ & $-59^{\circ} 35.0^{\prime}$ & 2248.6 & 10.2 & 259 & 42484. \\
\hline 19 & 1 & 1976 & 0.0 & 602 & $20^{\circ} 18.8^{\prime}$ & $-60^{\circ} 17.8^{\prime}$ & 2289.4 & 10.2 & 259 & 42572 \\
\hline 19 & 1 & 1976 & 0.0 & 832 & $20^{\circ} 14.1^{\prime}$ & $-60^{\circ} 44.6^{\prime}$ & 2315.0 & 10.4 & 259 & 42624 \\
\hline 19 & 1 & 1976 & 0.0 & 1016 & $20^{\circ} 10.8^{\prime}$ & $-61^{\circ} 03.4^{\prime}$ & 2332.9 & 10.4 & 260 & 42660. \\
\hline 19 & 1 & 1976 & 0.0 & 1206 & $20^{\circ} 07.4^{\prime}$ & $-61^{\circ} 23.4^{\prime}$ & 2352.0 & 10.3 & 259 & 42699. \\
\hline 19 & 1 & 1976 & 0.0 & 1418 & $20^{\circ} 03.1^{\prime}$ & $-61^{\circ} 47.2^{\prime}$ & 2374.7 & 9.3 & 260 & 42741. \\
\hline 19 & 1 & 1976 & 0.0 & 1830 & $19^{\circ} 56.6^{\prime}$ & $-62^{\circ} 28.3^{\prime}$ & 2413.9 & 10.2 & 249 & 42820. \\
\hline 20 & 1 & 1976 & 0.0 & 144 & $19^{\circ} 30.6^{\prime}$ & $-63^{\circ} 41.3^{\prime}$ & 2487.4 & 10.3 & 246 & 42796. \\
\hline 20 & 1 & 1976 & 0.0 & 408 & $19^{\circ} 20.5^{\prime}$ & $-64^{\circ} 05.2^{\prime}$ & 2512.1 & 10.0 & 247 & 42768 \\
\hline 20 & 1 & 1976 & 0.0 & 456 & $19^{\circ} 17.3^{\prime}$ & $-64^{\circ} 13.0^{\prime}$ & 2520.1 & 10.4 & 248 & 42759. \\
\hline 20 & 1 & 1976 & 0.0 & 516 & $19^{\circ} 16.0^{\prime}$ & $-64^{\circ} 16.4^{\prime}$ & 2523.6 & 10.2 & 246 & 42757. \\
\hline 20 & 1 & 1976 & 0.0 & 552 & $19^{\circ} 13.5^{\prime}$ & $-64^{\circ} 22.3^{\prime}$ & 2529.7 & 10.4 & 247 & 42749. \\
\hline 20 & 1 & 1976 & 0.0 & 658 & $19^{\circ} 09.0^{\prime}$ & $-64^{\circ} 33.4^{\prime}$ & 2541.1 & 10.5 & 247 & 42737. \\
\hline 20 & 1 & 1976 & 0.0 & 922 & $18^{\circ} 59.3^{\prime}$ & $-64^{\circ} 58.0^{\prime}$ & 2566.3 & 10.6 & 249 & 42711. \\
\hline 20 & 1 & 1976 & 0.0 & 1300 & $18^{\circ} 45.4^{\prime}$ & $-65^{\circ} 36.1^{\prime}$ & 2604.9 & & & 42678. \\
\hline
\end{tabular}


TABLE 2

Positioning Information (from satellite navigation system) and Magnetic Field Values, Leg 46

\begin{tabular}{|c|c|c|c|c|c|c|c|c|c|c|}
\hline Day & Mon & Year & $\begin{array}{l}\text { Time } \\
\text { Zone }\end{array}$ & Time & Latitude & Longitude & Distance & Speed & Course & $\begin{array}{l}\text { Regional Magnetic } \\
\text { Field Value (Gammas) }\end{array}$ \\
\hline 28 & 1 & 1976 & 0.0 & 2238 & $18^{\circ} 35.2^{\prime}$ & $-65^{\circ} 59.9^{\prime}$ & 0.0 & 5.4 & 87 & 42637. \\
\hline 28 & 1 & 1976 & 0.0 & 2315 & $18^{\circ} 35.4^{\prime}$ & $-65^{\circ} 56.4^{\prime}$ & 3.3 & 9.7 & 78 & 42629. \\
\hline 28 & 1 & 1976 & 0.0 & 2318 & $18^{\circ} 35.5^{\prime}$ & $-65^{\circ} 55.9^{\prime}$ & 3.8 & 9.2 & 77 & 42628. \\
\hline 29 & 1 & 1976 & 0.0 & 000 & $18^{\circ} 37.0^{\prime}$ & $-65^{\circ} 49.3^{\prime}$ & 10.2 & 9.1 & 76 & 42625. \\
\hline 29 & 1 & 1976 & 0.0 & 312 & $18^{\circ} 44.0^{\prime}$ & $-65^{\circ} 19.3^{\prime}$ & 39.5 & 8.7 & 76 & 42610 . \\
\hline 29 & 1 & 1976 & 0.0 & 812 & $18^{\circ} 54.7^{\prime}$ & $-64^{\circ} 34.7^{\prime}$ & 83.1 & 10.0 & 75 & 42586. \\
\hline 29 & 1 & 1976 & 0.0 & 1000 & $18^{\circ} 59.4^{\prime}$ & $-64^{\circ} 16.3^{\prime}$ & 101.1 & 9.3 & 78 & 42577. \\
\hline 29 & 1 & 1976 & 0.0 & 1106 & $19^{\circ} 01.6^{\prime}$ & $-64^{\circ} 05.7^{\prime}$ & 111.3 & 9.9 & 77 & 42566. \\
\hline 29 & 1 & 1976 & 0.0 & 1250 & $19^{\circ} 05.4^{\prime}$ & $-63^{\circ} 48.0^{\prime}$ & 128.5 & 10.3 & 76 & 42549. \\
\hline 29 & 1 & 1976 & 0.0 & 1312 & $19^{\circ} 06.3^{\prime}$ & $-63^{\circ} 44.1^{\prime}$ & 132.3 & 9.6 & 78 & 42545. \\
\hline 29 & 1 & 1976 & 0.0 & 1315 & $19^{\circ} 06.4^{\prime}$ & $-63^{\circ} 43.6^{\prime}$ & 132.8 & 9.8 & 101 & 42545. \\
\hline 29 & 1 & 1976 & 0.0 & 1456 & $19^{\circ} 03.3^{\prime}$ & $-63^{\circ} 26.5^{\prime}$ & 149.2 & 9.7 & 101 & 42455 . \\
\hline 29 & 1 & 1976 & 0.0 & 1540 & $19^{\circ} 02.0^{\prime}$ & $-63^{\circ} 19.1^{\prime}$ & 156.3 & 9.4 & 100 & 42416. \\
\hline 29 & 1 & 1976 & 0.0 & 1956 & $18^{\circ} 55.1^{\prime}$ & $-62^{\circ} 37.1^{\prime}$ & 196.7 & 9.9 & 90 & 42200. \\
\hline 29 & 1 & 1976 & 0.0 & 2000 & $18^{\circ} 55.1^{\prime}$ & $-62^{\circ} 36.4^{\prime}$ & 197.3 & 10.3 & 75 & 42198. \\
\hline 29 & 1 & 1976 & 0.0 & 2142 & $18^{\circ} 59.6^{\prime}$ & $-62^{\circ} 18.5^{\prime}$ & 214.8 & 9.8 & 75 & 42183. \\
\hline 30 & 1 & 1976 & 0.0 & 000 & $19^{\circ} 05.5^{\prime}$ & $-61^{\circ} 55.6^{\prime}$ & 237.3 & 9.7 & 75 & 42165. \\
\hline 30 & 1 & 1976 & 0.0 & 038 & $19^{\circ} 07.1^{\prime}$ & $-61^{\circ} 49.3^{\prime}$ & 243.4 & 9.8 & 76 & 42160. \\
\hline 30 & 1 & 1976 & 0.0 & 202 & $19^{\circ} 10.5^{\prime}$ & $-61^{\circ} 35.2^{\prime}$ & 257.2 & 9.5 & 81 & 42145. \\
\hline 30 & 1 & 1976 & 0.0 & 222 & $19^{\circ} 11.0^{\prime}$ & $-61^{\circ} 31.9^{\prime}$ & 260.3 & 10.2 & 67 & 42138. \\
\hline 30 & 1 & 1976 & 0.0 & 225 & $19^{\circ} 11.2^{\prime}$ & $-61^{\circ} 31.4^{\prime}$ & 260.9 & 9.5 & 77 & 42139. \\
\hline 30 & 1 & 1976 & 0.0 & 306 & $19^{\circ} 12.7^{\prime}$ & $-61^{\circ} 24.7^{\prime}$ & 267.4 & 9.6 & 78 & 42130. \\
\hline 30 & 1 & 1976 & 0.0 & 420 & $19^{\circ} 15.2^{\prime}$ & $-61^{\circ} 12.5^{\prime}$ & 279.1 & 9.4 & 77 & 42112. \\
\hline 30 & 1 & 1976 & 0.0 & 452 & $19^{\circ} 16.3^{\prime}$ & $-61^{\circ} 07.3^{\prime}$ & 284.2 & 9.6 & 78 & 42105. \\
\hline 30 & 1 & 1976 & 0.0 & 902 & $19^{\circ} 24.7^{\prime}$ & $-60^{\circ} 25.9^{\prime}$ & 324.1 & 9.1 & 77 & 42040. \\
\hline 30 & 1 & 1976 & 0.0 & 1202 & $19^{\circ} 30.9^{\prime}$ & $-59^{\circ} 57.8^{\prime}$ & 351.3 & 9.6 & 78 & 41998. \\
\hline 30 & 1 & 1976 & 0.0 & 1226 & $19^{\circ} 31.7^{\prime}$ & $-59^{\circ} 53.8^{\prime}$ & 355.2 & 9.0 & 75 & 41992. \\
\hline 30 & 1 & 1976 & 0.0 & 1410 & $19^{\circ} 35.6^{\prime}$ & $-59^{\circ} 37.8^{\prime}$ & 370.8 & 8.7 & 76 & 41971. \\
\hline 30 & 1 & 1976 & 0.0 & 1454 & $19^{\circ} 37.1^{\prime}$ & $-59^{\circ} 31.2^{\prime}$ & 377.2 & 8.6 & 76 & 41961. \\
\hline 30 & 1 & 1976 & 0.0 & 1530 & $19^{\circ} 38.3^{\prime}$ & $-59^{\circ} 25.9^{\prime}$ & 382.3 & 8.5 & 76 & 41953. \\
\hline 30 & 1 & 1976 & 0.0 & 1638 & $19^{\circ} 40.6^{\prime}$ & $-59^{\circ} 16.0^{\prime}$ & 391.9 & 8.8 & 79 & 41939. \\
\hline 30 & 1 & 1976 & 0.0 & 1716 & $19^{\circ} 41.7^{\prime}$ & $-59^{\circ} 10.2^{\prime}$ & 397.5 & 8.9 & 77 & 41928. \\
\hline 30 & 1 & 1976 & 0.0 & 2000 & $19^{\circ} 47.1^{\prime}$ & $-58^{\circ} 44.9^{\prime}$ & 421.9 & 9.0 & 78 & 41885. \\
\hline 30 & 1 & 1976 & 0.0 & 2324 & $19^{\circ} 53.4^{\prime}$ & $-58^{\circ} 13.2^{\prime}$ & 452.4 & 9.1 & 77 & 41824. \\
\hline 31 & 1 & 1976 & 0.0 & 112 & $19^{\circ} 57.1^{\prime}$ & $-57^{\circ} 56.2^{\prime}$ & 468.8 & 9.0 & 78 & 41794. \\
\hline 31 & 1 & 1976 & 0.0 & 314 & $20^{\circ} 01.0^{\prime}$ & $-57^{\circ} 37.1^{\prime}$ & 487.1 & 9.5 & 79 & 41757. \\
\hline 31 & 1 & 1976 & 0.0 & 402 & $20^{\circ} 02.5^{\prime}$ & $-57^{\circ} 29.2^{\prime}$ & 494.7 & 8.6 & 79 & 41741. \\
\hline 31 & 1 & 1976 & 0.0 & 808 & $20^{\circ} 09.5^{\prime}$ & $-56^{\circ} 52.4^{\prime}$ & 530.0 & 8.2 & 78 & 41662. \\
\hline 31 & 1 & 1976 & 0.0 & 954 & $20^{\circ} 12.6^{\prime}$ & $-56^{\circ} 37.4^{\prime}$ & 544.4 & 8.3 & 76 & 41632. \\
\hline 31 & 1 & 1976 & 0.0 & 1114 & $20^{\circ} 15.2^{\prime}$ & $-56^{\circ} 26.0^{\prime}$ & 555.4 & 8.1 & 77 & 41612. \\
\hline 31 & 1 & 1976 & 0.0 & 1300 & $20^{\circ} 18.3^{\prime}$ & $-56^{\circ} 11.2^{\prime}$ & 569.6 & 7.9 & 77 & 41582. \\
\hline 31 & 1 & 1976 & 0.0 & 1426 & $20^{\circ} 20.8^{\prime}$ & $-55^{\circ} 59.5^{\prime}$ & 580.9 & 7.9 & 78 & 41558. \\
\hline 31 & 1 & 1976 & 0.0 & 1612 & $20^{\circ} 23.8^{\prime}$ & $-55^{\circ} 45.0^{\prime}$ & 594.8 & 8.4 & 77 & 41528. \\
\hline 31 & 1 & 1976 & 0.0 & 1954 & $20^{\circ} 31.0^{\prime}$ & $-55^{\circ} 12.9^{\prime}$ & 625.7 & 8.1 & 77 & 41466. \\
\hline 31 & 1 & 1976 & 0.0 & 2140 & $20^{\circ} 34.2^{\prime}$ & $-54^{\circ} 58.0^{\prime}$ & 640.0 & 7.8 & 76 & 41435. \\
\hline 31 & 1 & 1976 & 0.0 & 2236 & $20^{\circ} 36.0^{\prime}$ & $-54^{\circ} 50.5^{\prime}$ & 647.3 & 7.7 & 77 & 41421. \\
\hline 1 & 2 & 1976 & 0.0 & 000 & $20^{\circ} 38.4^{\prime}$ & $-54^{\circ} 39.2^{\prime}$ & 658.1 & 7.8 & 78 & 41397. \\
\hline 1 & 2 & 1976 & 0.0 & 022 & $20^{\circ} 39.0^{\prime}$ & $-54^{\circ} 36.2^{\prime}$ & 661.0 & 7.7 & 78 & 41391. \\
\hline 1 & 2 & 1976 & 0.0 & 208 & $20^{\circ} 41.9^{\prime}$ & $-54^{\circ} 21.9^{\prime}$ & 674.7 & 7.6 & 81 & 41359. \\
\hline 1 & 2 & 1976 & 0.0 & 232 & $20^{\circ} 42.4^{\prime}$ & $-54^{\circ} 18.7^{\prime}$ & 677.7 & 7.8 & 78 & 41350. \\
\hline 1 & 2 & 1976 & 0.0 & 312 & $20^{\circ} 43.5^{\prime}$ & $-54^{\circ} 13.3^{\prime}$ & 682.9 & 7.9 & 80 & 41338. \\
\hline 1 & 2 & 1976 & 0.0 & 346 & $20^{\circ} 44.3^{\prime}$ & $-54^{\circ} 08.6^{\prime}$ & 687.4 & 8.3 & 79 & 41326. \\
\hline 1 & 2 & 1976 & 0.0 & 500 & $20^{\circ} 46.2^{\prime}$ & $-53^{\circ} 57.9^{\prime}$ & 697.5 & 7.9 & 78 & 41299. \\
\hline 1 & 2 & 1976 & 0.0 & 534 & $20^{\circ} 47.1^{\prime}$ & $-53^{\circ} 53.2^{\prime}$ & 702.0 & 8.0 & 76 & 41288. \\
\hline 1 & 2 & 1976 & 0.0 & 714 & $20^{\circ} 50.4^{\prime}$ & $-53^{\circ} 39.4^{\prime}$ & 715.3 & 7.9 & 78 & 41262. \\
\hline 1 & 2 & 1976 & 0.0 & 858 & $20^{\circ} 53.3^{\prime}$ & $-53^{\circ} 25.0^{\prime}$ & 729.1 & 8.1 & 76 & 41229. \\
\hline 1 & 2 & 1976 & 0.0 & 1026 & $20^{\circ} 56.1^{\prime}$ & $-53^{\circ} 12.7^{\prime}$ & 740.9 & 7.7 & 77 & 41203. \\
\hline 1 & 2 & 1976 & 0.0 & 1212 & $20^{\circ} 59.2^{\prime}$ & $-52^{\circ} 58.6^{\prime}$ & 754.5 & 7.4 & 75 & 41173. \\
\hline 1 & 2 & 1976 & 0.0 & 1322 & $21^{\circ} 01.4^{\prime}$ & $-52^{\circ} 49.6^{\prime}$ & 763.2 & 7.5 & 77 & 41156. \\
\hline 1 & 2 & 1976 & 0.0 & 1502 & $21^{\circ} 04.3^{\prime}$ & $-52^{\circ} 36.6^{\prime}$ & 775.6 & 6.7 & 77 & 41127. \\
\hline 1 & 2 & 1976 & 0.0 & 1650 & $21^{\circ} 07.1^{\prime}$ & $-52^{\circ} 24.0^{\prime}$ & 787.7 & 7.3 & 81 & 41100. \\
\hline 1 & 2 & 1976 & 0.0 & 1722 & $21^{\circ} 07.7^{\prime}$ & $-52^{\circ} 19.9^{\prime}$ & 791.6 & 7.6 & 75 & 41088. \\
\hline 1 & 2 & 1976 & 0.0 & 1900 & $21^{\circ} 10.9^{\prime}$ & $-52^{\circ} 07.0^{\prime}$ & 804.0 & 7.2 & 78 & 41064. \\
\hline 1 & 2 & 1976 & 0.0 & 2044 & $21^{\circ} 13.5^{\prime}$ & $-51^{\circ} 53.9^{\prime}$ & 816.5 & 7.4 & 76 & 41032. \\
\hline 1 & 2 & 1976 & 0.0 & 2334 & $21^{\circ} 18.5^{\prime}$ & $-51^{\circ} 32.0^{\prime}$ & 837.5 & 7.1 & 77 & 40986. \\
\hline 1 & 2 & 1976 & 0.0 & 2356 & $21^{\circ} 19.1^{\prime}$ & $-51^{\circ} 29.3^{\prime}$ & 840.1 & 7.1 & 78 & 40980. \\
\hline 2 & 2 & 1976 & 0.0 & 000 & $21^{\circ} 19.2^{\prime}$ & $-51^{\circ} 28.8^{\prime}$ & 840.6 & 7.1 & 79 & 40979. \\
\hline
\end{tabular}


TABLE 2 - Continued

\begin{tabular}{|c|c|c|c|c|c|c|c|c|c|c|}
\hline Day & Mon & Year & $\begin{array}{l}\text { Time } \\
\text { Zone }\end{array}$ & Time & Latitude & Longitude & Distance & Speed & Course & $\begin{array}{l}\text { Regional Magnetic } \\
\text { Field Value (Gammas) }\end{array}$ \\
\hline 2 & 2 & 1976 & 0.0 & 144 & $21^{\circ} 21.6^{\prime}$ & $-51^{\circ} 15.8^{\prime}$ & 852.9 & 7.1 & 79 & 40946. \\
\hline 2 & 2 & 1976 & 0.0 & 224 & $21^{\circ} 22.5^{\prime}$ & $-51^{\circ} 10.8^{\prime}$ & 857.7 & 7.3 & 79 & 40933. \\
\hline 2 & 2 & 1976 & 0.0 & 410 & $21^{\circ} 25.0^{\prime}$ & $-50^{\circ} 57.3^{\prime}$ & 870.5 & 7.1 & 79 & 40898. \\
\hline 2 & 2 & 1976 & 0.0 & 802 & $21^{\circ} 30.1^{\prime}$ & $-50^{\circ} 28.2^{\prime}$ & 898.1 & 6.7 & 79 & 40821. \\
\hline 2 & 2 & 1976 & 0.0 & 1124 & $21^{\circ} 34.3^{\prime}$ & $-50^{\circ} 04.4^{\prime}$ & 920.6 & 7.6 & 81 & 40757. \\
\hline 2 & 2 & 1976 & 0.0 & 1144 & $21^{\circ} 34.7^{\prime}$ & $-50^{\circ} 01.7^{\prime}$ & 923.1 & 6.7 & 81 & 40749 . \\
\hline 2 & 2 & 1976 & 0.0 & 1330 & $21^{\circ} 36.6^{\prime}$ & $-49^{\circ} 49.1^{\prime}$ & 935.0 & 6.5 & 79 & 40713. \\
\hline 2 & 2 & 1976 & 0.0 & 1420 & $21^{\circ} 37.6^{\prime}$ & $-49^{\circ} 43.4^{\prime}$ & 940.4 & 6.7 & 77 & 40698. \\
\hline 2 & 2 & 1976 & 0.0 & 1444 & $21^{\circ} 38.2^{\prime}$ & $-49^{\circ} 40.6^{\prime}$ & 943.1 & 6.8 & 76 & 40691. \\
\hline 2 & 2 & 1976 & 0.0 & 1544 & $21^{\circ} 39.8^{\prime}$ & $-49^{\circ} 33.5^{\prime}$ & 949.8 & 6.5 & 79 & 40676. \\
\hline 2 & 2 & 1976 & 0.0 & 1604 & $21^{\circ} 40.2^{\prime}$ & $-49^{\circ} 31.2^{\prime}$ & 952.0 & 6.7 & 77 & 40669 . \\
\hline 2 & 2 & 1976 & 0.0 & 1628 & $21^{\circ} 40.8^{\prime}$ & $-49^{\circ} 28.4^{\prime}$ & 954.7 & 6.7 & 79 & 40663. \\
\hline 2 & 2 & 1976 & 0.0 & 1948 & $21^{\circ} 45.2^{\prime}$ & $-49^{\circ} 04.9^{\prime}$ & 977.0 & 6.7 & 78 & 40603 . \\
\hline 2 & 2 & 1976 & 0.0 & 2246 & $21^{\circ} 49.2^{\prime}$ & $-48^{\circ} 43.8^{\prime}$ & 997.0 & 6.8 & 77 & 40549 . \\
\hline 3 & 2 & 1976 & 0.0 & 000 & $21^{\circ} 51.1^{\prime}$ & $-48^{\circ} 35.0^{\prime}$ & 1005.3 & 6.7 & 76 & 40529. \\
\hline 3 & 2 & 1976 & 0.0 & 034 & $21^{\circ} 52.0^{\prime}$ & $-48^{\circ} 31.0^{\prime}$ & 1009.2 & 6.7 & 81 & 40521 . \\
\hline 3 & 2 & 1976 & 0.0 & 136 & $21^{\circ} 53.1^{\prime}$ & $-48^{\circ} 23.6^{\prime}$ & 1016.1 & 6.8 & 79 & 40499. \\
\hline 3 & 2 & 1976 & 0.0 & 708 & $22^{\circ} 00.1^{\prime}$ & $-47^{\circ} 43.9^{\prime}$ & 1053.6 & 6.9 & 78 & 40393. \\
\hline 3 & 2 & 1976 & 0.0 & 854 & $22^{\circ} 02.6^{\prime}$ & $-47^{\circ} 31.0^{\prime}$ & 1065.8 & 7.0 & 78 & 40361. \\
\hline 3 & 2 & 1976 & 0.0 & 1034 & $22^{\circ} 05.0^{\prime}$ & $-47^{\circ} 18.6^{\prime}$ & 1077.6 & 7.5 & 81 & 40331. \\
\hline 3 & 2 & 1976 & 0.0 & 1148 & $22^{\circ} 06.5^{\prime}$ & $-47^{\circ} 08.7^{\prime}$ & 1086.9 & 7.6 & 51 & 40302 . \\
\hline 3 & 2 & 1976 & 0.0 & 1222 & $22^{\circ} 09.2^{\prime}$ & $-47^{\circ} 05.1^{\prime}$ & 1091.1 & 8.1 & 53 & 40312. \\
\hline 3 & 2 & 1976 & 0.0 & 1510 & $22^{\circ} 22.9^{\prime}$ & $-46^{\circ} 45.6^{\prime}$ & 1113.8 & 7.7 & 55 & 40358. \\
\hline 3 & 2 & 1976 & 0.0 & 1545 & $22^{\circ} 25.5^{\prime}$ & $-46^{\circ} 41.6^{\prime}$ & 1118.3 & 7.9 & 61 & 40365. \\
\hline 3 & 2 & 1976 & 0.0 & 1854 & $22^{\circ} 37.7^{\prime}$ & $-46^{\circ} 18.1^{\prime}$ & 1143.2 & 8.7 & 60 & 40379. \\
\hline 3 & 2 & 1976 & 0.0 & 2040 & $22^{\circ} 45.4^{\prime}$ & $-46^{\circ} 03.6^{\prime}$ & 1158.7 & 0.9 & 264 & 40389. \\
\hline 3 & 2 & 1976 & 0.0 & 2344 & $22^{\circ} 45.1^{\prime}$ & $-46^{\circ} 06.7^{\prime}$ & 1161.5 & 6.4 & 82 & 40400 . \\
\hline 3 & 2 & 1976 & 0.0 & 2358 & $22^{\circ} 45.3^{\prime}$ & $-46^{\circ} 05.1^{\prime}$ & 1163.0 & 8.0 & 68 & 40395. \\
\hline 4 & 2 & 1976 & 0.0 & 004 & $22^{\circ} 45.6^{\prime}$ & $-46^{\circ} 04.3^{\prime}$ & 1163.8 & 7.4 & 82 & 40394. \\
\hline 4 & 2 & 1976 & 0.0 & 236 & $22^{\circ} 48.3^{\prime}$ & $-45^{\circ} 44.3^{\prime}$ & 1182.5 & 7.1 & 86 & 40334. \\
\hline 4 & 2 & 1976 & 0.0 & 258 & $22^{\circ} 48.5^{\prime}$ & $-45^{\circ} 41.5^{\prime}$ & 1185.0 & 8.8 & 70 & 40324. \\
\hline 4 & 2 & 1976 & 0.0 & 300 & $22^{\circ} 48.6^{\prime}$ & $-45^{\circ} 41.2^{\prime}$ & 1185.3 & 7.3 & 87 & 40324. \\
\hline 4 & 2 & 1976 & 0.0 & 444 & $22^{\circ} 49.2^{\prime}$ & $-45^{\circ} 27.4^{\prime}$ & 1198.1 & 7.8 & 87 & 40270 . \\
\hline 4 & 2 & 1976 & 0.0 & 530 & $22^{\circ} 49.5^{\prime}$ & $-45^{\circ} 20.9^{\prime}$ & 1204.1 & 7.7 & 84 & 40246. \\
\hline 4 & 2 & 1976 & 0.0 & 614 & $22^{\circ} 50.1^{\prime}$ & $-45^{\circ} 14.8^{\prime}$ & 1209.7 & 7.9 & 82 & 40225 . \\
\hline 4 & 2 & 1976 & 0.0 & 758 & $22^{\circ} 51.9^{\prime}$ & $-45^{\circ} 00.1^{\prime}$ & 1223.4 & 8.0 & 83 & 40180. \\
\hline 4 & 2 & 1976 & 0.0 & 948 & $22^{\circ} 53.7^{\prime}$ & $-44^{\circ} 44.4^{\prime}$ & 1238.0 & 7.9 & 83 & 40131. \\
\hline 4 & 2 & 1976 & 0.0 & 1000 & $22^{\circ} 53.9^{\prime}$ & $-44^{\circ} 42.7^{\prime}$ & 1239.5 & 7.6 & 83 & 40125 . \\
\hline 4 & 2 & 1976 & 0.0 & 1134 & $22^{\circ} 55.3^{\prime}$ & $-44^{\circ} 29.8^{\prime}$ & 1251.5 & 8.3 & 84 & 40084 . \\
\hline 4 & 2 & 1976 & 0.0 & 1154 & $22^{\circ} 55.6^{\prime}$ & $-44^{\circ} 26.8^{\prime}$ & 1254.3 & 7.6 & 84 & 40074 . \\
\hline 4 & 2 & 1976 & 0.0 & 1328 & $22^{\circ} 56.9^{\prime}$ & $-44^{\circ} 13.9^{\prime}$ & 1266.2 & 7.7 & 83 & 40033. \\
\hline 4 & 2 & 1976 & 0.0 & 1422 & $22^{\circ} 57.7^{\prime}$ & $-44^{\circ} 06.4^{\prime}$ & 1273.2 & 7.6 & 84 & 40009. \\
\hline 4 & 2 & 1976 & 0.0 & 1446 & $22^{\circ} 58.0^{\prime}$ & $-44^{\circ} 03.1^{\prime}$ & 1276.2 & 7.6 & 82 & 39998. \\
\hline 4 & 2 & 1976 & 0.0 & 1516 & $22^{\circ} 58.5^{\prime}$ & $-43^{\circ} 59.0^{\prime}$ & 1280.1 & 7.7 & 84 & 39985. \\
\hline 4 & 2 & 1976 & 0.0 & 1610 & $22^{\circ} 59.2^{\prime}$ & $-43^{\circ} 51.5^{\prime}$ & 1287.0 & 7.6 & 84 & 39961. \\
\hline 4 & 2 & 1976 & 0.0 & 1632 & $22^{\circ} 59.5^{\prime}$ & $-43^{\circ} 48.5^{\prime}$ & 1289.8 & 7.7 & 82 & 39951. \\
\hline 4 & 2 & 1976 & 0.0 & 1802 & $23^{\circ} 01.1^{\prime}$ & $-43^{\circ} 36.1^{\prime}$ & 1301.3 & 9.0 & 78 & 39914. \\
\hline 4 & 2 & 1976 & 0.0 & 1842 & $23^{\circ} 02.4^{\prime}$ & $-43^{\circ} 29.7^{\prime}$ & 1307.3 & 8.7 & 185 & 39900. \\
\hline 4 & 2 & 1976 & 0.0 & 1929 & $22^{\circ} 55.6^{\prime}$ & $-43^{\circ} 30.3^{\prime}$ & 1314.2 & 6.0 & 0 & 39840 . \\
\hline 4 & 2 & 1976 & 0.0 & 1930 & $22^{\circ} 55.7^{\prime}$ & $-43^{\circ} 30.3^{\prime}$ & 1314.3 & 7.3 & 354 & 39840 . \\
\hline 4 & 2 & 1976 & 0.0 & 1944 & $22^{\circ} 57.4^{\prime}$ & $-43^{\circ} 30.5^{\prime}$ & 1316.0 & 6.6 & 352 & 39857. \\
\hline 4 & 2 & 1976 & 0.0 & 2007 & $22^{\circ} 59.9^{\prime}$ & $-43^{\circ} 30.9^{\prime}$ & 1318.5 & 7.4 & 272 & 39882. \\
\hline 4 & 2 & 1976 & 0.0 & 2028 & $23^{\circ} 00.0^{\prime}$ & $-43^{\circ} 33.7^{\prime}$ & 1321.1 & 6.1 & 191 & 39894. \\
\hline 4 & 2 & 1976 & 0.0 & 2042 & $22^{\circ} 58.6^{\prime}$ & $-43^{\circ} 34.0^{\prime}$ & 1322.5 & 5.1 & 88 & 39883. \\
\hline 4 & 2 & 1976 & 0.0 & 2110 & $22^{\circ} 58.7^{\prime}$ & $-43^{\circ} 31.4^{\prime}$ & 1324.9 & 4.8 & 103 & 39873. \\
\hline 4 & 2 & 1976 & 0.0 & 2143 & $22^{\circ} 58.1^{\prime}$ & $-43^{\circ} 28.6^{\prime}$ & 1327.5 & 4.6 & 340 & 39856. \\
\hline 4 & 2 & 1976 & 0.0 & 2150 & $22^{\circ} 58.6^{\prime}$ & $-43^{\circ} 28.8^{\prime}$ & 1328.1 & 7.9 & 264 & 39861. \\
\hline 4 & 2 & 1976 & 0.0 & 2157 & $22^{\circ} 58.5^{\prime}$ & $-43^{\circ} 29.8^{\prime}$ & 1329.0 & 7.8 & 254 & 39864. \\
\hline 4 & 2 & 1976 & 0.0 & 2225 & $22^{\circ} 57.5^{\prime}$ & $-43^{\circ} 33.6^{\prime}$ & 1332.6 & 5.1 & 343 & 39871. \\
\hline 4 & 2 & 1976 & 0.0 & 2236 & $22^{\circ} 58.4^{\prime}$ & $-43^{\circ} 33.9^{\prime}$ & 1333.6 & 4.8 & 106 & 39880 . \\
\hline 4 & 2 & 1976 & 0.0 & 2254 & $22^{\circ} 58.0^{\prime}$ & $-43^{\circ} 32.4^{\prime}$ & 1335.0 & 4.9 & 96 & 39870 . \\
\hline 4 & 2 & 1976 & 0.0 & 2318 & $22^{\circ} 57.8^{\prime}$ & $-43^{\circ} 30.3^{\prime}$ & 1337.0 & 5.0 & 83 & 39860. \\
\hline 4 & 2 & 1976 & 0.0 & 2328 & $22^{\circ} 57.9^{\prime}$ & $-43^{\circ} 29.4^{\prime}$ & 1337.8 & 7.8 & 280 & 39857. \\
\hline 5 & 2 & 1976 & 0.0 & 014 & $22^{\circ} 58.9^{\prime}$ & $-43^{\circ} 35.8^{\prime}$ & 1343.8 & 4.8 & 93 & 39893. \\
\hline 5 & 2 & 1976 & 0.0 & 038 & $22^{\circ} 58.8^{\prime}$ & $-43^{\circ} 33.7^{\prime}$ & 1345.7 & 4.6 & 104 & 39883. \\
\hline 5 & 2 & 1976 & 0.0 & 100 & $22^{\circ} 58.4^{\prime}$ & $-43^{\circ} 31.9^{\prime}$ & 1347.4 & 5.0 & 94 & 39872. \\
\hline 5 & 2 & 1976 & 0.0 & 131 & $22^{\circ} 58.2^{\prime}$ & $-43^{\circ} 29.1^{\prime}$ & 1350.0 & 7.4 & 281 & 39859. \\
\hline 5 & 2 & 1976 & 0.0 & 144 & $22^{\circ} 58.5^{\prime}$ & $-43^{\circ} 30.8^{\prime}$ & 1351.6 & 7.2 & 280 & 39868. \\
\hline
\end{tabular}


TABLE 2 - Continued

\begin{tabular}{|c|c|c|c|c|c|c|c|c|c|c|}
\hline Day & Mon & Year & $\begin{array}{l}\text { Time } \\
\text { Zone }\end{array}$ & Time & Latitude & Longitude & Distance & Speed & Course & $\begin{array}{l}\text { Regional Magnetic } \\
\text { Field Value (Gammas) }\end{array}$ \\
\hline 5 & 2 & 1976 & 0.0 & 208 & $22^{\circ} 59.0^{\prime}$ & $-43^{\circ} 33.9^{\prime}$ & 1354.5 & 5.5 & 94 & 39886. \\
\hline 5 & 2 & 1976 & 0.0 & 223 & $22^{\circ} 58.9^{\prime}$ & $-43^{\circ} 32.4^{\prime}$ & 1355.9 & 5.2 & 82 & 39879. \\
\hline 5 & 2 & 1976 & 0.0 & 240 & $22^{\circ} 59.1^{\prime}$ & $-43^{\circ} 30.8^{\prime}$ & 1357.4 & 1.4 & 270 & 39874. \\
\hline 5 & 2 & 1976 & 0.0 & 244 & $22^{\circ} 59.1^{\prime}$ & $-43^{\circ} 30.9^{\prime}$ & 1357.4 & 0.0 & 180 & 39874. \\
\hline 3 & 3 & 1976 & 0.0 & 512 & $22^{\circ} 59.0^{\prime}$ & $-43^{\circ} 30.9^{\prime}$ & 1357.5 & 6.9 & 84 & 39868. \\
\hline 3 & 3 & 1976 & 0.0 & 520 & $22^{\circ} 59.1^{\prime}$ & $-43^{\circ} 29.9^{\prime}$ & 1358.5 & 8.2 & 80 & 39865 . \\
\hline 3 & 3 & 1976 & 0.0 & 706 & $23^{\circ} 01.5^{\prime}$ & $-43^{\circ} 14.4^{\prime}$ & 1372.9 & 7.9 & 80 & 39824 . \\
\hline 3 & 3 & 1976 & 0.0 & 828 & $23^{\circ} 03.3^{\prime}$ & $-43^{\circ} 02.8^{\prime}$ & 1383.8 & 8.1 & 81 & 39793. \\
\hline 3 & 3 & 1976 & 0.0 & 1112 & $23^{\circ} 06.8^{\prime}$ & $-42^{\circ} 39.1^{\prime}$ & 1405.8 & 8.0 & 78 & 39729. \\
\hline 3 & 3 & 1976 & 0.0 & 1330 & $23^{\circ} 10.7^{\prime}$ & $-42^{\circ} 19.6^{\prime}$ & 1424.2 & 7.8 & 78 & 39686. \\
\hline 3 & 3 & 1976 & 0.0 & 1348 & $23^{\circ} 11.2^{\prime}$ & $-42^{\circ} 17.1^{\prime}$ & 1426.5 & 7.6 & 78 & 39681. \\
\hline 3 & 3 & 1976 & 0.0 & 1706 & $23^{\circ} 16.5^{\prime}$ & $-41^{\circ} 50.6^{\prime}$ & 1451.5 & 8.1 & 78 & 39623. \\
\hline 3 & 3 & 1976 & 0.0 & 1852 & $23^{\circ} 19.4^{\prime}$ & $-41^{\circ} 35.4^{\prime}$ & 1465.7 & 8.1 & 74 & 39590 . \\
\hline 3 & 3 & 1976 & 0.0 & 1952 & $23^{\circ} 21.6^{\prime}$ & $-41^{\circ} 26.9^{\prime}$ & 1473.8 & 8.2 & 74 & 39576. \\
\hline 3 & 3 & 1976 & 0.0 & 2136 & $23^{\circ} 25.5^{\prime}$ & $-41^{\circ} 12.0^{\prime}$ & 1488.1 & 8.3 & 75 & 39553. \\
\hline 4 & 3 & 1976 & 0.0 & 000 & $23^{\circ} 30.5^{\prime}$ & $-40^{\circ} 51.0^{\prime}$ & 1508.0 & 8.5 & 76 & 39517. \\
\hline 4 & 3 & 1976 & 0.0 & 018 & $23^{\circ} 31.1^{\prime}$ & $-40^{\circ} 48.3^{\prime}$ & 1510.5 & 8.3 & 77 & 39512 . \\
\hline 4 & 3 & 1976 & 0.0 & 108 & $23^{\circ} 32.7^{\prime}$ & $-40^{\circ} 41.0^{\prime}$ & 1517.4 & 8.5 & 74 & 39498. \\
\hline 4 & 3 & 1976 & 0.0 & 204 & $23^{\circ} 34.9^{\prime}$ & $-40^{\circ} 32.7^{\prime}$ & 1525.3 & 8.8 & 78 & 39486. \\
\hline 4 & 3 & 1976 & 0.0 & 307 & $23^{\circ} 36.8^{\prime}$ & $-40^{\circ} 22.8^{\prime}$ & 1534.6 & 6.2 & 77 & 39465 . \\
\hline 4 & 3 & 1976 & 0.0 & 347 & $23^{\circ} 37.7^{\prime}$ & $-40^{\circ} 18.4^{\prime}$ & 1538.7 & 8.8 & 78 & 39456. \\
\hline 4 & 3 & 1976 & 0.0 & 424 & $23^{\circ} 38.8^{\prime}$ & $-40^{\circ} 12.6^{\prime}$ & 1544.1 & 9.0 & 78 & 39444. \\
\hline 4 & 3 & 1976 & 0.0 & 700 & $23^{\circ} 43.6^{\prime}$ & $-39^{\circ} 47.6^{\prime}$ & 1567.5 & 8.9 & 80 & 39393. \\
\hline 4 & 3 & 1976 & 0.0 & 740 & $23^{\circ} 44.6^{\prime}$ & $-39^{\circ} 41.2^{\prime}$ & 1573.5 & 9.2 & 80 & 39377. \\
\hline 4 & 3 & 1976 & 0.0 & 926 & $23^{\circ} 47.5^{\prime}$ & $-39^{\circ} 23.8^{\prime}$ & 1589.7 & 8.9 & 77 & 39338. \\
\hline 4 & 3 & 1976 & 0.0 & 1104 & $23^{\circ} 50.7^{\prime}$ & $-39^{\circ} 08.3^{\prime}$ & 1604.2 & 9.0 & 80 & 39310 . \\
\hline 4 & 3 & 1976 & 0.0 & 1206 & $23^{\circ} 52.3^{\prime}$ & $-38^{\circ} 58.3^{\prime}$ & 1613.5 & 9.0 & 79 & 39287. \\
\hline 4 & 3 & 1976 & 0.0 & 1248 & $23^{\circ} 53.5^{\prime}$ & $-38^{\circ} 51.5^{\prime}$ & 1619.8 & 8.4 & 77 & 39273. \\
\hline 4 & 3 & 1976 & 0.0 & 1500 & $23^{\circ} 57.5^{\prime}$ & $-38^{\circ} 31.8^{\prime}$ & 1638.3 & 5.6 & 78 & 39237. \\
\hline 4 & 3 & 1976 & 0.0 & 1510 & $23^{\circ} 57.7^{\prime}$ & $-38^{\circ} 30.8^{\prime}$ & 1639.2 & 2.8 & 72 & 39235 . \\
\hline 4 & 3 & 1976 & 0.0 & 1645 & $23^{\circ} 59.1^{\prime}$ & $-38^{\circ} 26.2^{\prime}$ & 1643.6 & 5.7 & 74 & 39231 . \\
\hline 4 & 3 & 1976 & 0.0 & 1700 & $23^{\circ} 59.5^{\prime}$ & $-38^{\circ} 24.7^{\prime}$ & 1645.0 & 8.4 & 78 & 39229. \\
\hline 4 & 3 & 1976 & 0.0 & 1756 & $24^{\circ} 01.2^{\prime}$ & $-38^{\circ} 16.3^{\prime}$ & 1652.9 & 9.0 & 79 & 39214. \\
\hline 4 & 3 & 1976 & 0.0 & 1902 & $24^{\circ} 03.1^{\prime}$ & $-38^{\circ} 05.7^{\prime}$ & 1662.8 & 9.2 & 78 & 39193. \\
\hline 4 & 3 & 1976 & 0.0 & 2328 & $24^{\circ} 11.4^{\prime}$ & $-37^{\circ} 22.1^{\prime}$ & 1703.4 & 9.3 & 78 & 39112. \\
\hline 5 & 3 & 1976 & 0.0 & 000 & $24^{\circ} 12.4^{\prime}$ & $-37^{\circ} 16.8^{\prime}$ & 1708.4 & 9.4 & 79 & 39103. \\
\hline 5 & 3 & 1976 & 0.0 & 016 & $24^{\circ} 12.9^{\prime}$ & $-37^{\circ} 14.1^{\prime}$ & 1710.9 & 9.4 & 79 & 39098 \\
\hline 5 & 3 & 1976 & 0.0 & 116 & $24^{\circ} 14.7^{\prime}$ & $-37^{\circ} 04.0^{\prime}$ & 1720.3 & 9.1 & 78 & 39079. \\
\hline 5 & 3 & 1976 & 0.0 & 204 & $24^{\circ} 16.2^{\prime}$ & $-36^{\circ} 56.2^{\prime}$ & 1727.5 & 9.1 & 78 & 39065 . \\
\hline 5 & 3 & 1976 & 0.0 & 652 & $24^{\circ} 25.0^{\prime}$ & $-36^{\circ} 09.4^{\prime}$ & 1771.1 & 9.2 & 79 & 38984. \\
\hline 5 & 3 & 1976 & 0.0 & 838 & $24^{\circ} 28.1^{\prime}$ & $-35^{\circ} 51.8^{\prime}$ & 1787.4 & 8.9 & 81 & 38953. \\
\hline 5 & 3 & 1976 & 0.0 & 958 & $24^{\circ} 30.0^{\prime}$ & $-35^{\circ} 39.0^{\prime}$ & 1799.2 & 8.9 & 81 & 38928. \\
\hline 5 & 3 & 1976 & 0.0 & 1024 & $24^{\circ} 30.6^{\prime}$ & $-35^{\circ} 34.8^{\prime}$ & 1803.0 & 8.8 & 79 & 38919. \\
\hline 5 & 3 & 1976 & 0.0 & 1118 & $24^{\circ} 32.1^{\prime}$ & $-35^{\circ} 26.3^{\prime}$ & 1810.9 & 10.1 & 81 & 38905. \\
\hline 5 & 3 & 1976 & 0.0 & 1140 & $24^{\circ} 32.7^{\prime}$ & $-35^{\circ} 22.3^{\prime}$ & 1814.6 & 8.8 & 79 & 38897. \\
\hline 5 & 3 & 1976 & 0.0 & 1206 & $24^{\circ} 33.4^{\prime}$ & $-35^{\circ} 18.2^{\prime}$ & 1818.4 & 9.5 & 81 & 38890 . \\
\hline 5 & 3 & 1976 & 0.0 & 1308 & $24^{\circ} 34.9^{\prime}$ & $-35^{\circ} 07.5^{\prime}$ & 1828.3 & 9.5 & 81 & 38869 . \\
\hline 5 & 3 & 1976 & 0.0 & 1352 & $24^{\circ} 36.0^{\prime}$ & $-34^{\circ} 59.9^{\prime}$ & 1835.3 & 9.3 & 80 & 38854 . \\
\hline 5 & 3 & 1976 & 0.0 & 1702 & $24^{\circ} 40.9^{\prime}$ & $-34^{\circ} 27.8^{\prime}$ & 1864.8 & 9.6 & 80 & 38796. \\
\hline 5 & 3 & 1976 & 0.0 & 2240 & $24^{\circ} 50.1^{\prime}$ & $-33^{\circ} 29.1^{\prime}$ & 1918.9 & 9.8 & 81 & 38697. \\
\hline 6 & 3 & 1976 & 0.0 & 000 & $24^{\circ} 52.2^{\prime}$ & $-33^{\circ} 14.9^{\prime}$ & 1932.0 & 10.0 & 81 & 38674 . \\
\hline 6 & 3 & 1976 & 0.0 & 026 & $24^{\circ} 52.9^{\prime}$ & $-33^{\circ} 10.2^{\prime}$ & 1936.3 & 9.7 & 80 & 38666. \\
\hline 6 & 3 & 1976 & 0.0 & 420 & $24^{\circ} 59.7^{\prime}$ & $-32^{\circ} 29.0^{\prime}$ & 1974.3 & 9.7 & 80 & 38607. \\
\hline 6 & 3 & 1976 & 0.0 & 500 & $25^{\circ} 00.8^{\prime}$ & $-32^{\circ} 22.0^{\prime}$ & 1980.7 & 9.6 & 79 & 38596 . \\
\hline 6 & 3 & 1976 & 0.0 & 606 & $25^{\circ} 02.8^{\prime}$ & $-32^{\circ} 10.5^{\prime}$ & 1991.3 & 10.0 & 79 & 38582 . \\
\hline 6 & 3 & 1976 & 0.0 & 1000 & $25^{\circ} 10.1^{\prime}$ & $-31^{\circ} 28.1^{\prime}$ & 2030.4 & 7.5 & 80 & 38529. \\
\hline 6 & 3 & 1976 & 0.0 & 1116 & $25^{\circ} 11.8^{\prime}$ & $-31^{\circ} 17.8^{\prime}$ & 2039.9 & 6.8 & 79 & 38516. \\
\hline 6 & 3 & 1976 & 0.0 & 1125 & $25^{\circ} 12.0^{\prime}$ & $-31^{\circ} 16.7^{\prime}$ & 2040.9 & 9.9 & 78 & 38515. \\
\hline 6 & 3 & 1976 & 0.0 & 1216 & $25^{\circ} 13.8^{\prime}$ & $-31^{\circ} 07.6^{\prime}$ & 2049.3 & 9.7 & 79 & 38507 . \\
\hline 6 & 3 & 1976 & 0.0 & 1300 & $25^{\circ} 15.2^{\prime}$ & $-30^{\circ} 59.9^{\prime}$ & 2056.4 & 9.7 & 78 & 38499. \\
\hline 6 & 3 & 1976 & 0.0 & 1606 & $25^{\circ} 21.3^{\prime}$ & $-30^{\circ} 27.5^{\prime}$ & 2086.3 & 9.8 & 79 & 38468. \\
\hline 6 & 3 & 1976 & 0.0 & 1754 & $25^{\circ} 24.7^{\prime}$ & $-30^{\circ} 08.4^{\prime}$ & 2103.9 & 9.6 & 78 & 38450 . \\
\hline 6 & 3 & 1976 & 0.0 & 1912 & $25^{\circ} 27.2^{\prime}$ & $-29^{\circ} 54.9^{\prime}$ & 2116.4 & 9.9 & 80 & 38438. \\
\hline 6 & 3 & 1976 & 0.0 & 2220 & $25^{\circ} 32.6^{\prime}$ & $-29^{\circ} 21.1^{\prime}$ & 2147.4 & 9.2 & 80 & 38403. \\
\hline 6 & 3 & 1976 & 0.0 & 2238 & $25^{\circ} 33.1^{\prime}$ & $-29^{\circ} 18.1^{\prime}$ & 2150.1 & 9.8 & 80 & 38400 . \\
\hline 7 & 3 & 1976 & 0.0 & 000 & $25^{\circ} 35.4^{\prime}$ & $-29^{\circ} 03.5^{\prime}$ & 2163.5 & 10.9 & 90 & 38386. \\
\hline 7 & 3 & 1976 & 0.0 & 002 & $25^{\circ} 35.4^{\prime}$ & $-29^{\circ} 03.1^{\prime}$ & 2163.8 & 9.9 & 78 & 38385 . \\
\hline 7 & 3 & 1976 & 0.0 & 324 & $25^{\circ} 42.5^{\prime}$ & $-28^{\circ} 26.8^{\prime}$ & 2197.3 & 10.5 & 73 & 38364 . \\
\hline
\end{tabular}


TABLE 2 - Continued

\begin{tabular}{|c|c|c|c|c|c|c|c|c|c|c|}
\hline Day & Mon & Year & $\begin{array}{l}\text { Time } \\
\text { Zoile }\end{array}$ & Time & Latitude & Longitude & Distance & Speed & Course & $\begin{array}{c}\text { Regional Magnetic } \\
\text { Field Value (Gammas) }\end{array}$ \\
\hline 7 & 3 & 1976 & 0.0 & 510 & $25^{\circ} 48.0^{\prime}$ & $-28^{\circ} 07.1^{\prime}$ & 2215.9 & 10.0 & 83 & 38368. \\
\hline 7 & 3 & 1976 & 0.0 & 700 & $25^{\circ} 50.1^{\prime}$ & $-27^{\circ} 46.8^{\prime}$ & 2234.3 & 9.5 & 78 & 38342. \\
\hline 7 & 3 & 1976 & 0.0 & 846 & $25^{\circ} 53.7^{\prime}$ & $-27^{\circ} 28.5^{\prime}$ & 2251.2 & 10.6 & 79 & 38335 . \\
\hline 7 & 3 & 1976 & 0.0 & 928 & $25^{\circ} 55.1^{\prime}$ & $-27^{\circ} 20.4^{\prime}$ & 2258.6 & 10.1 & 80 & 38330 . \\
\hline 7 & 3 & 1976 & 0.0 & 1112 & $25^{\circ} 58.1^{\prime}$ & $-27^{\circ} 01.3^{\prime}$ & 2276.0 & 9.3 & 79 & 38317. \\
\hline 7 & 3 & 1976 & 0.0 & 1148 & $25^{\circ} 59.2^{\prime}$ & $-26^{\circ} 55.2^{\prime}$ & 2281.6 & 8.9 & 78 & 38314. \\
\hline 7 & 3 & 1976 & 0.0 & 1514 & $26^{\circ} 05.3^{\prime}$ & $-26^{\circ} 21.9^{\prime}$ & 2312.1 & 8.6 & 79 & 38302 . \\
\hline 7 & 3 & 1976 & 0.0 & 1658 & $26^{\circ} 08.1^{\prime}$ & $-26^{\circ} 05.5^{\prime}$ & 2327.1 & 9.4 & 79 & 38295. \\
\hline 7 & 3 & 1976 & 0.0 & 1705 & $26^{\circ} 08.3^{\prime}$ & $-26^{\circ} 04.3^{\prime}$ & 2328.2 & 11.0 & 77 & 38294. \\
\hline 7 & 3 & 1976 & 0.0 & 1710 & $26^{\circ} 08.5^{\prime}$ & $-26^{\circ} 03.3^{\prime}$ & 2329.1 & 9.9 & 79 & 38294. \\
\hline 7 & 3 & 1976 & 0.0 & 1730 & $26^{\circ} 09.1^{\prime}$ & $-25^{\circ} 59.7^{\prime}$ & 2332.4 & 7.4 & 80 & 38293. \\
\hline 7 & 3 & 1976 & 0.0 & 1815 & $26^{\circ} 10.1^{\prime}$ & $-25^{\circ} 53.6^{\prime}$ & 2338.0 & 10.2 & 80 & 38290 . \\
\hline 7 & 3 & 1976 & 0.0 & 1822 & $26^{\circ} 10.3^{\prime}$ & $-25^{\circ} 52.3^{\prime}$ & 2339.2 & 9.2 & 79 & 38289. \\
\hline 7 & 3 & 1976 & 0.0 & 2006 & $26^{\circ} 13.2^{\prime}$ & $-25^{\circ} 34.9^{\prime}$ & 2355.1 & 9.0 & 78 & 38283. \\
\hline 7 & 3 & 1976 & 0.0 & 2114 & $26^{\circ} 15.3^{\prime}$ & $-25^{\circ} 23.8^{\prime}$ & 2365.2 & 9.2 & 80 & 38281. \\
\hline 7 & 3 & 1976 & 0.0 & 2152 & $26^{\circ} 16.3^{\prime}$ & $-25^{\circ} 17.4^{\prime}$ & 2371.1 & 9.1 & 80 & 38278 . \\
\hline 7 & 3 & 1976 & 0.0 & 2248 & $26^{\circ} 17.8^{\prime}$ & $-25^{\circ} 08.1^{\prime}$ & 2379.5 & 9.1 & 79 & 38275 . \\
\hline 7 & 3 & 1976 & 0.0 & 2328 & $26^{\circ} 19.0^{\prime}$ & $-25^{\circ} 01.5^{\prime}$ & 2385.6 & 9.4 & 80 & 38274. \\
\hline 8 & 3 & 1976 & 0.0 & 000 & $26^{\circ} 19.9^{\prime}$ & $-24^{\circ} 56.0^{\prime}$ & 2390.6 & 9.3 & 80 & 38272 . \\
\hline 8 & 3 & 1976 & 0.0 & 034 & $26^{\circ} 20.8^{\prime}$ & $-24^{\circ} 50.2^{\prime}$ & 2395.9 & 9.6 & 80 & 38270 . \\
\hline 8 & 3 & 1976 & 0.0 & 116 & $26^{\circ} 22.0^{\prime}$ & $-24^{\circ} 42.8^{\prime}$ & 2402.6 & 9.5 & 80 & 38268. \\
\hline 8 & 3 & 1976 & 0.0 & 245 & $26^{\circ} 24.5^{\prime}$ & $-24^{\circ} 27.4^{\prime}$ & 2416.6 & 9.5 & 78 & 38264. \\
\hline 8 & 3 & 1976 & 0.0 & 300 & $26^{\circ} 25.0^{\prime}$ & $-24^{\circ} 24.8^{\prime}$ & 2419.0 & 8.8 & 78 & 38264 . \\
\hline 8 & 3 & 1976 & 0.0 & 310 & $26^{\circ} 25.3^{\prime}$ & $-24^{\circ} 23.2^{\prime}$ & 2420.5 & 9.5 & 77 & 38264 . \\
\hline 8 & 3 & 1976 & 0.0 & 800 & $26^{\circ} 35.8^{\prime}$ & $-23^{\circ} 33.3^{\prime}$ & 2466.3 & 9.5 & 77 & 38277. \\
\hline 8 & 3 & 1976 & 0.0 & 940 & $26^{\circ} 39.3^{\prime}$ & $-23^{\circ} 16.0^{\prime}$ & 2482.2 & 8.5 & 77 & 38282 . \\
\hline 8 & 3 & 1976 & 0.0 & 1015 & $26^{\circ} 40.4^{\prime}$ & $-23^{\circ} 10.6^{\prime}$ & 2487.1 & 8.5 & 79 & 38284 . \\
\hline 8 & 3 & 1976 & 0.0 & 1038 & $26^{\circ} 41.0^{\prime}$ & $-23^{\circ} 07.0^{\prime}$ & 2490.4 & 9.3 & 79 & 38284 . \\
\hline 8 & 3 & 1976 & 0.0 & 1118 & $26^{\circ} 42.2^{\prime}$ & $-23^{\circ} 00.2^{\prime}$ & 2496.6 & 9.1 & 80 & 38284. \\
\hline 8 & 3 & 1976 & 0.0 & 1152 & $26^{\circ} 43.1^{\prime}$ & $-22^{\circ} 54.5^{\prime}$ & 2501.8 & 8.8 & 78 & 38284 . \\
\hline 8 & 3 & 1976 & 0.0 & 1226 & $26^{\circ} 44.1^{\prime}$ & $-22^{\circ} 49.0^{\prime}$ & 2506.8 & 9.1 & 81 & 38285. \\
\hline 8 & 3 & 1976 & 0.0 & 1306 & $26^{\circ} 45.0^{\prime}$ & $-22^{\circ} 42.3^{\prime}$ & 2512.8 & 8.5 & 80 & 38284 . \\
\hline 8 & 3 & 1976 & 0.0 & 1734 & $26^{\circ} 51.6^{\prime}$ & $-22^{\circ} 00.2^{\prime}$ & 2551.0 & 8.5 & 82 & 38285 . \\
\hline 8 & 3 & 1976 & 0.0 & 2102 & $26^{\circ} 55.6^{\prime}$ & $-21^{\circ} 27.3^{\prime}$ & 2580.6 & 8.4 & 76 & 38279. \\
\hline 8 & 3 & 1976 & 0.0 & 2148 & $26^{\circ} 57.1^{\prime}$ & $-21^{\circ} 20.3^{\prime}$ & 2587.0 & 8.2 & 78 & 38284. \\
\hline 8 & 3 & 1976 & 0.0 & 2236 & $26^{\circ} 58.5^{\prime}$ & $-21^{\circ} 13.1^{\prime}$ & 2593.6 & 8.8 & 83 & 38288. \\
\hline 8 & 3 & 1976 & 0.0 & 2334 & $26^{\circ} 59.5^{\prime}$ & $-21^{\circ} 03.6^{\prime}$ & 2602.1 & 8.3 & 82 & 38285 . \\
\hline 9 & 3 & 1976 & 0.0 & 000 & $27^{\circ} 00.0^{\prime}$ & $-20^{\circ} 59.6^{\prime}$ & 2605.7 & 8.4 & 81 & 38285 . \\
\hline 9 & 3 & 1976 & 0.0 & 022 & $27^{\circ} 00.5^{\prime}$ & $-20^{\circ} 56.2^{\prime}$ & 2608.8 & 9.3 & 81 & 38286. \\
\hline 9 & 3 & 1976 & 0.0 & 320 & $27^{\circ} 05.0^{\prime}$ & $-20^{\circ} 25.7^{\prime}$ & 2636.3 & 8.5 & 81 & 38292. \\
\hline 9 & 3 & 1976 & 0.0 & 506 & $27^{\circ} 07.4^{\prime}$ & $-20^{\circ} 09.0^{\prime}$ & 2651.4 & 9.2 & 82 & 38295 . \\
\hline 9 & 3 & 1976 & 0.0 & 520 & $27^{\circ} 07.7^{\prime}$ & $-20^{\circ} 06.6^{\prime}$ & 2653.5 & 9.1 & 77 & 38296. \\
\hline 9 & 3 & 1976 & 0.0 & 526 & $27^{\circ} 07.9^{\prime}$ & $-20^{\circ} 05.6^{\prime}$ & 2654.4 & 8.9 & 80 & 38296. \\
\hline 9 & 3 & 1976 & 0.0 & 708 & $27^{\circ} 10.6^{\prime}$ & $-19^{\circ} 48.9^{\prime}$ & 2669.5 & 8.6 & 79 & 38303. \\
\hline 9 & 3 & 1976 & 0.0 & 815 & $27^{\circ} 12.5^{\prime}$ & $-19^{\circ} 38.3^{\prime}$ & 2679.2 & 8.6 & 77 & 38310. \\
\hline 9 & 3 & 1976 & 0.0 & 952 & $27^{\circ} 15.7^{\prime}$ & $-19^{\circ} 23.0^{\prime}$ & 2693.1 & 9.0 & 76 & 38323. \\
\hline 9 & 3 & 1976 & 0.0 & 1028 & $27^{\circ} 17.0^{\prime}$ & $-19^{\circ} 17.1^{\prime}$ & 2698.5 & 8.8 & 76 & 38329. \\
\hline 9 & 3 & 1976 & 0.0 & 1048 & $27^{\circ} 17.7^{\prime}$ & $-19^{\circ} 13.9^{\prime}$ & 2701.5 & 9.0 & 74 & 38332. \\
\hline 9 & 3 & 1976 & 0.0 & 1138 & $27^{\circ} 19.7^{\prime}$ & $-19^{\circ} 05.8^{\prime}$ & 2708.9 & 8.1 & 72 & 38343. \\
\hline 9 & 3 & 1976 & 0.0 & 1214 & $27^{\circ} 21.2^{\prime}$ & $-19^{\circ} 00.6^{\prime}$ & 2713.8 & 8.4 & 72 & 38351 . \\
\hline 9 & 3 & 1976 & 0.0 & 1508 & $27^{\circ} 28.6^{\prime}$ & $-18^{\circ} 34.3^{\prime}$ & 2738.3 & 8.7 & 73 & 38393. \\
\hline 9 & 3 & 1976 & 0.0 & 1700 & $27^{\circ} 33.3^{\prime}$ & $-18^{\circ} 16.7^{\prime}$ & 2754.6 & 8.7 & 80 & 38419. \\
\hline 9 & 3 & 1976 & 0.0 & 1735 & $27^{\circ} 34.2^{\prime}$ & $-18^{\circ} 11.1^{\prime}$ & 2759.6 & 8.7 & 85 & 38423. \\
\hline 9 & 3 & 1976 & 0.0 & 1843 & $27^{\circ} 35.0^{\prime}$ & $-18^{\circ} 00.0^{\prime}$ & 2769.5 & 8.7 & 75 & 38422 . \\
\hline 9 & 3 & 1976 & 0.0 & 2014 & $27^{\circ} 38.5^{\prime}$ & $-17^{\circ} 45.6^{\prime}$ & 2782.7 & 10.0 & 84 & 38442 . \\
\hline 9 & 3 & 1976 & 0.0 & 2030 & $27^{\circ} 38.8^{\prime}$ & $-17^{\circ} 42.6^{\prime}$ & 2785.4 & 9.3 & 84 & 38443. \\
\hline 9 & 3 & 1976 & 0.0 & 2050 & $27^{\circ} 39.1^{\prime}$ & $-17^{\circ} 39.1^{\prime}$ & 2788.5 & 9.9 & 83 & 38443. \\
\hline 9 & 3 & 1976 & 0.0 & 2110 & $27^{\circ} 39.5^{\prime}$ & $-17^{\circ} 35.4^{\prime}$ & 2791.8 & 9.5 & 66 & 38444 . \\
\hline 9 & 3 & 1976 & 0.0 & 2300 & $27^{\circ} 46.6^{\prime}$ & $-17^{\circ} 17.4^{\prime}$ & 2809.3 & 4.0 & 53 & 38493. \\
\hline 9 & 3 & 1976 & 0.0 & 2305 & $27^{\circ} 46.8^{\prime}$ & $-17^{\circ} 17.1^{\prime}$ & 2809.6 & & & 38494. \\
\hline
\end{tabular}




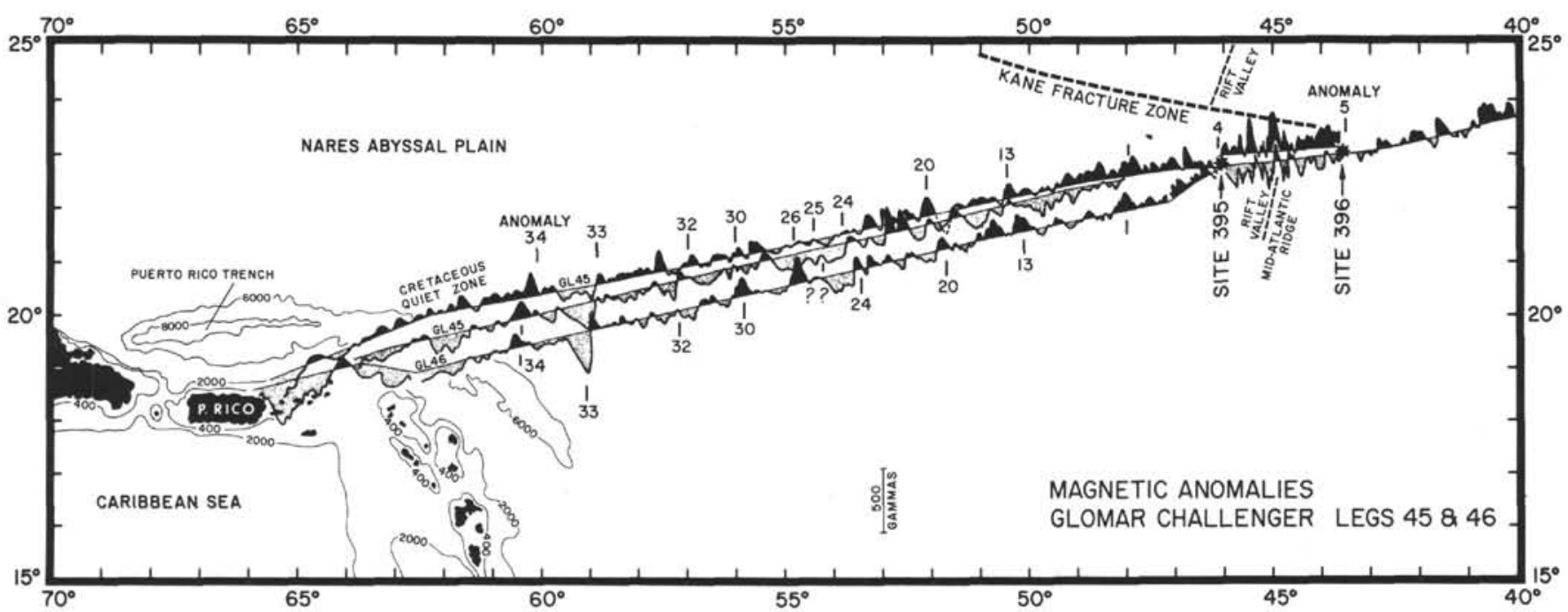

Figure 4. Magnetic anomalies plotted normal to ship's tracks for Glomar Challenger Legs 45 and 46 between San Juan, Puerto Rico, and Site 396. Magnetic anomaly numbering identification after Heirtzler et al. (1968) and LaBrecque et al. (1977).

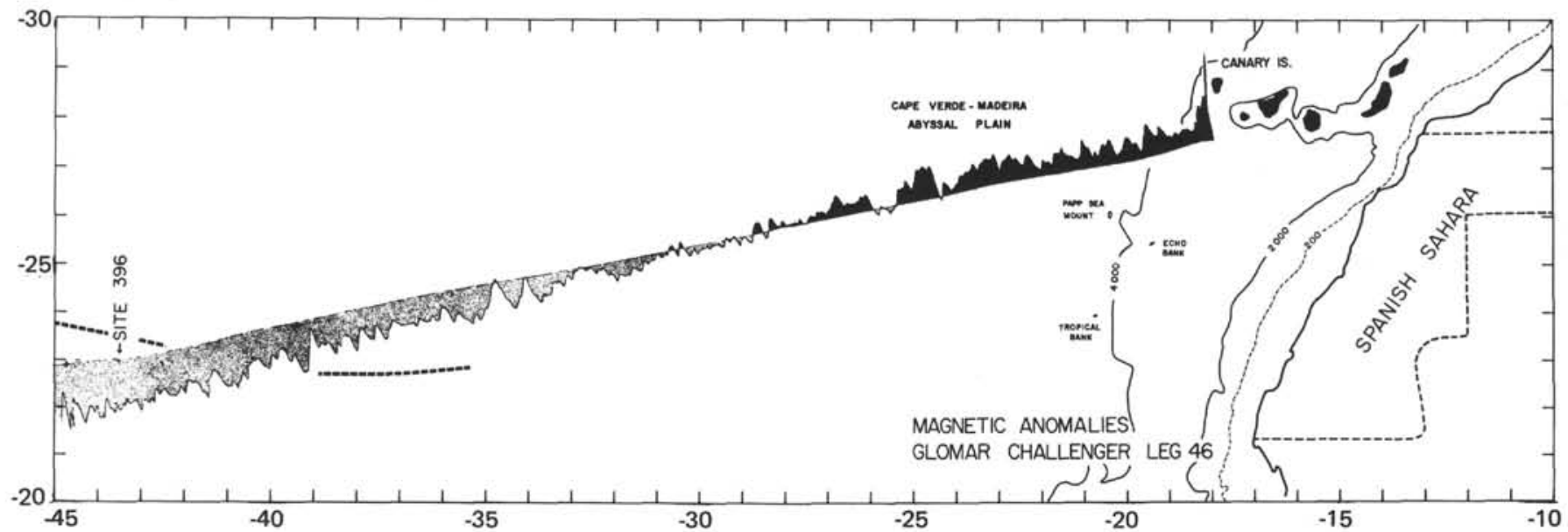

Figure 5. Magnetic anomalies plotted normal to ship's track for Glomar Challenger Leg 46 between Site 396 and Las Palmas, Canary Islands. 
(A) GL- 45

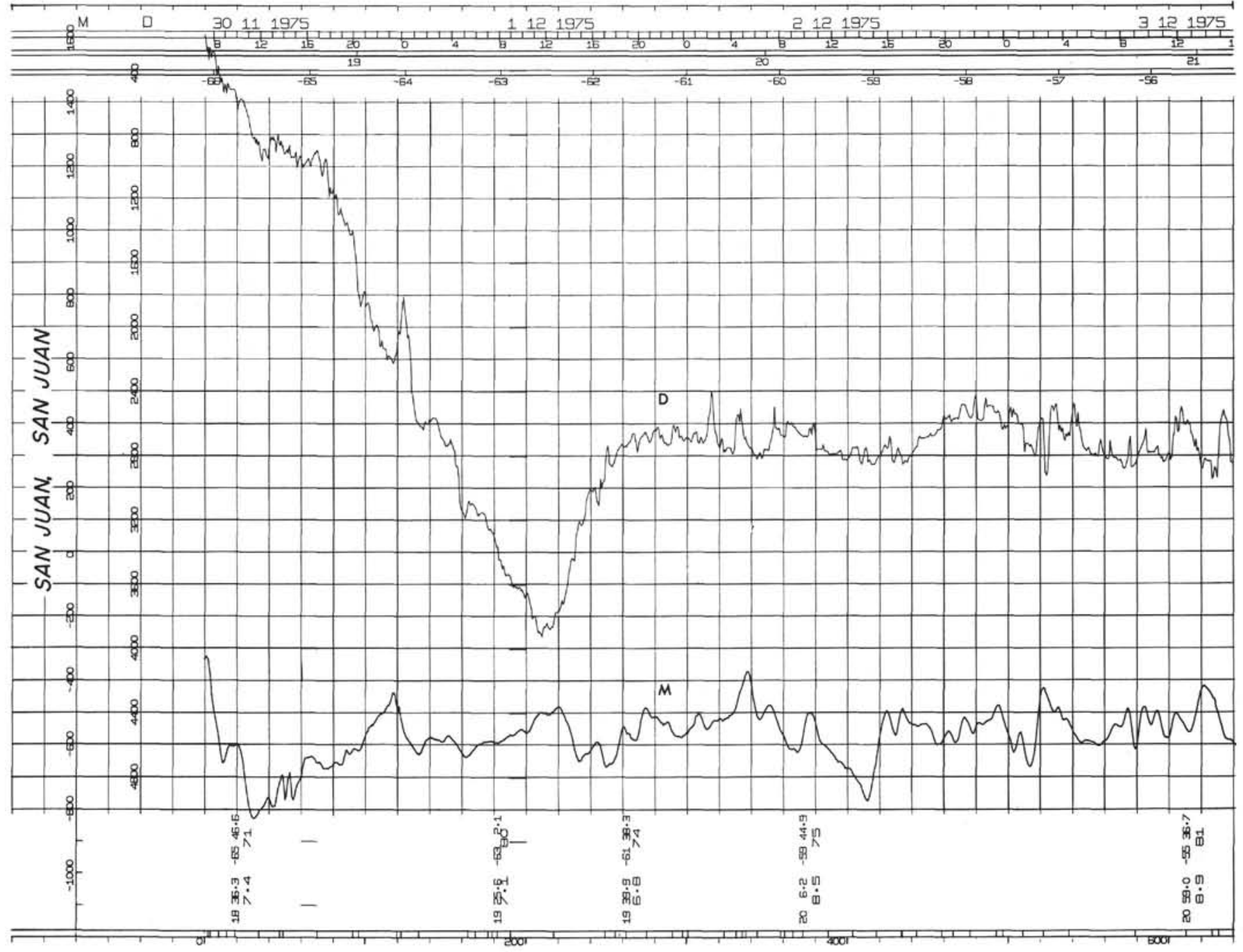

Figure 6. (A to D) Magnetic anomaly and bathymetric profiles along track of Leg 45 of Glomar Challenger. Plots and scales explained in text. 
(B)

$G L-45$

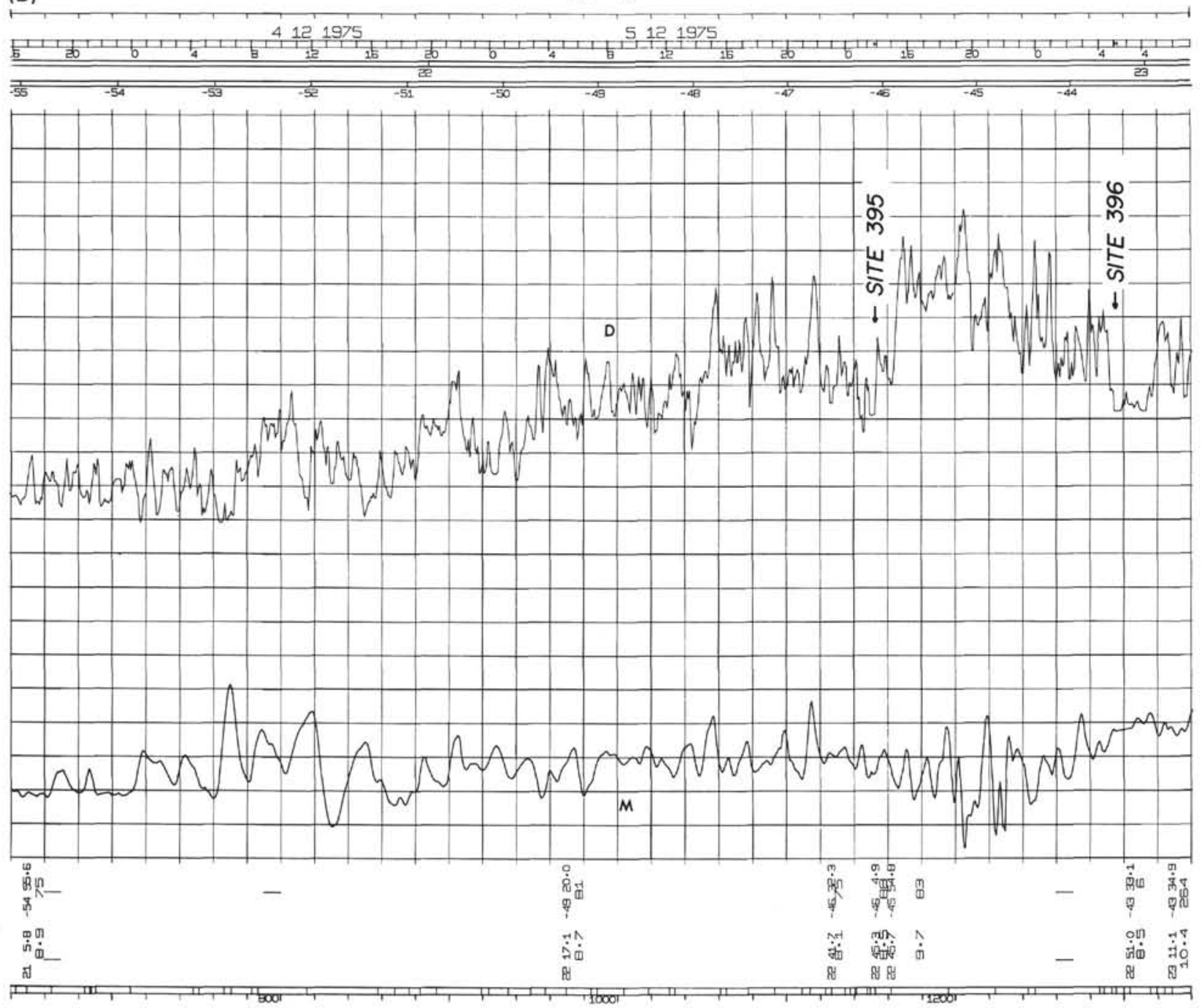

Figure 6. (Continued). 
(C)

$\mathrm{GL}-45$

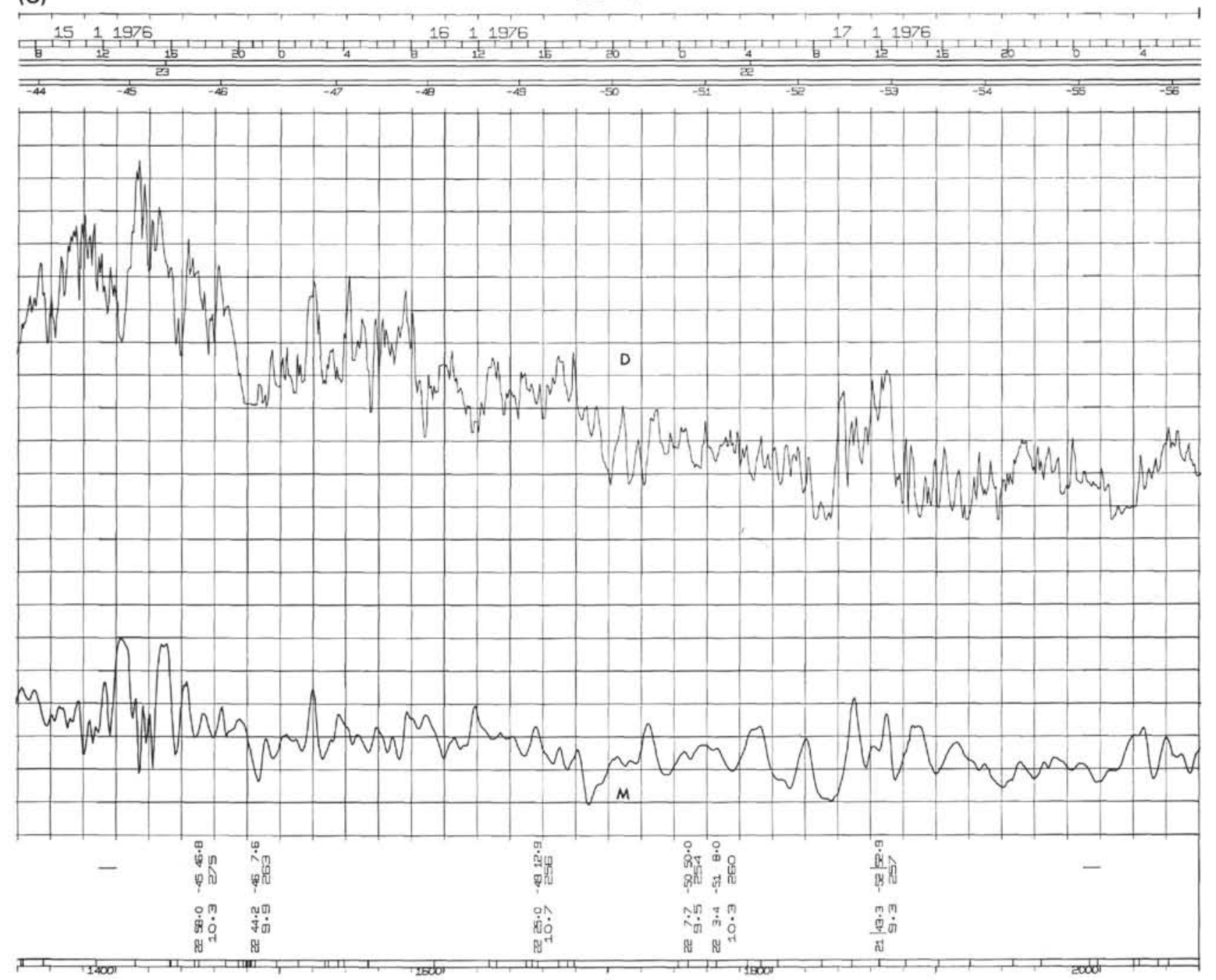

Figure 6. (Continued). 
(D)

$G L-45$

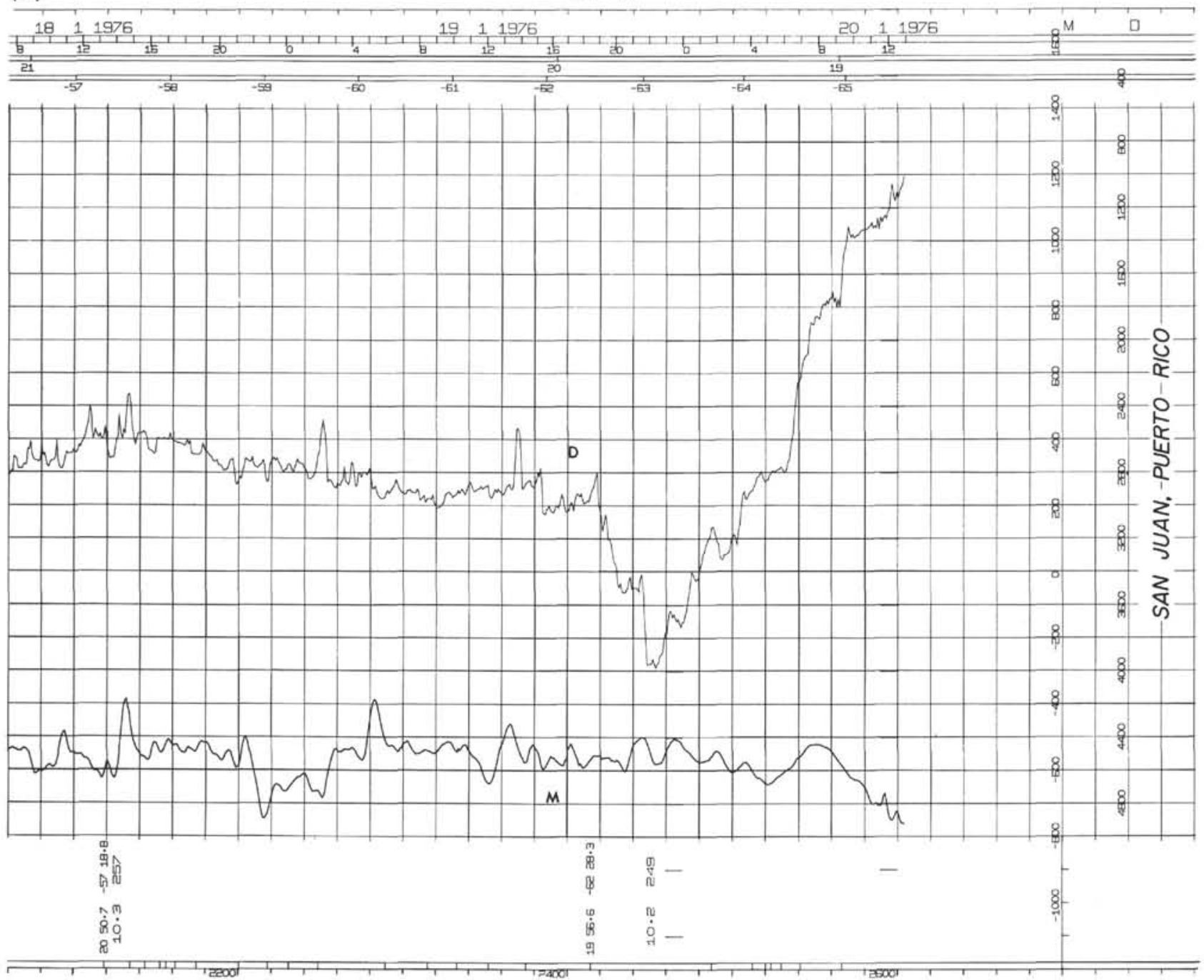

Figure 6. (Continued). 
(A)

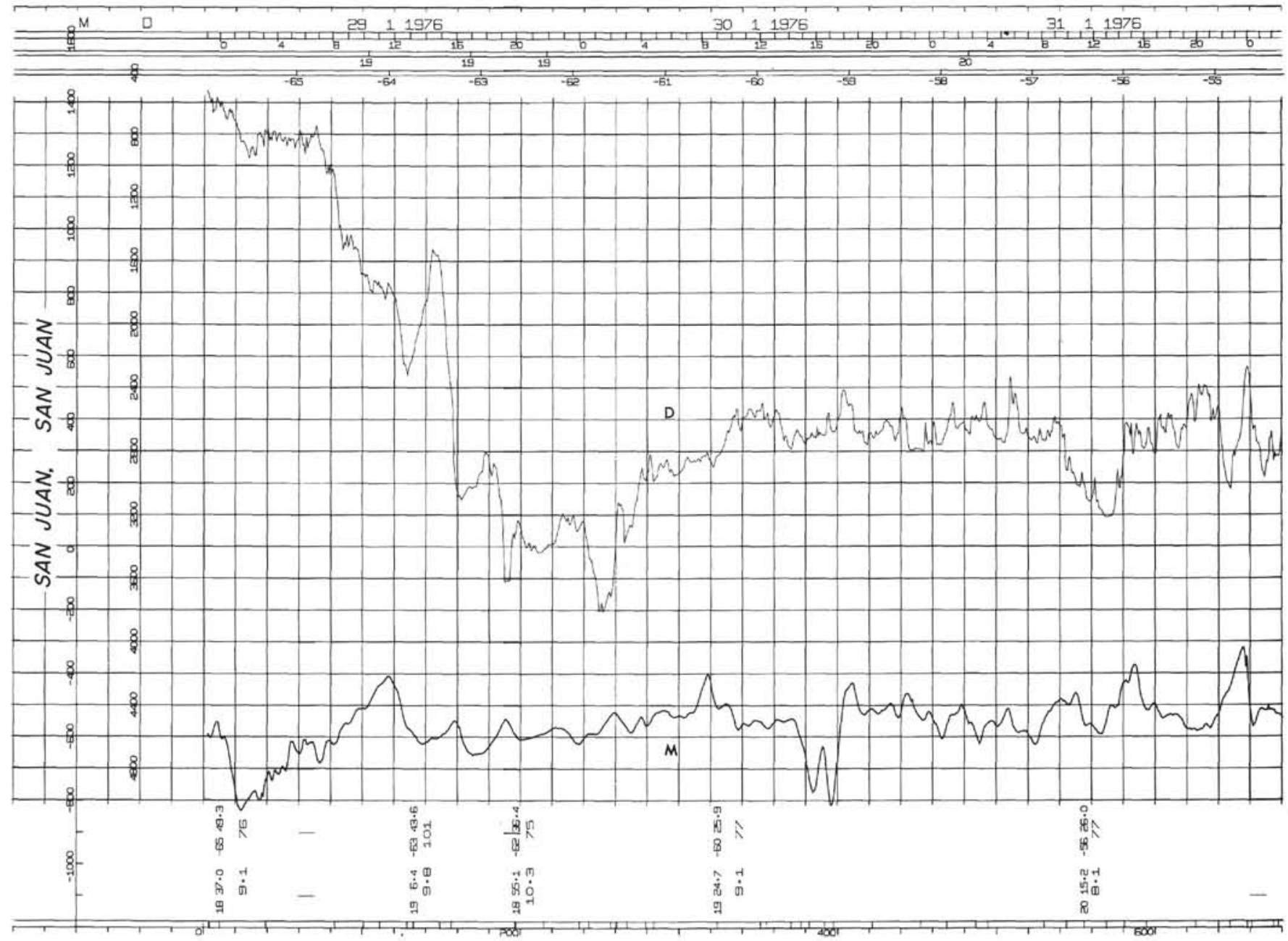

Figure 7. (A to D) Magnetic anomaly and bathymetric profiles along track of Leg 46 of Glomar Challenger. Plots and scales explained in text. 
(B)

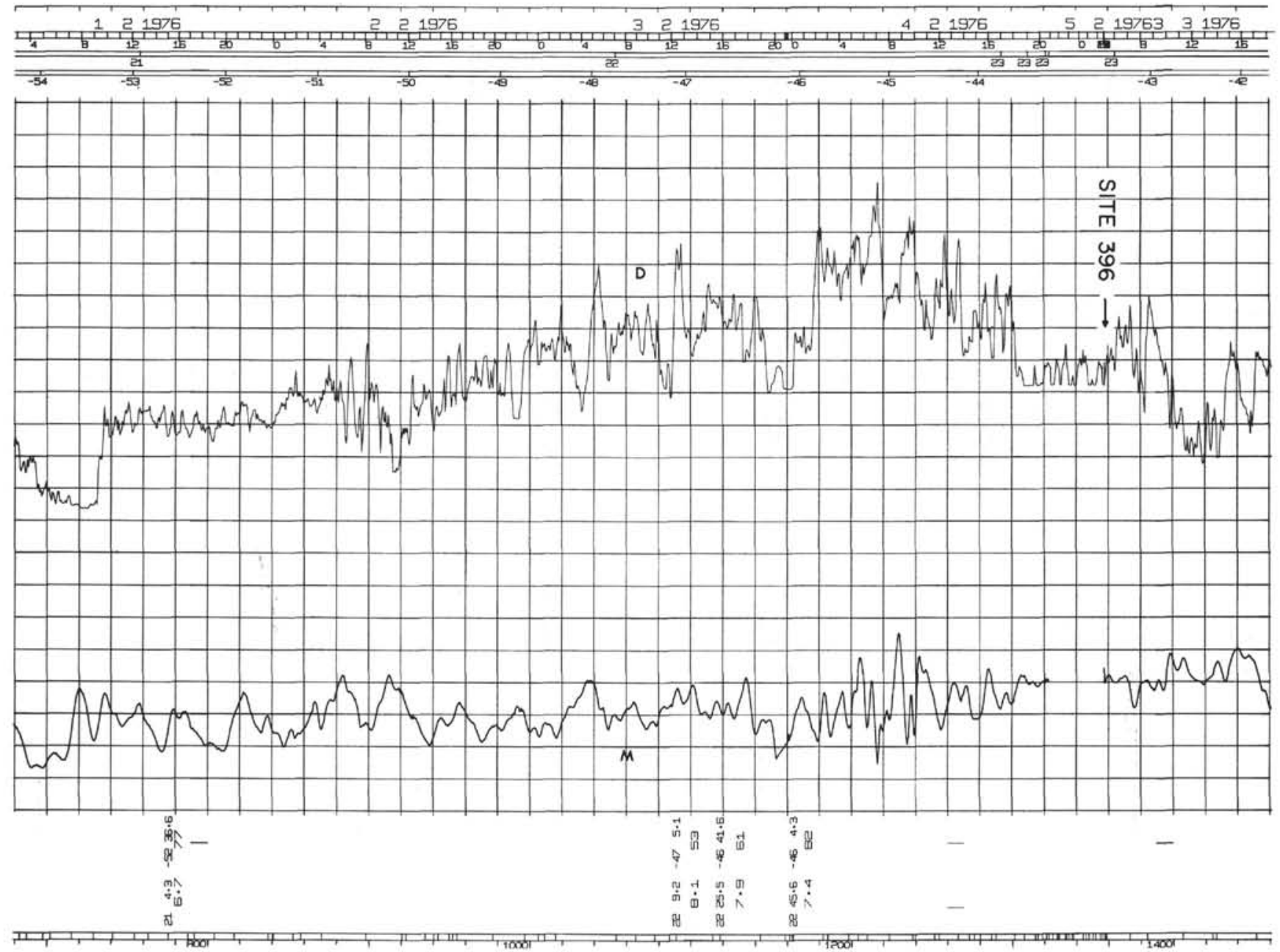

Figure 7. (Continued). 
(C)

GL-46

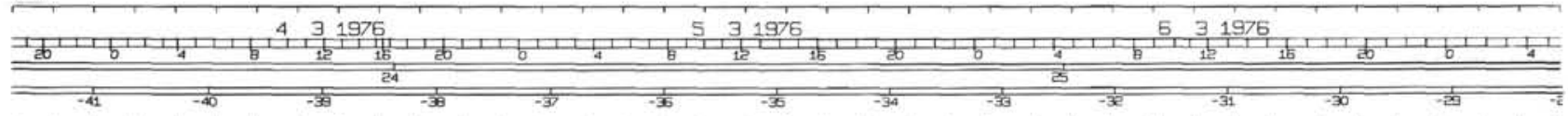

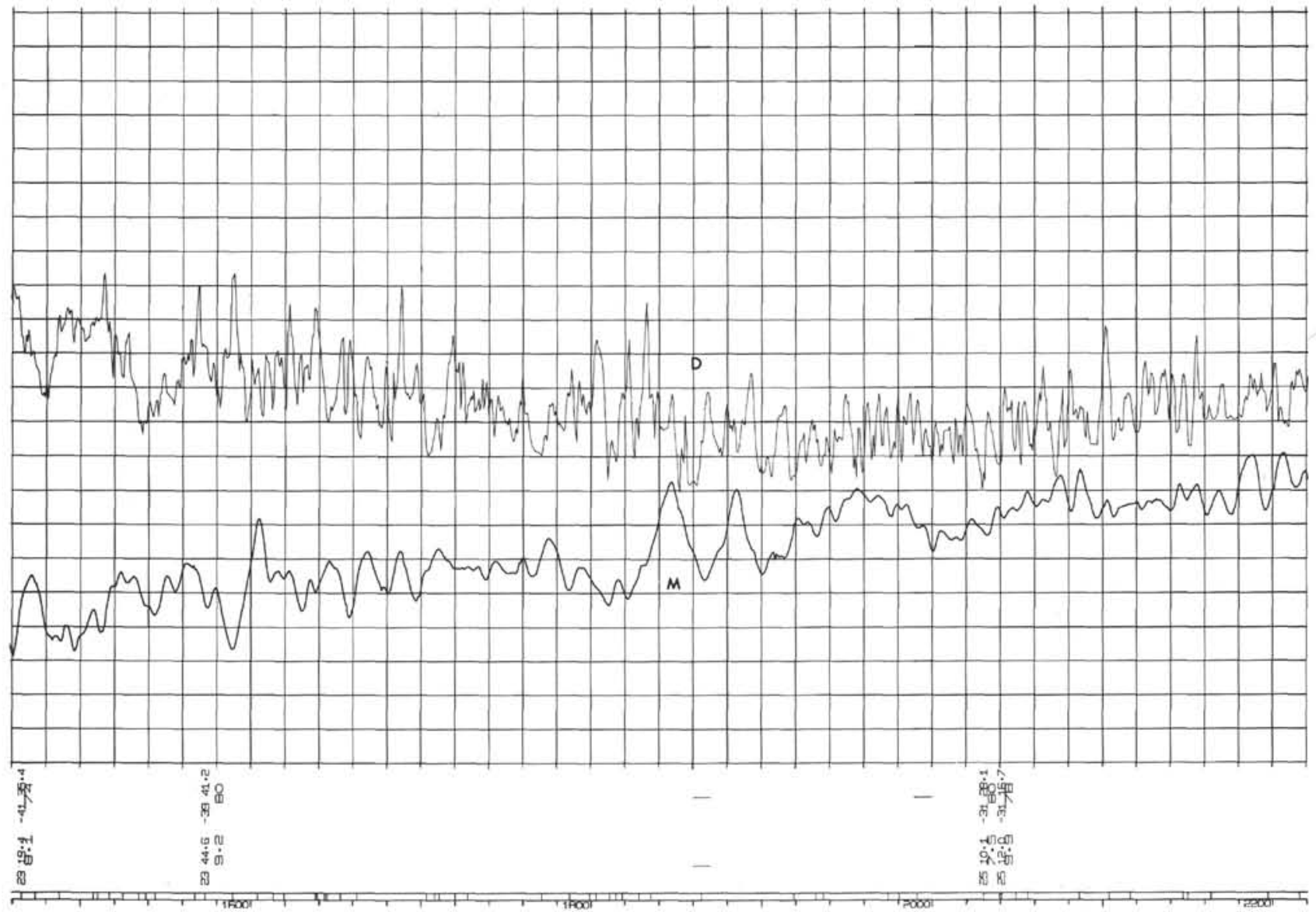

Figure 7. (Continued). 
(D)

$\mathrm{GL}-46$

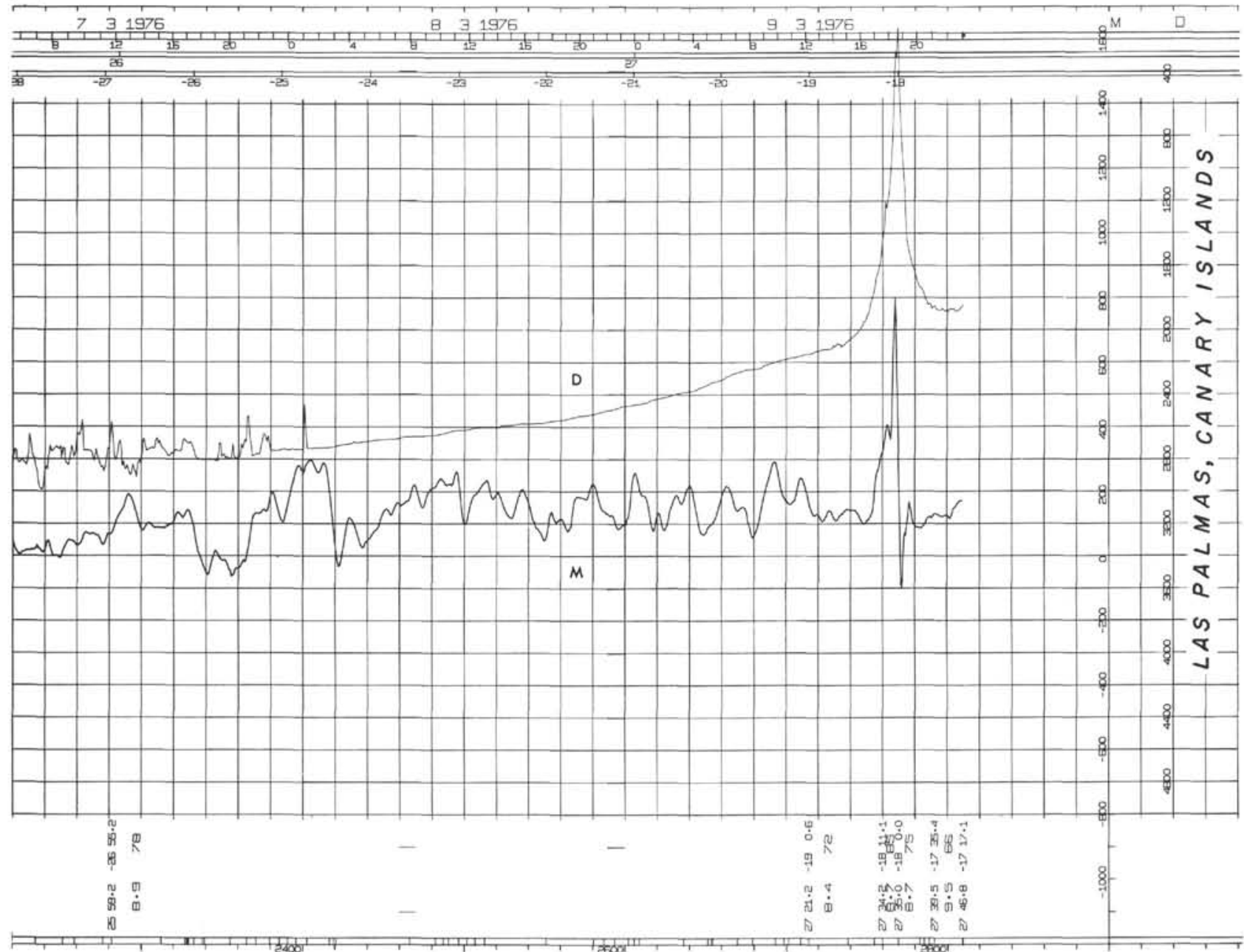

Figure 7. (Continued). 


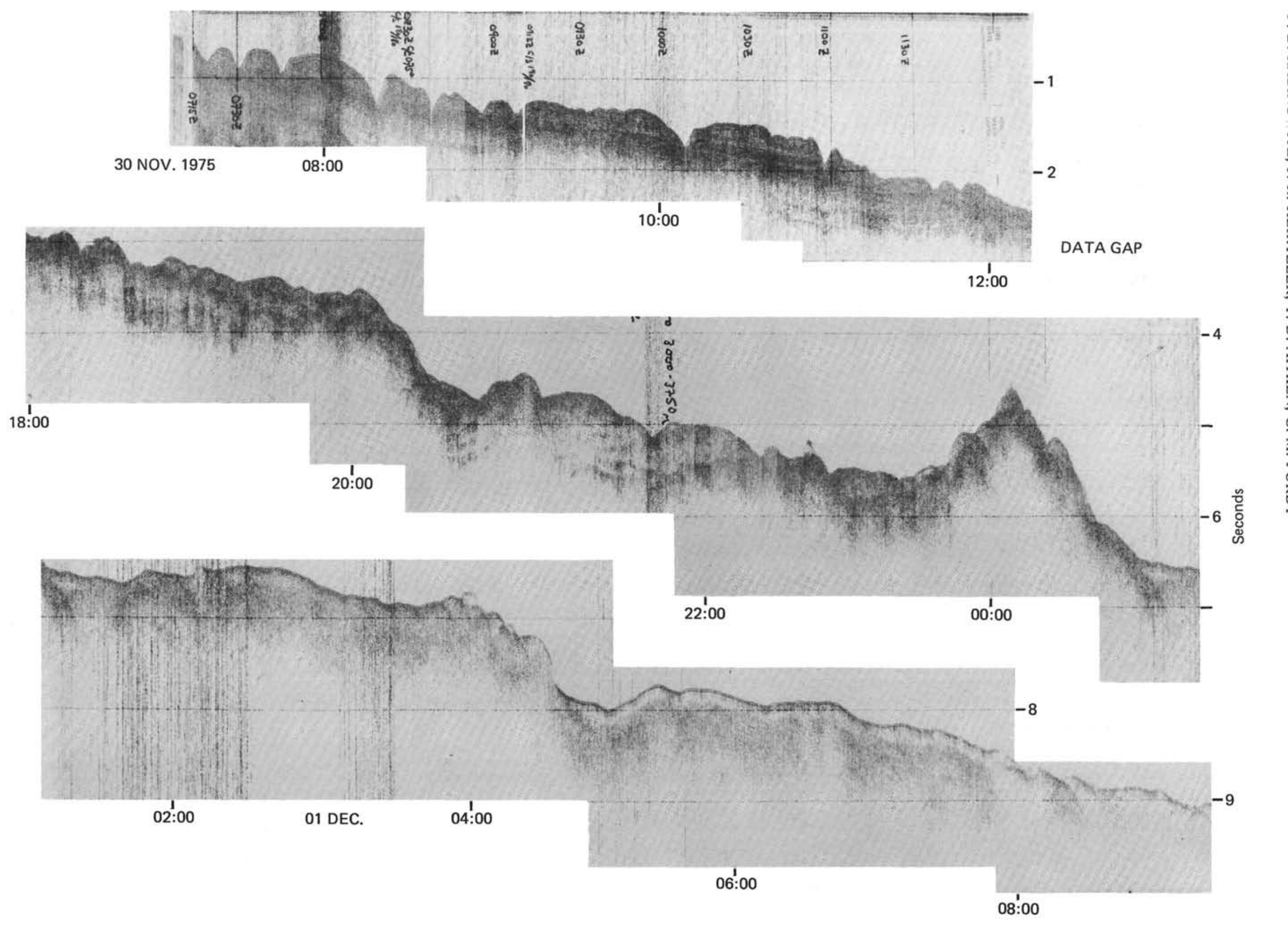

Figure 8. (8-1 to 8-18) Seismic reflection profiles along track of Leg 45 of Glomar Challenger. 

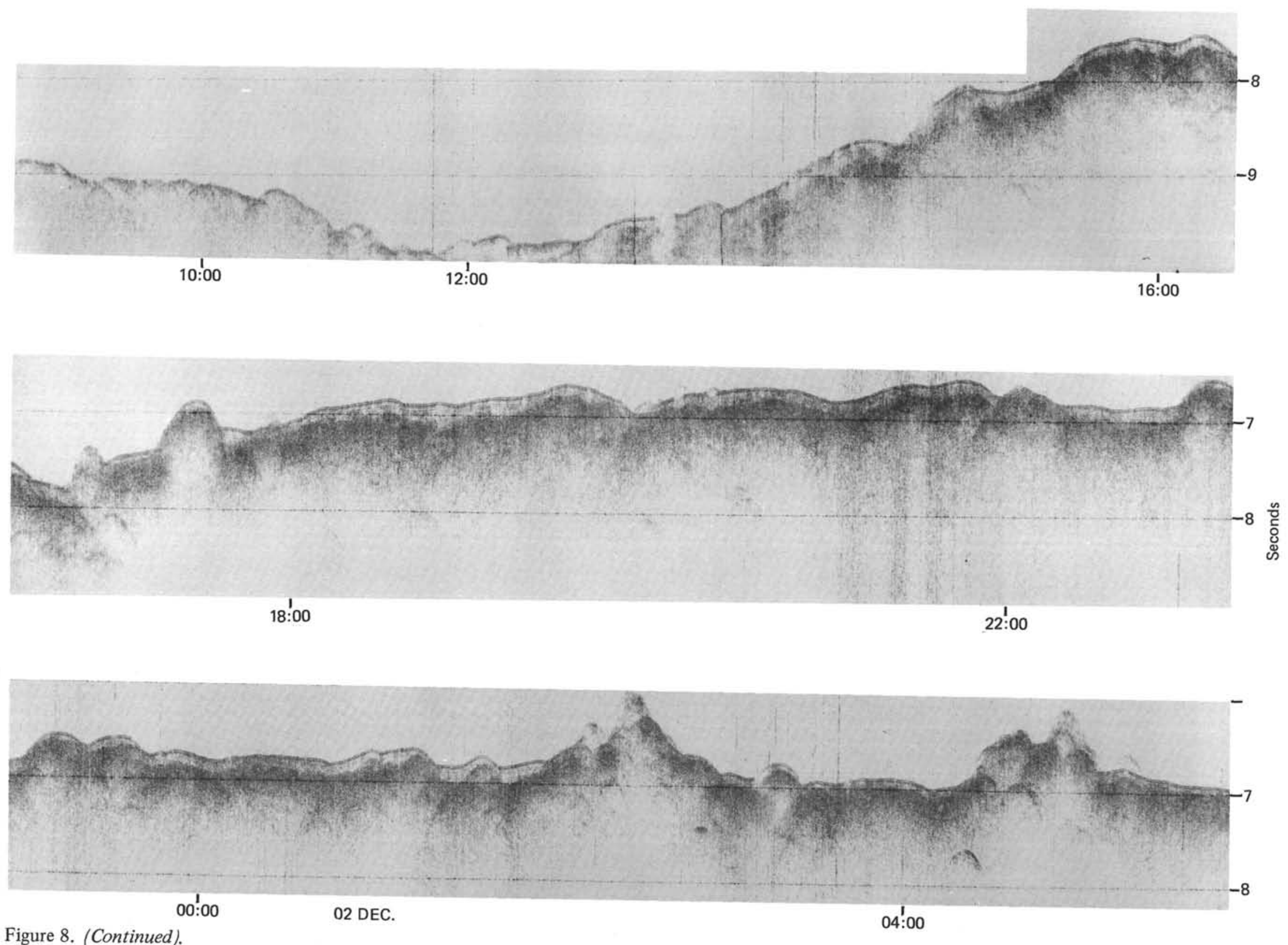

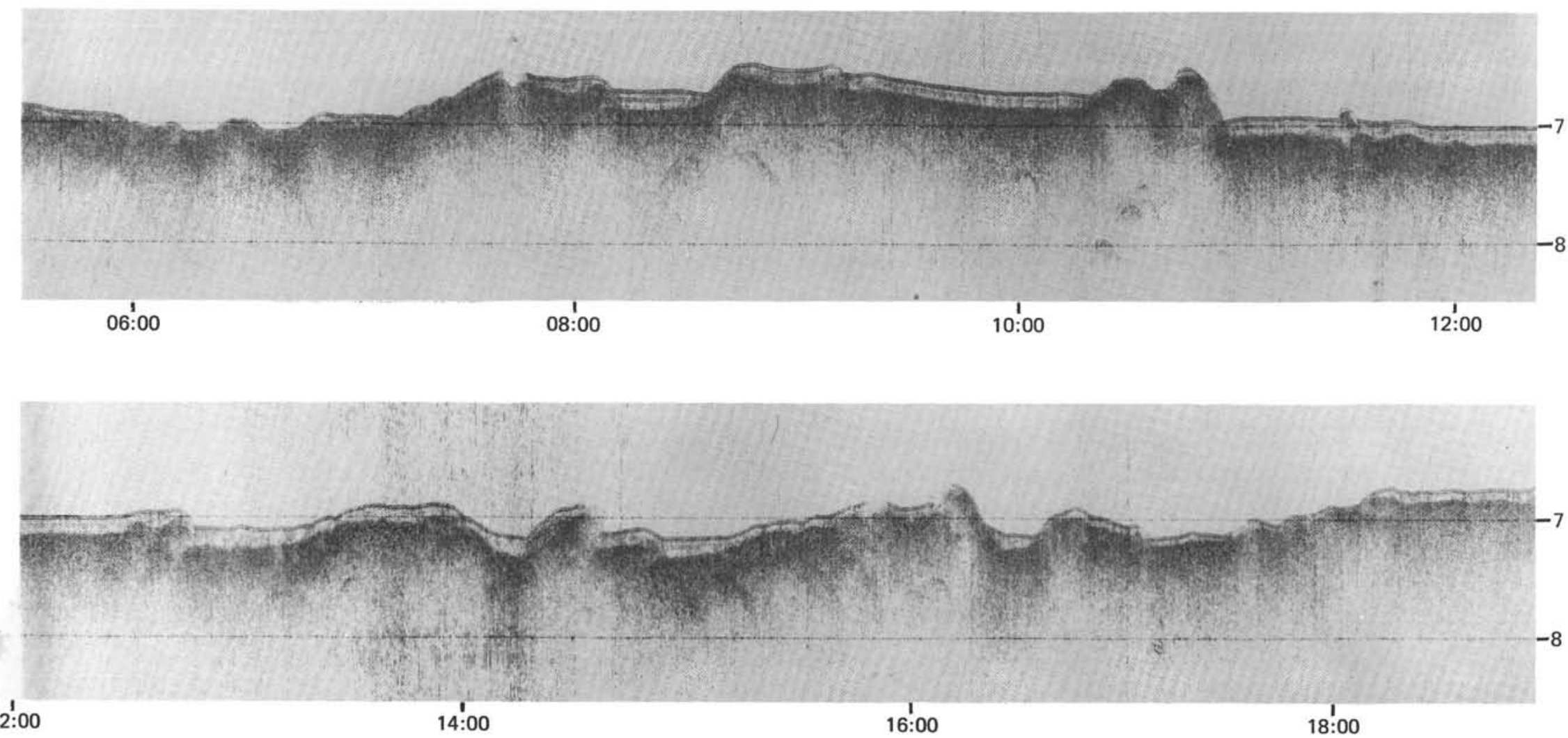

12:00 14:00

16:00

18:00

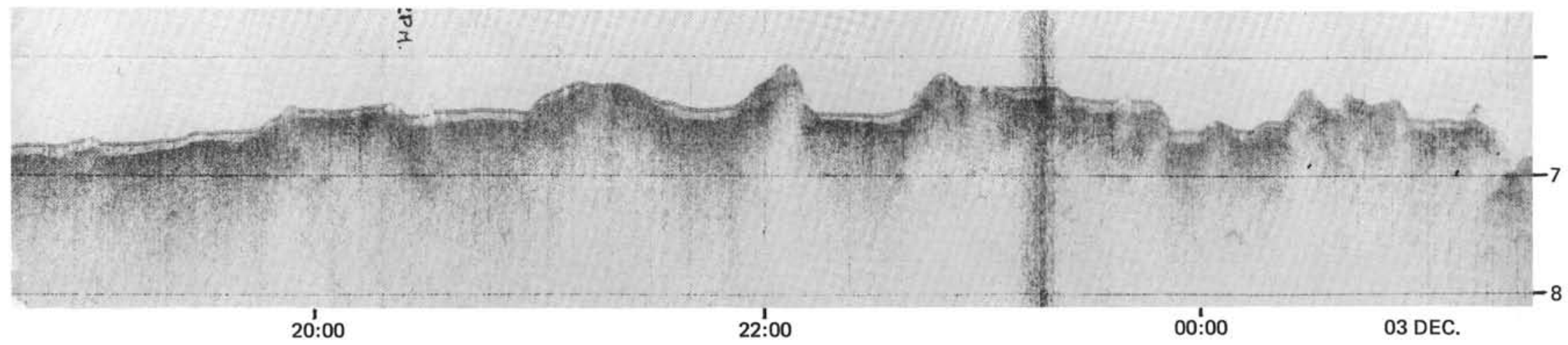

Figure 8. (Continued). 

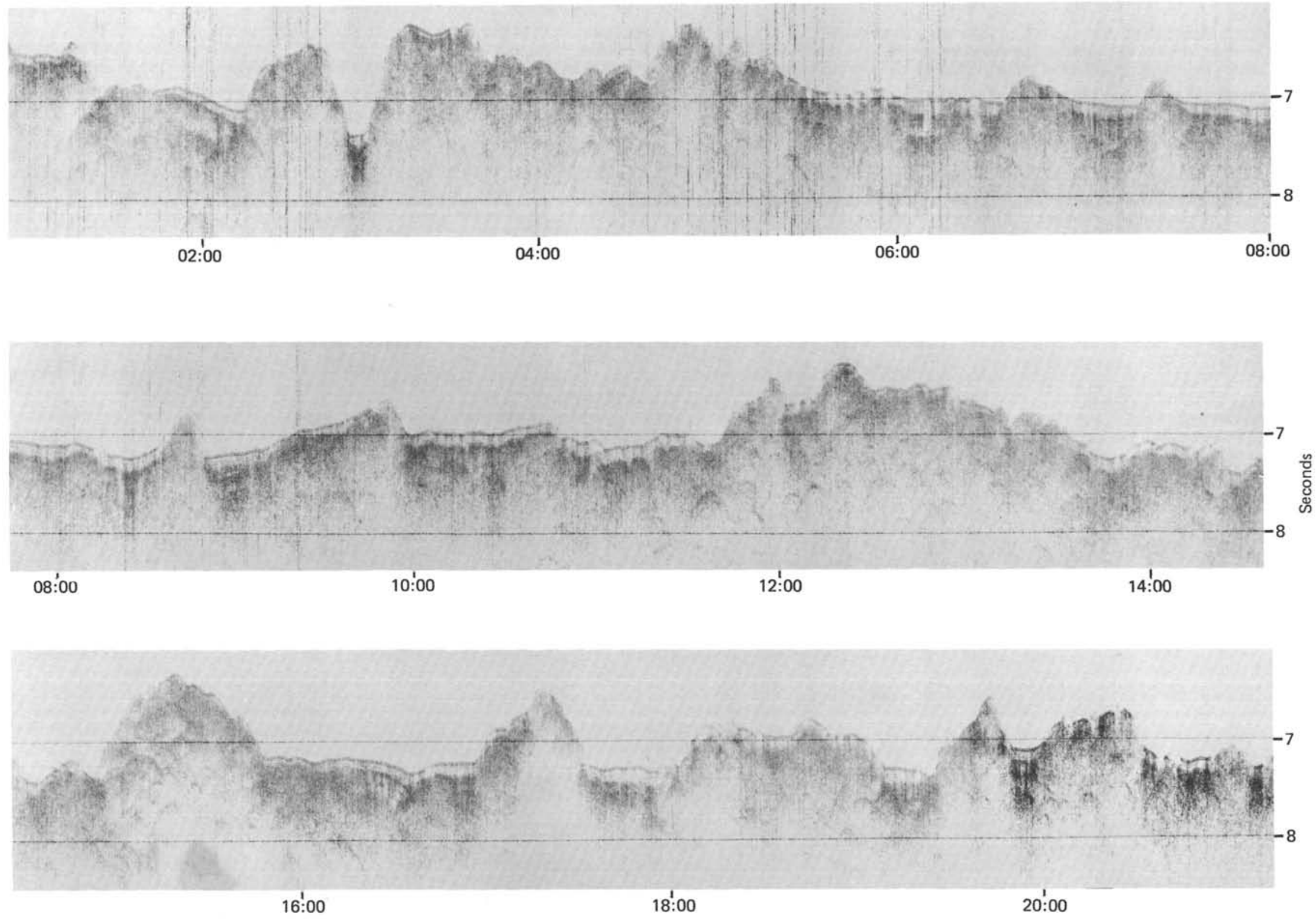

Figure 8. (Continued). 

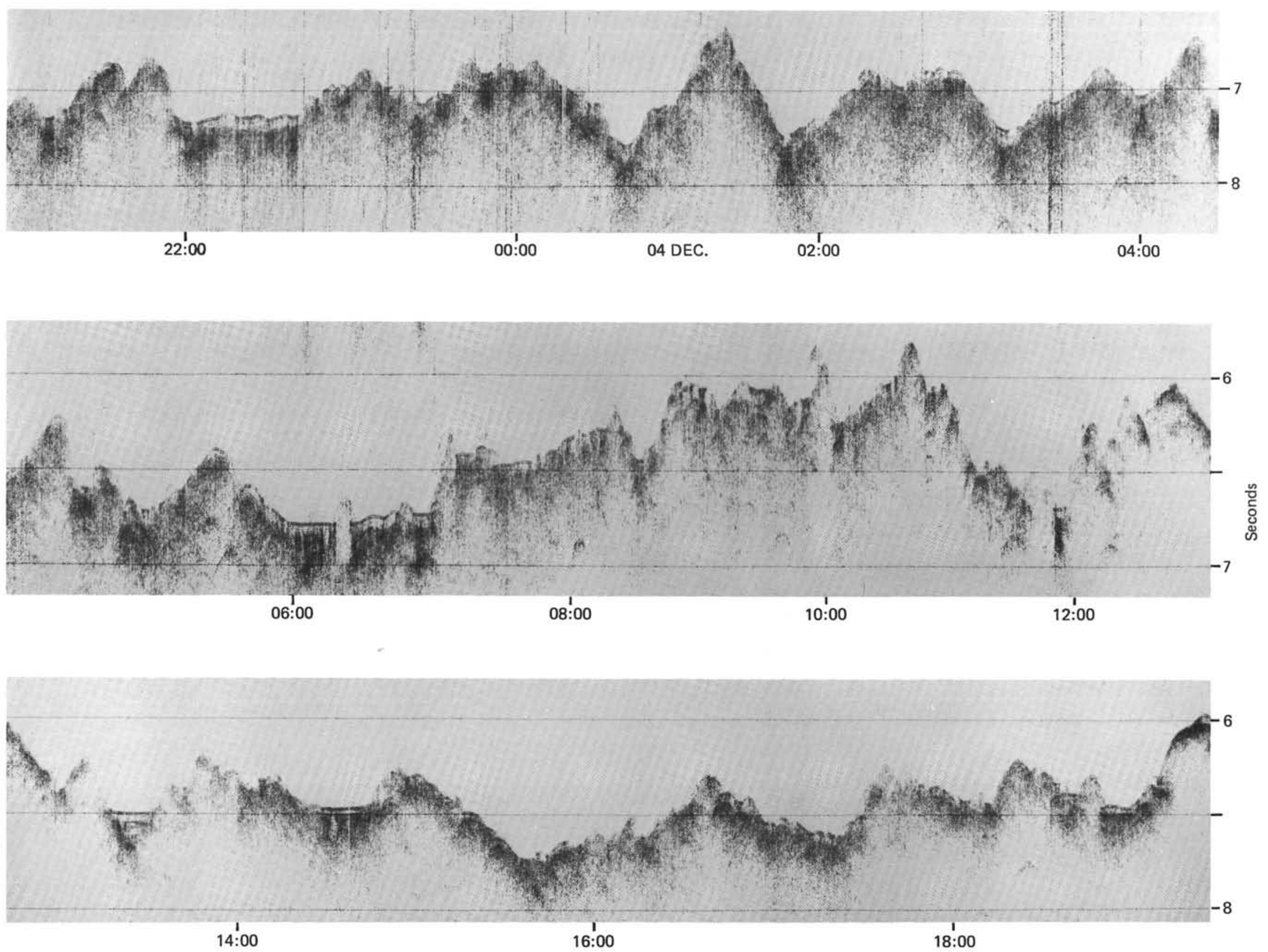

Figure 8. (Continued). 

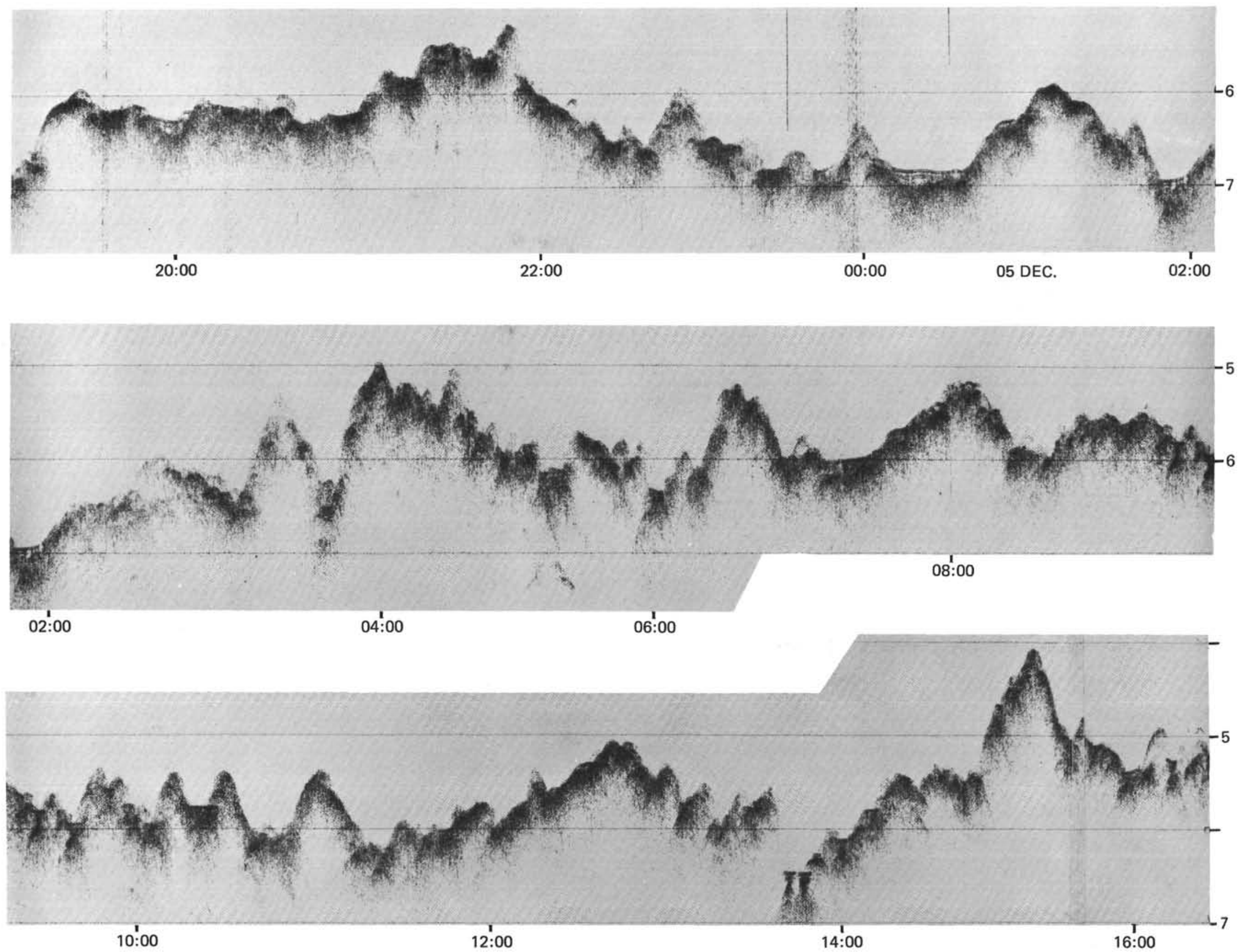

Figure 8. (Continued).

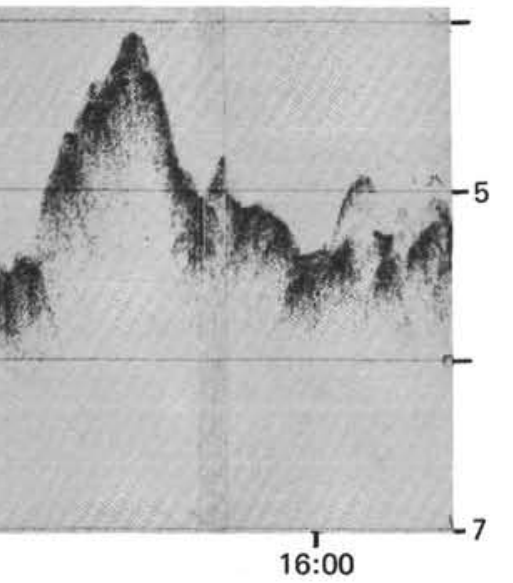



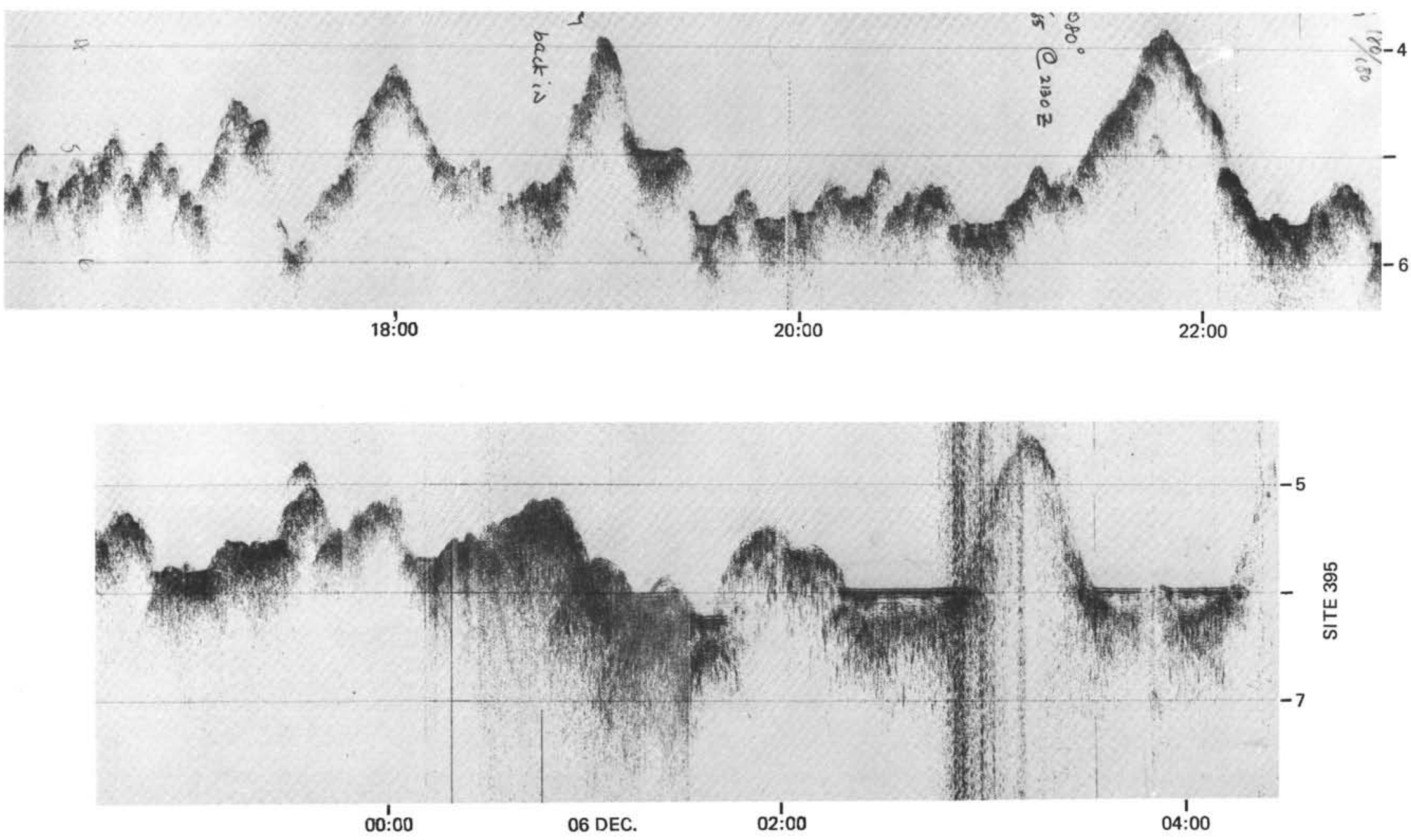

Figure 8. (Continued). 

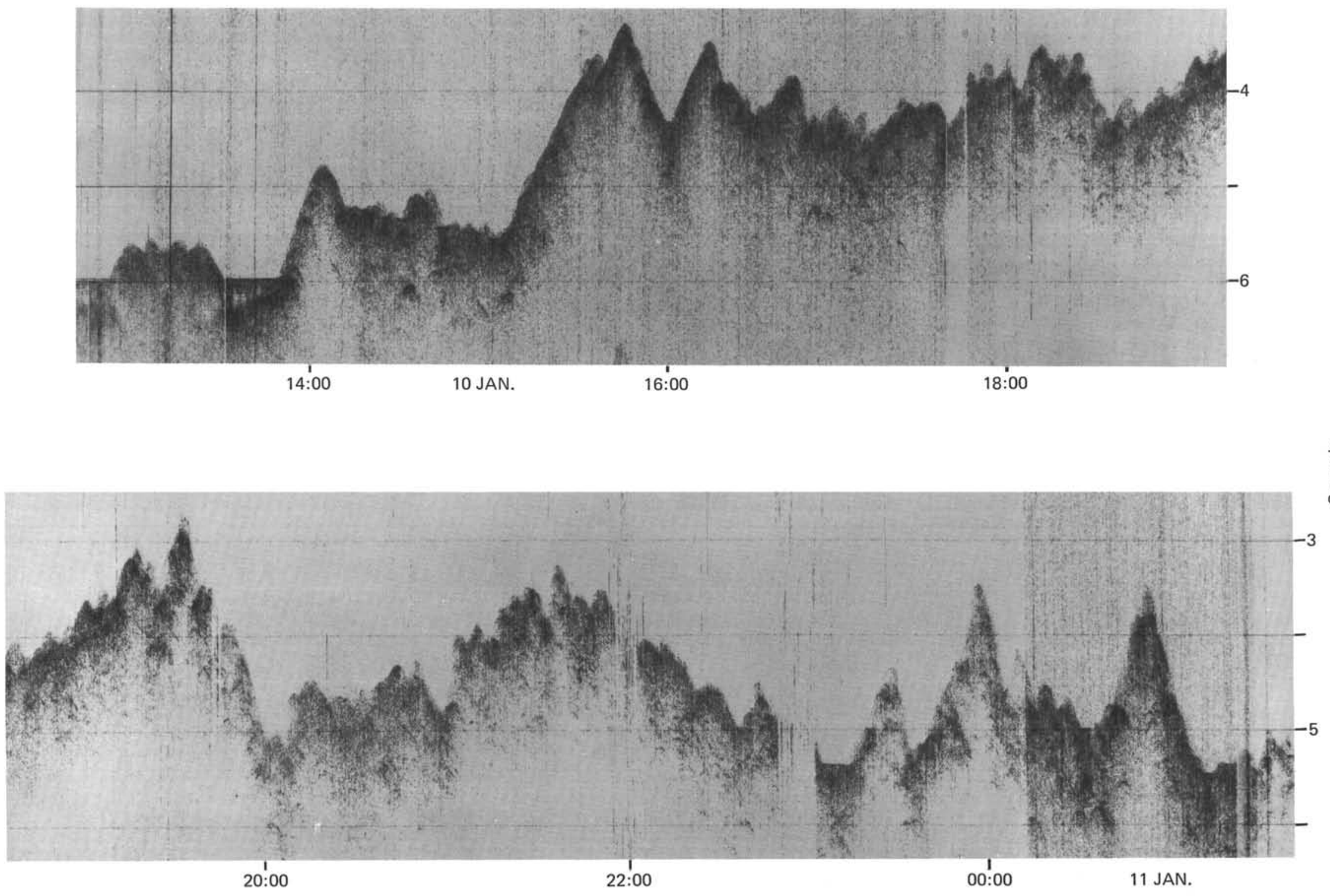

Figure 8. (Continued). 


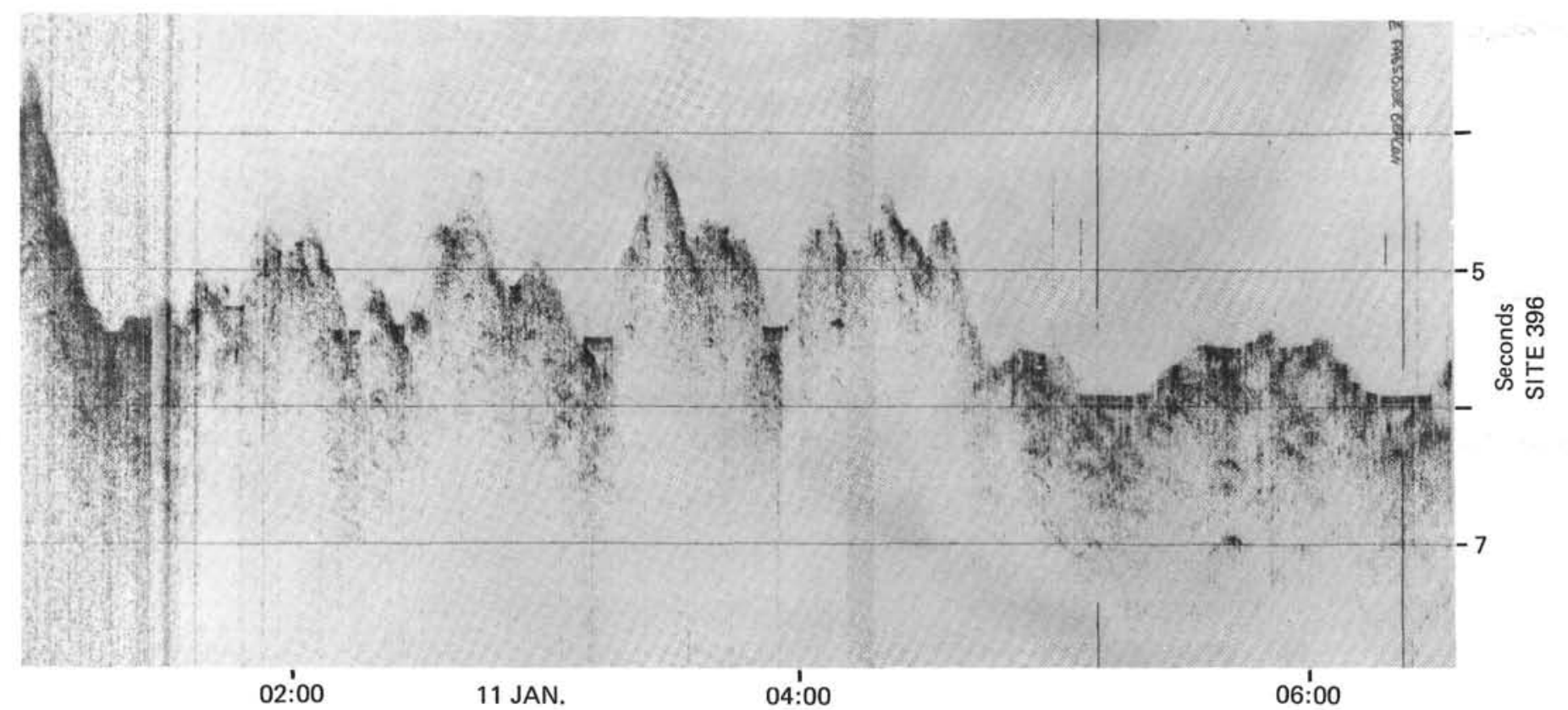

Figure 8. (Continued). 

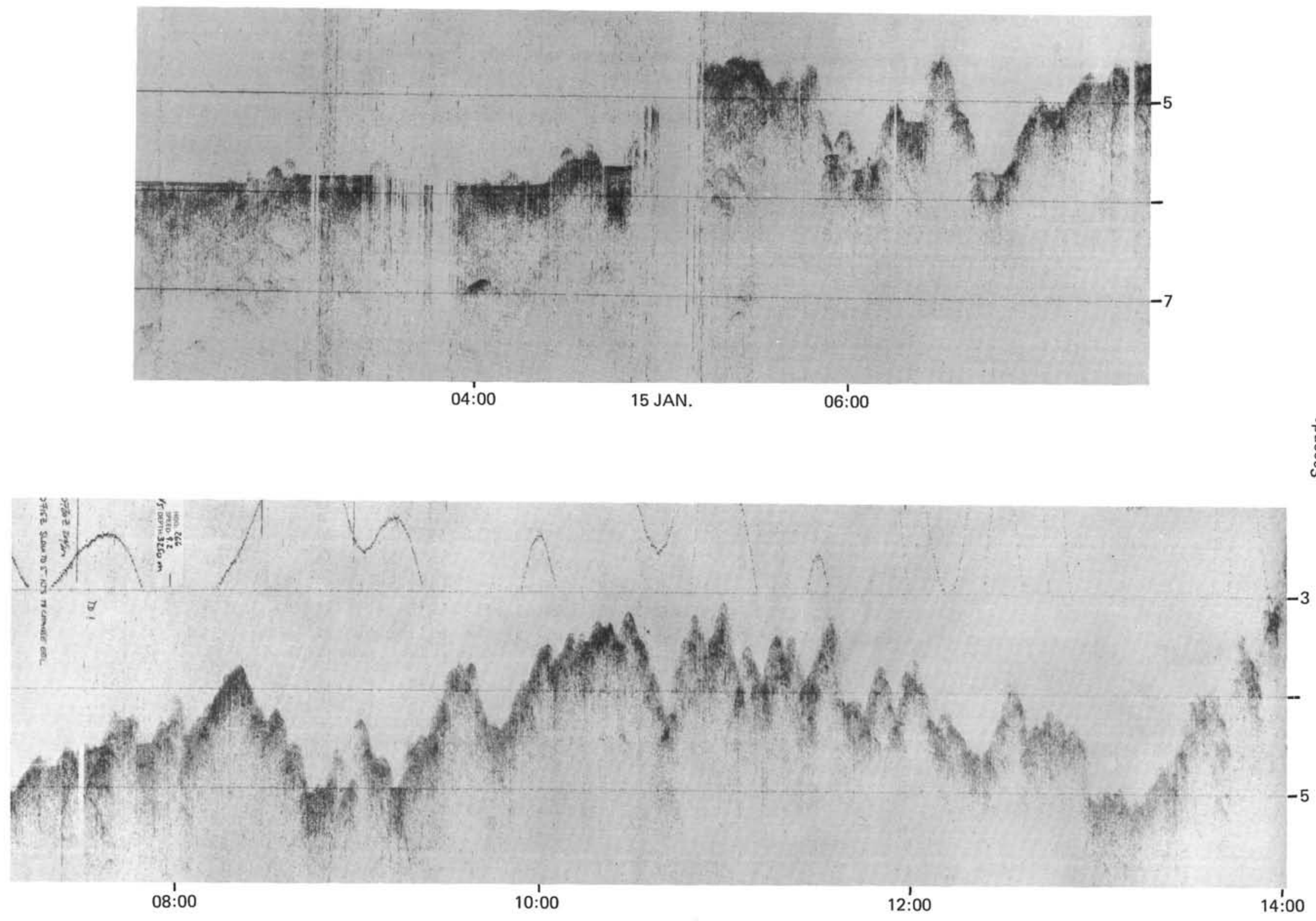

Figure 8. (Continued). 

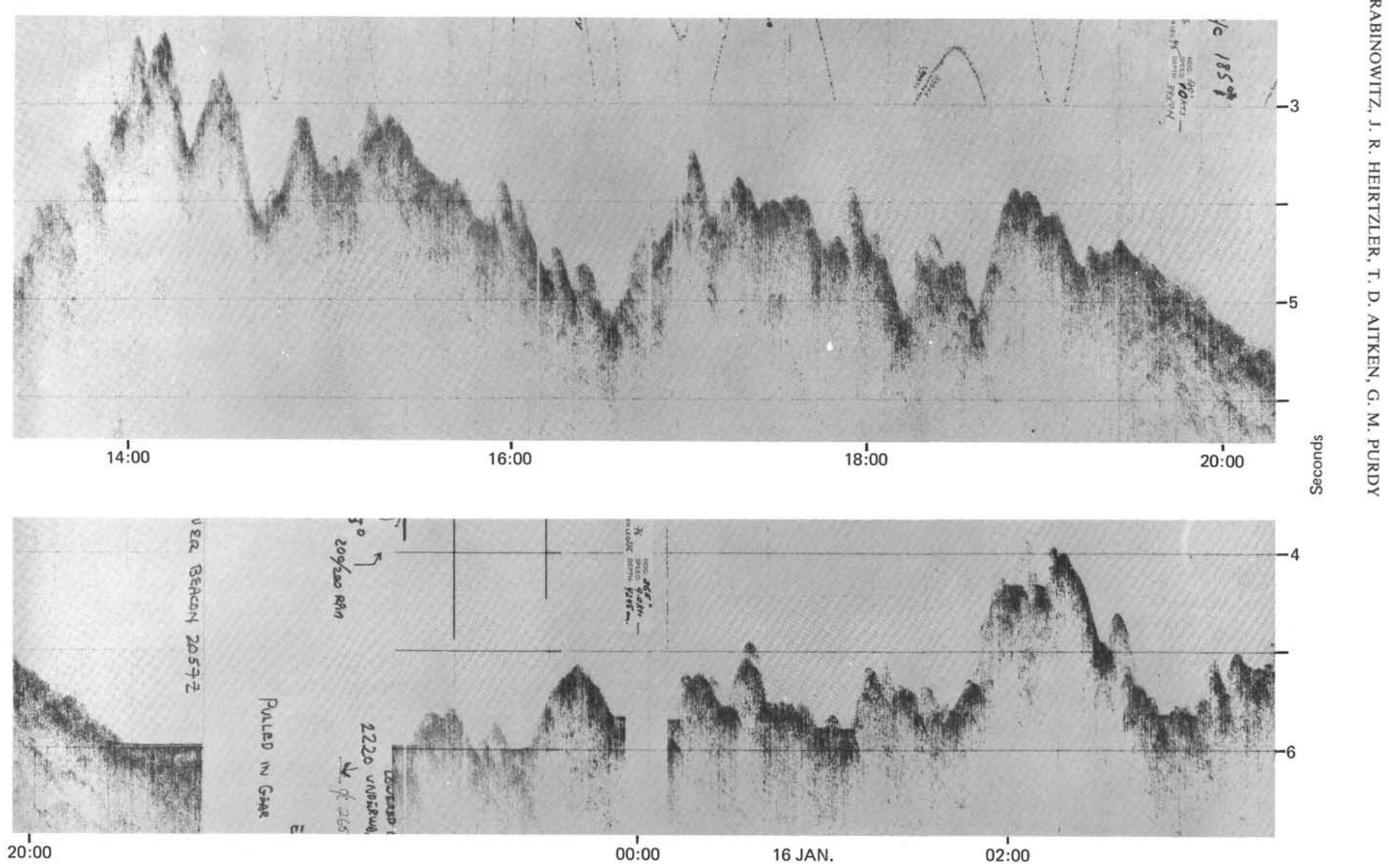

Figure 8. (Continued). 

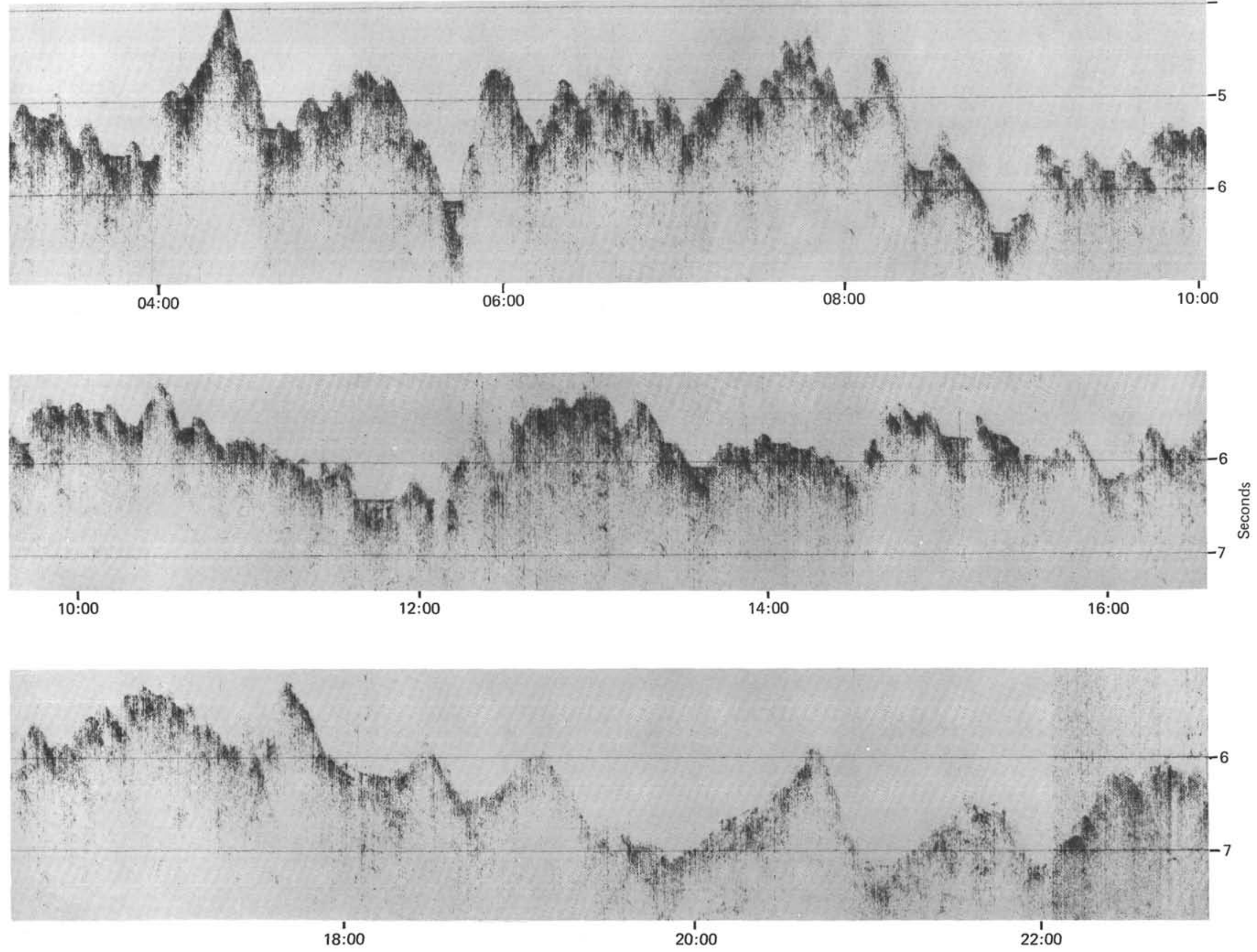

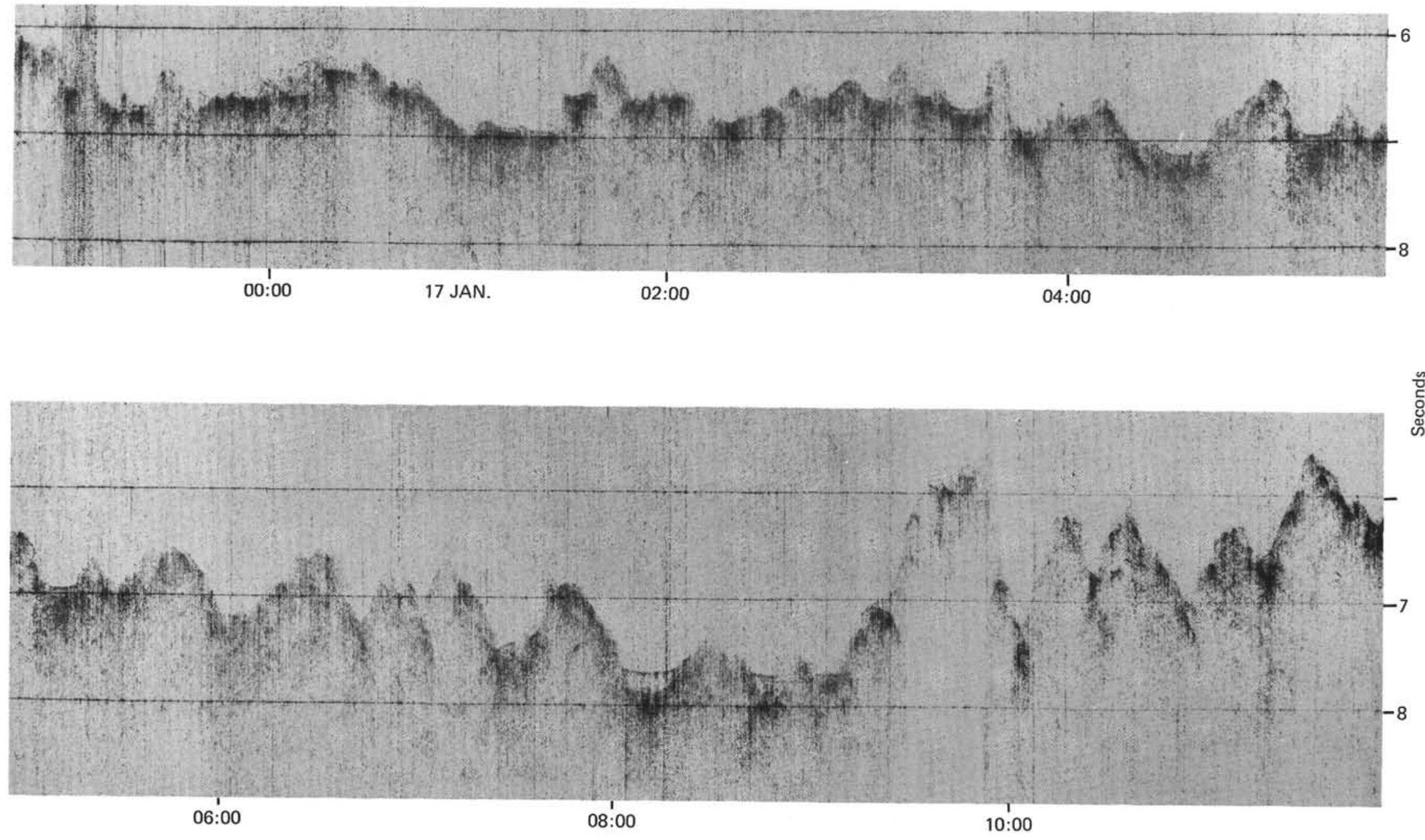

Figure 8. (Continued). 

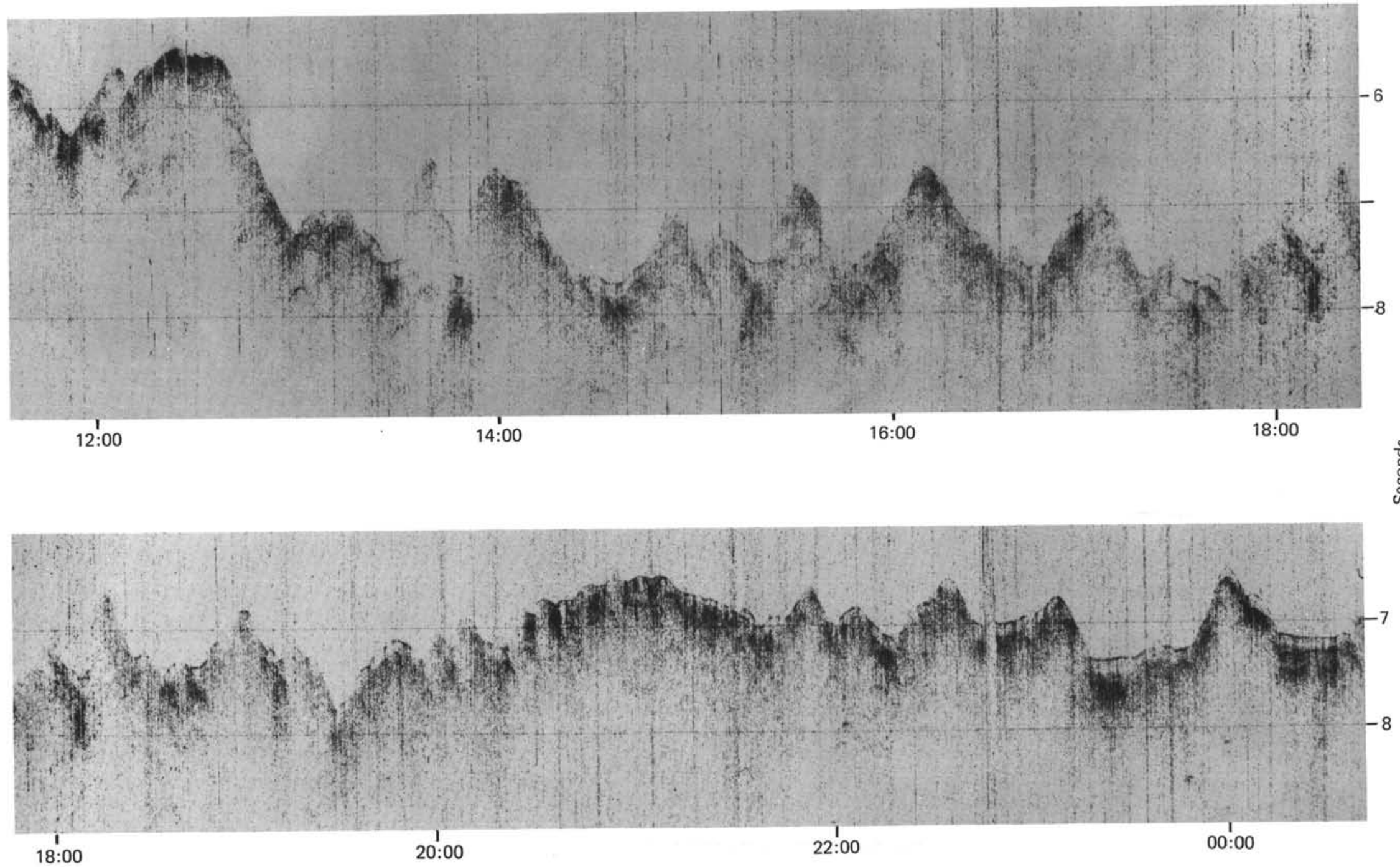

Figure 8. (Continued). 

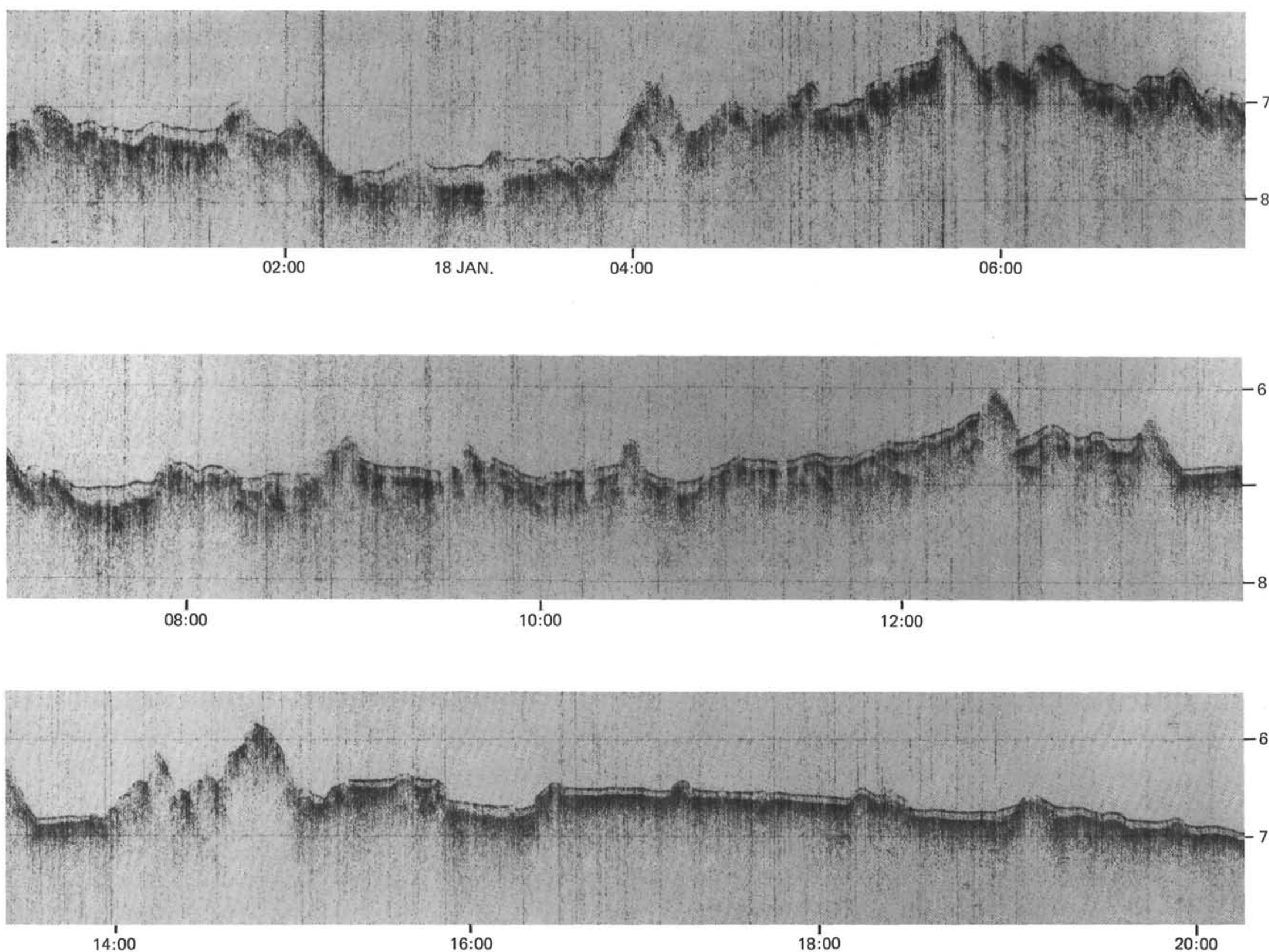

Figure 8. (Continued). 

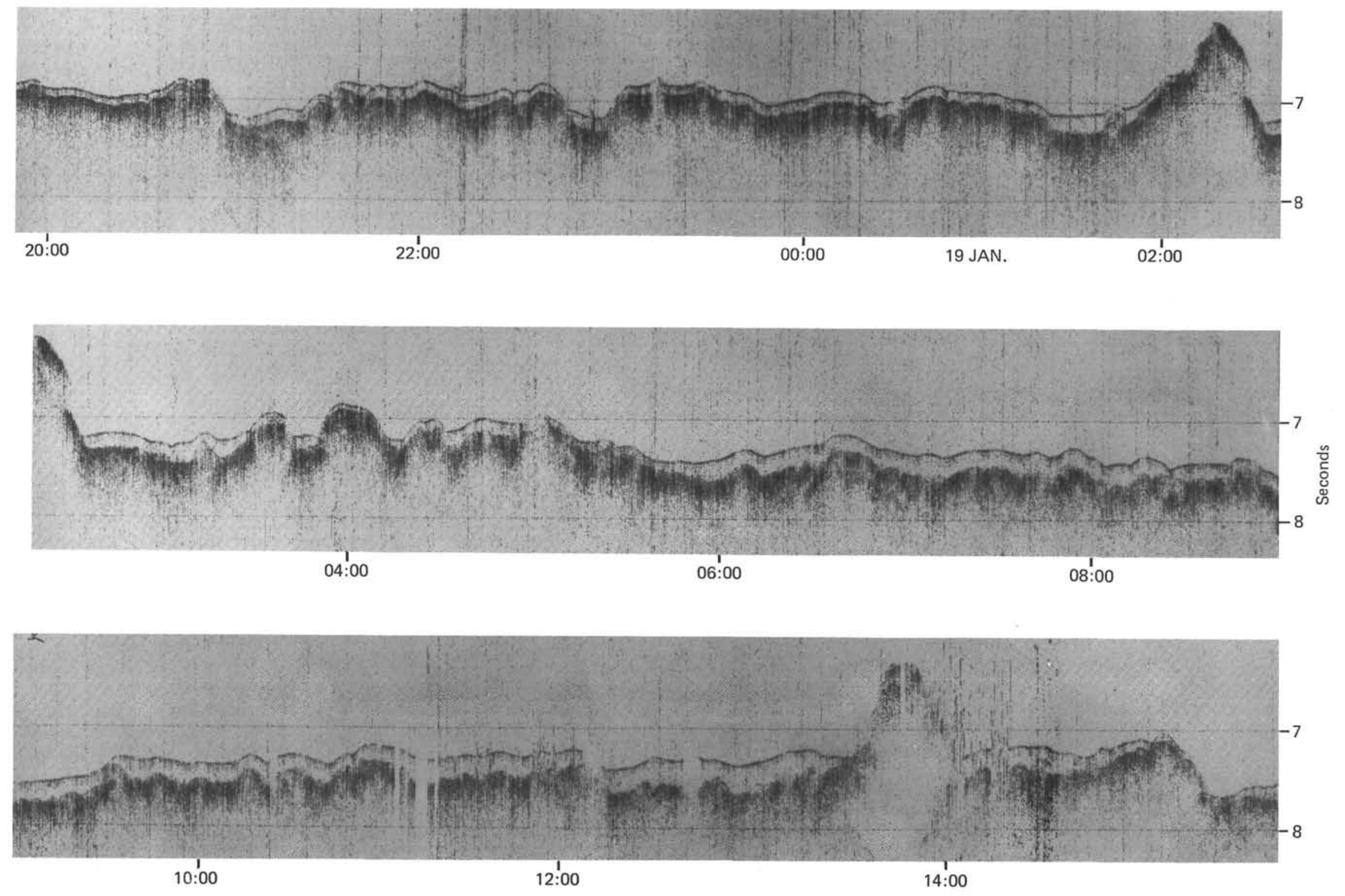

Figure 8. (Continued). 

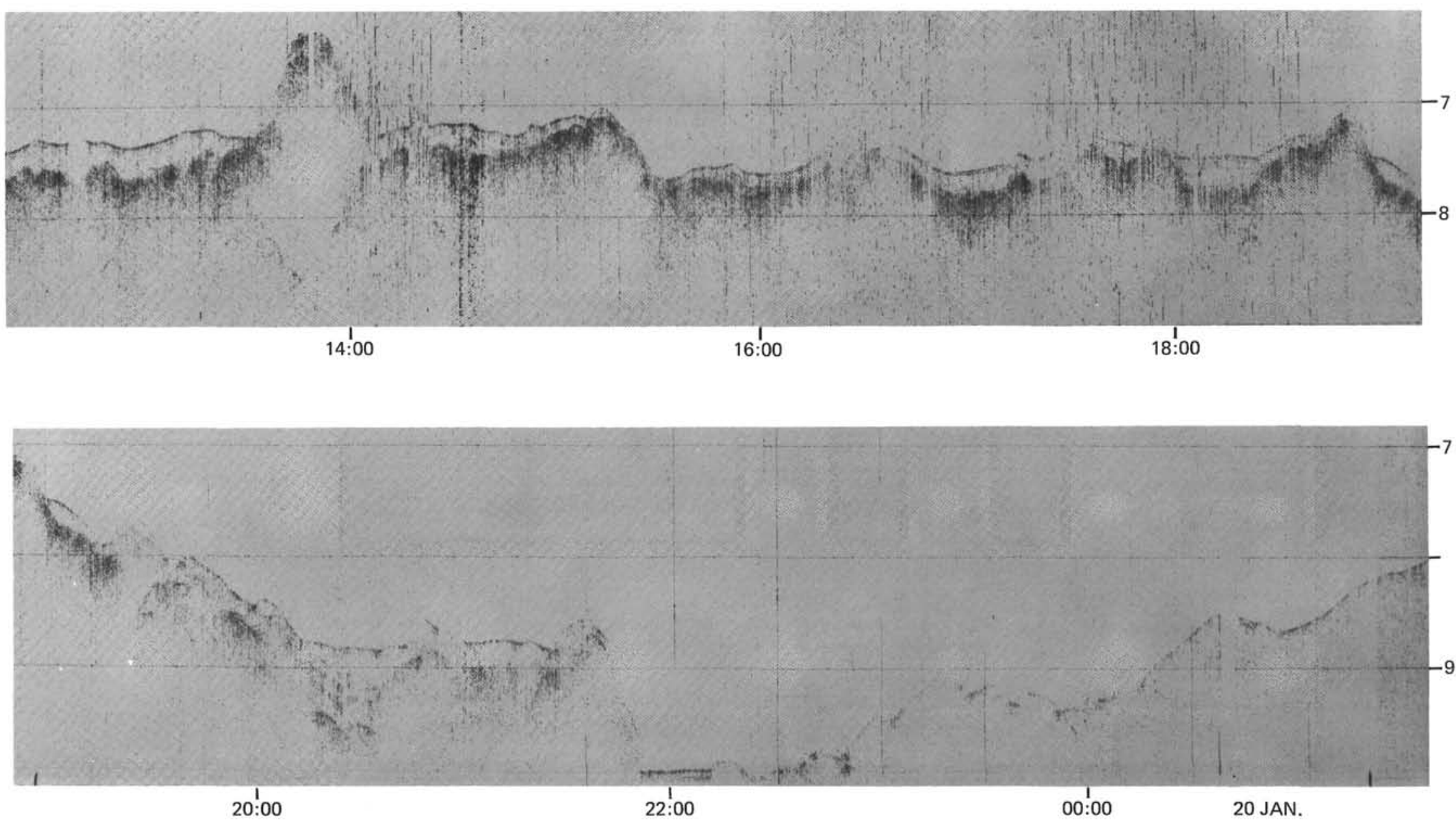

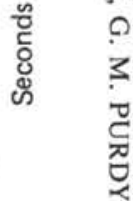

Figure 8. (Continued). 

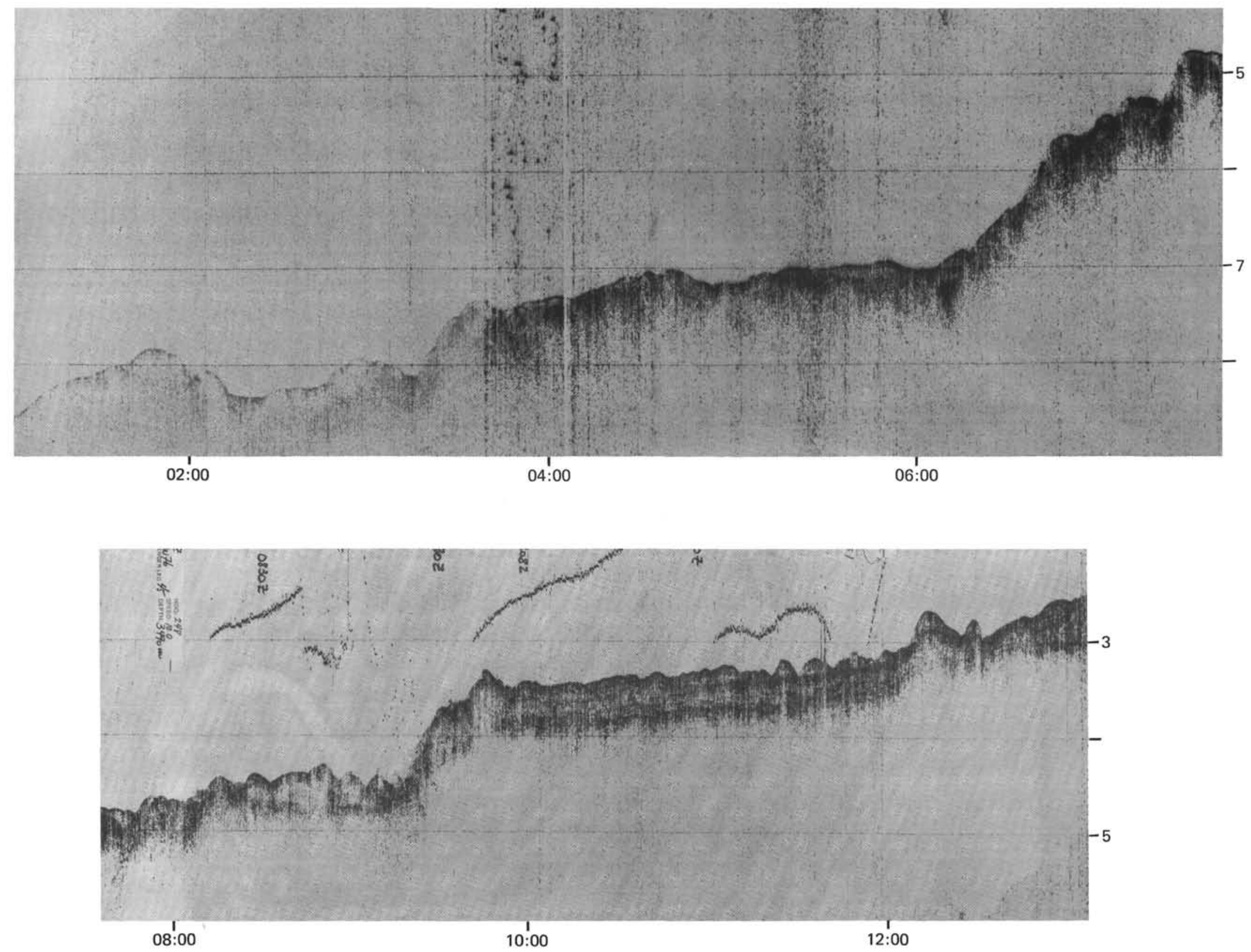

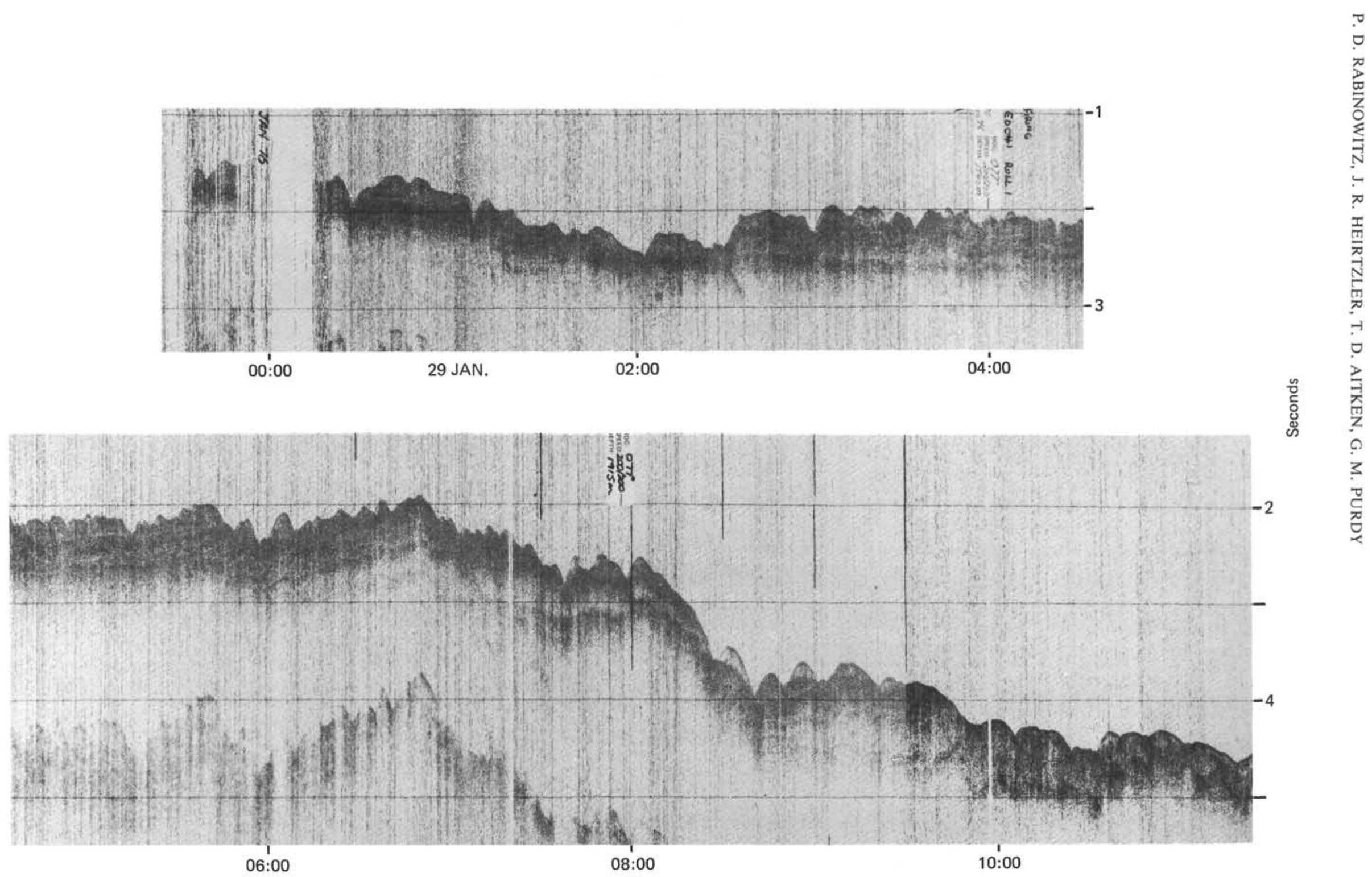

Figure 9. (9-1 to 9-27) Seismic reflection profiles along track of Leg 46 of Glomar Challenger. 


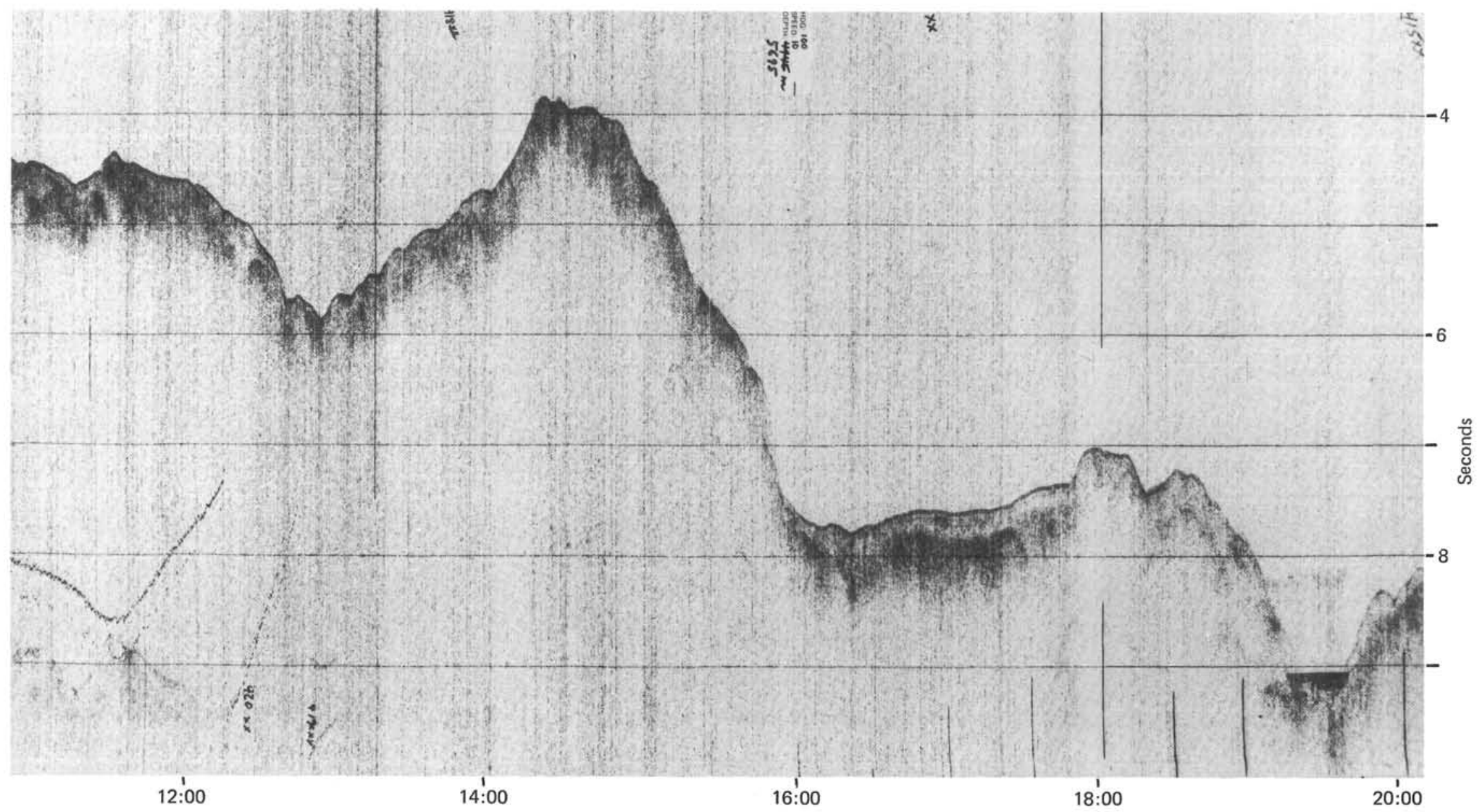

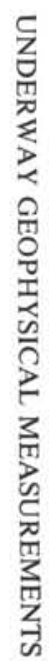

Figure 9. (Continued) 

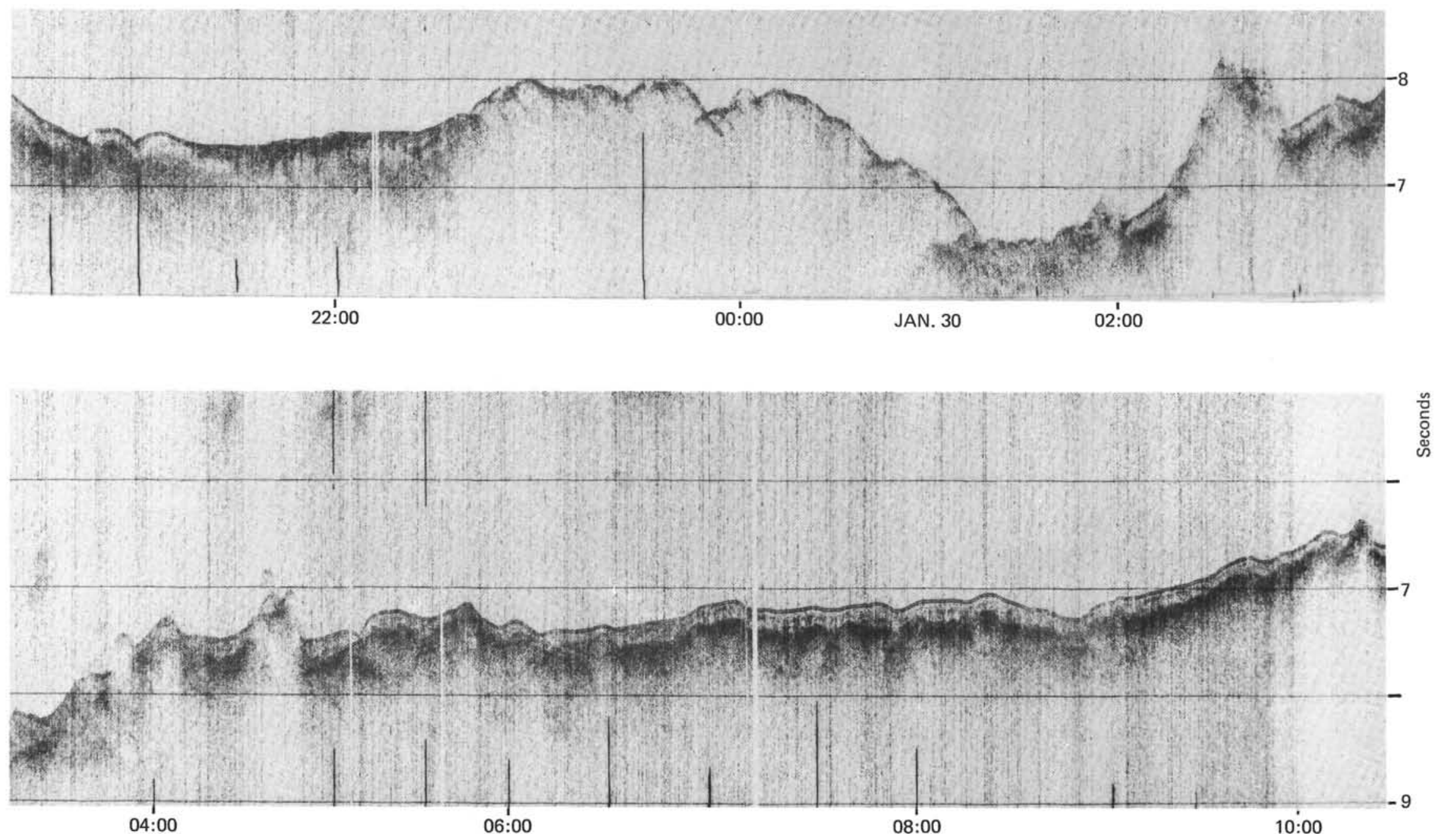

Figure 9. (Continued). 

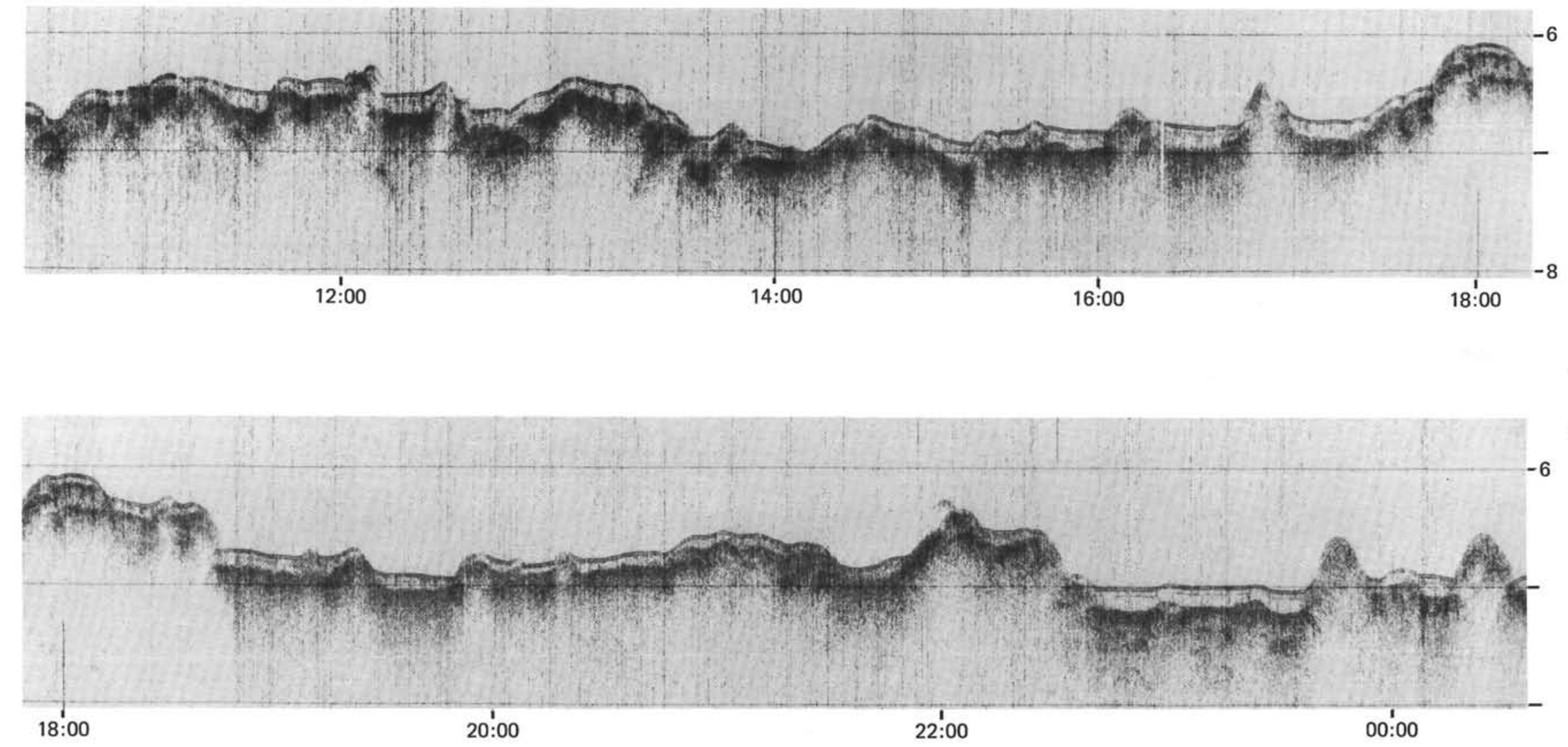

Figure 9. (Continued). 


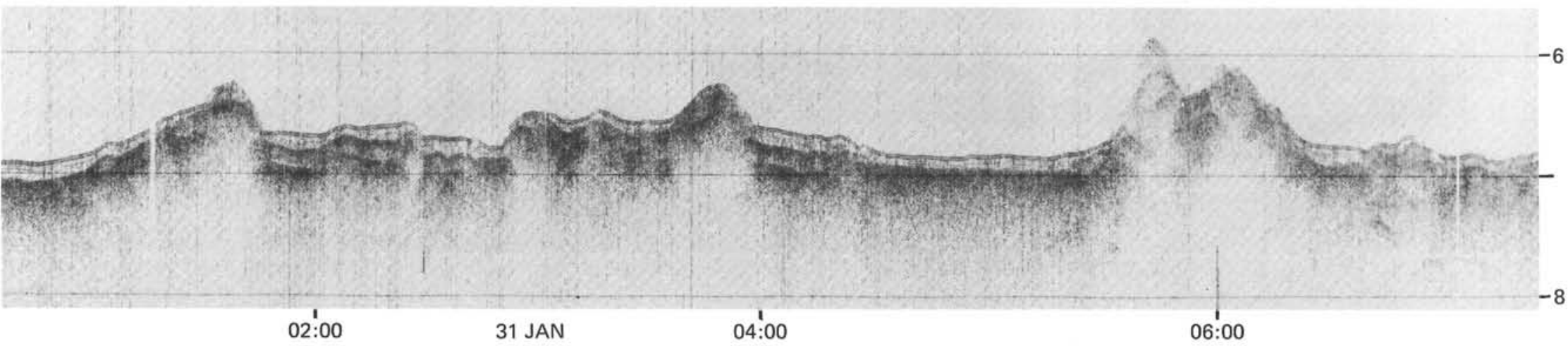

A

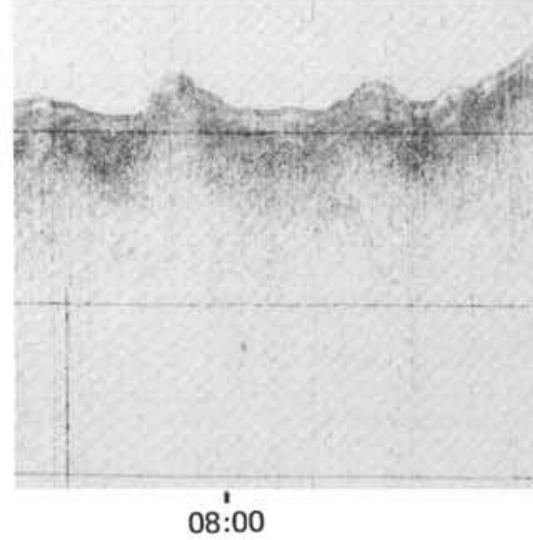

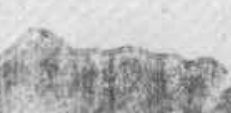

4:00

Figure 9. (Continued). 

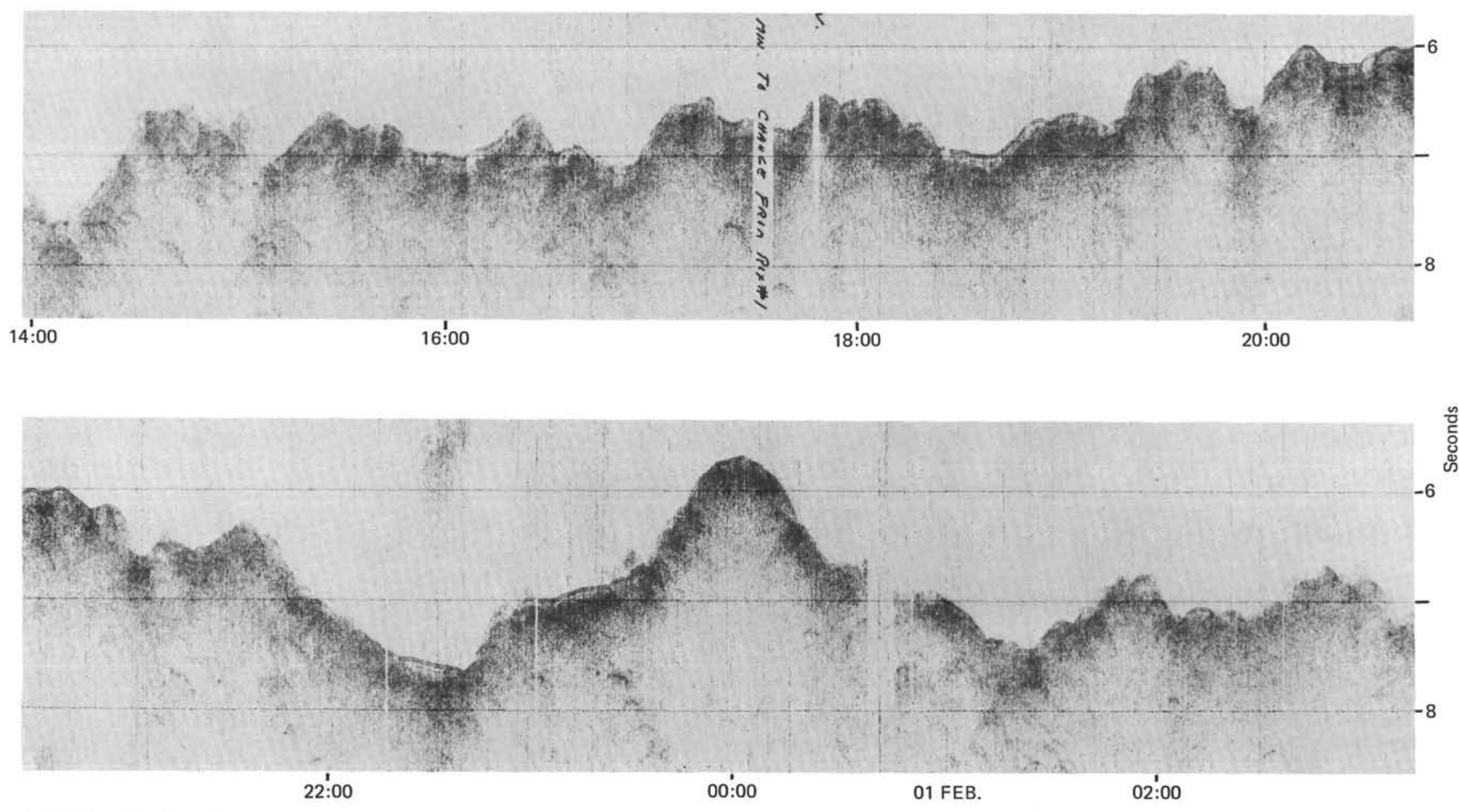

Figure 9. (Continued) 

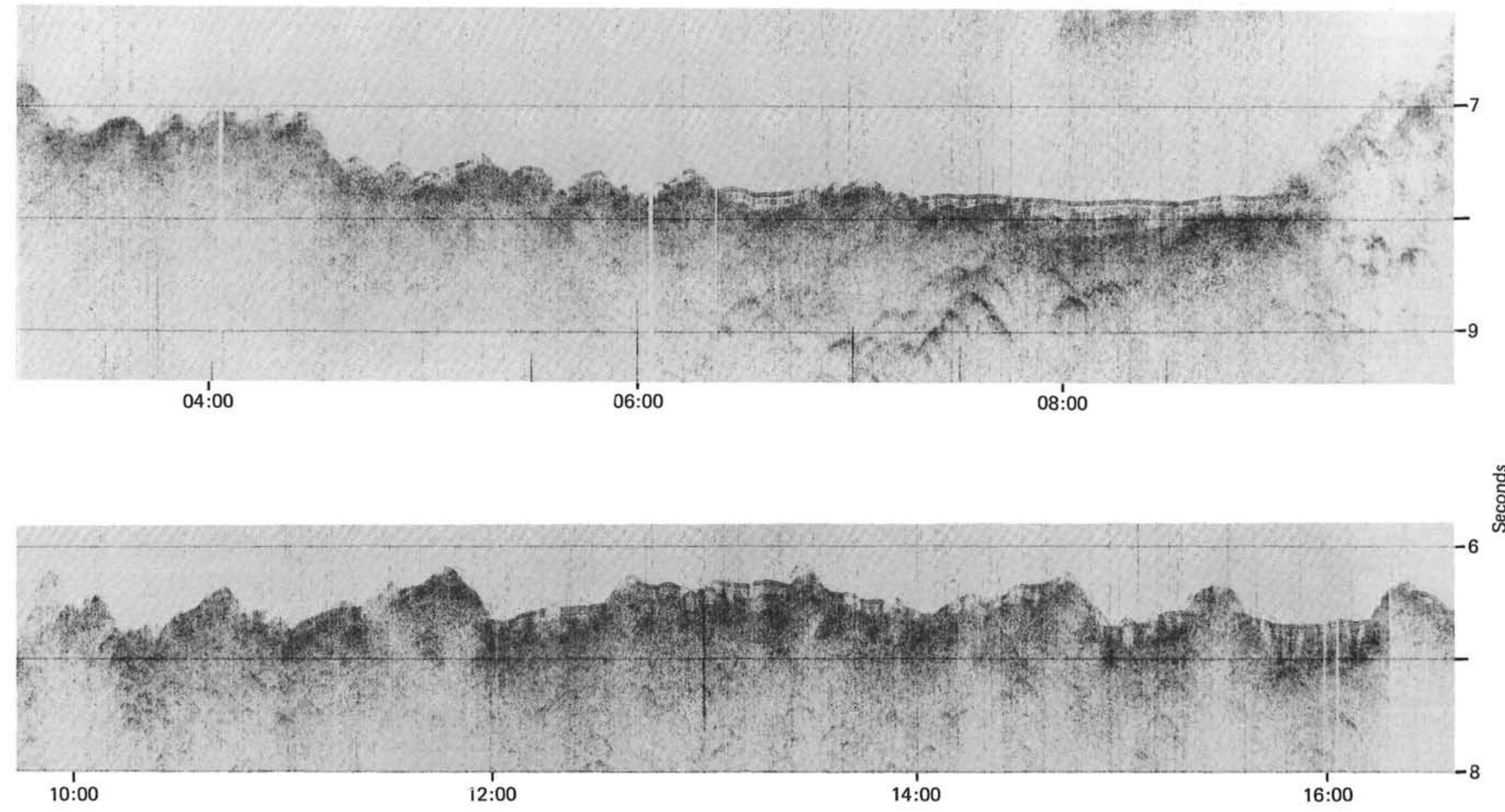

Figure 9. (Continued). 

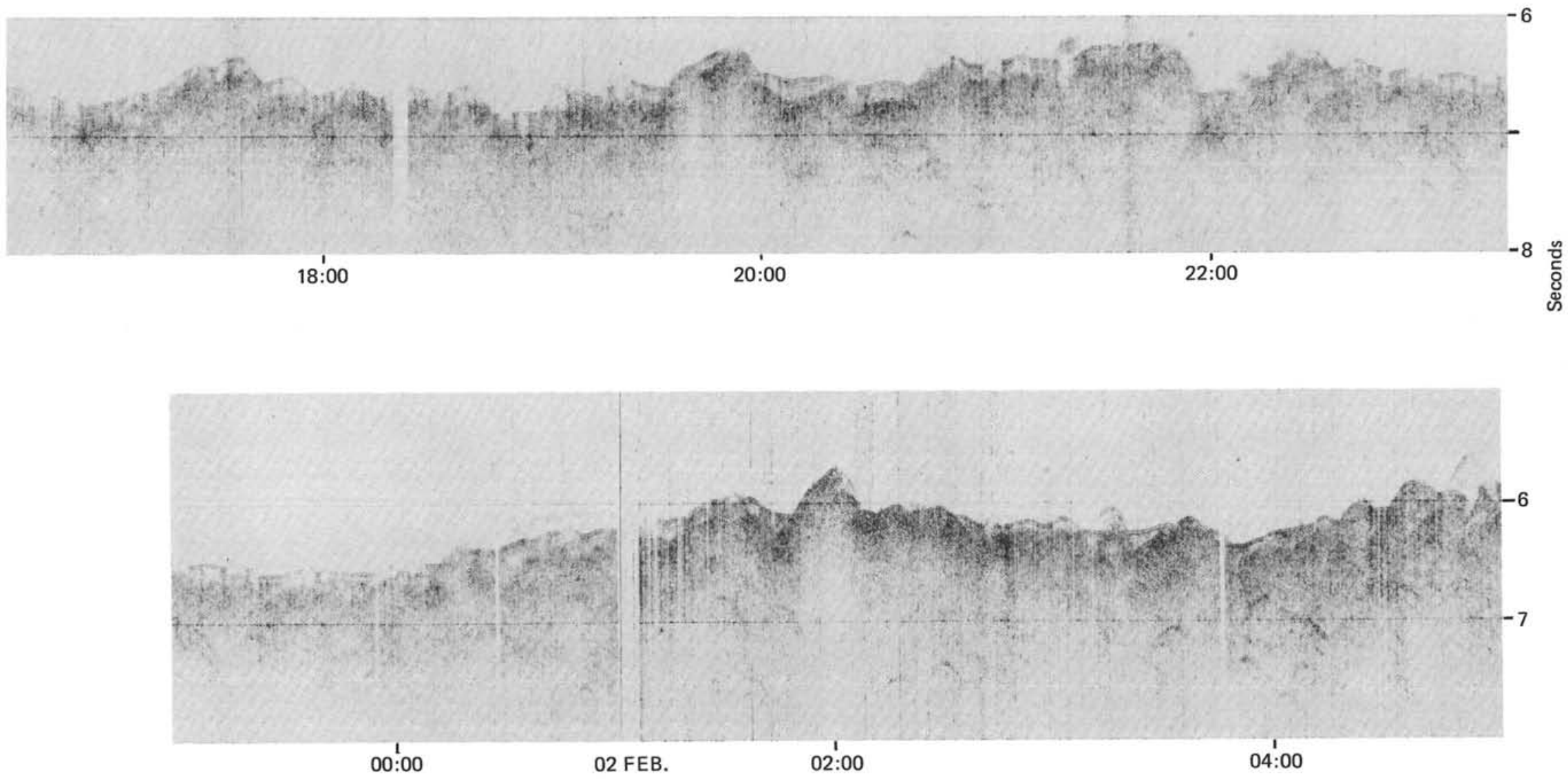

Figure 9. (Continued). 

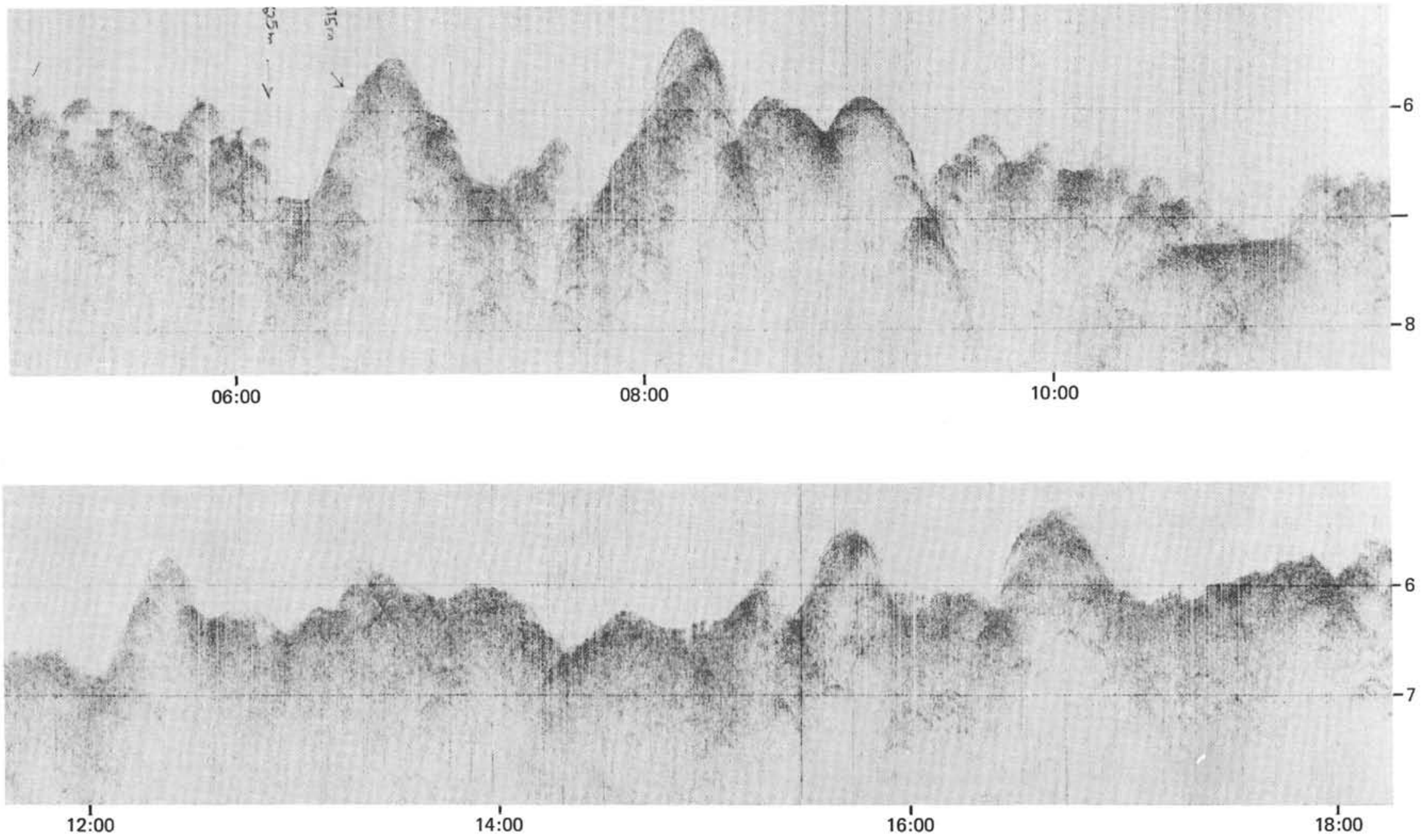

Figure 9. (Continued). 

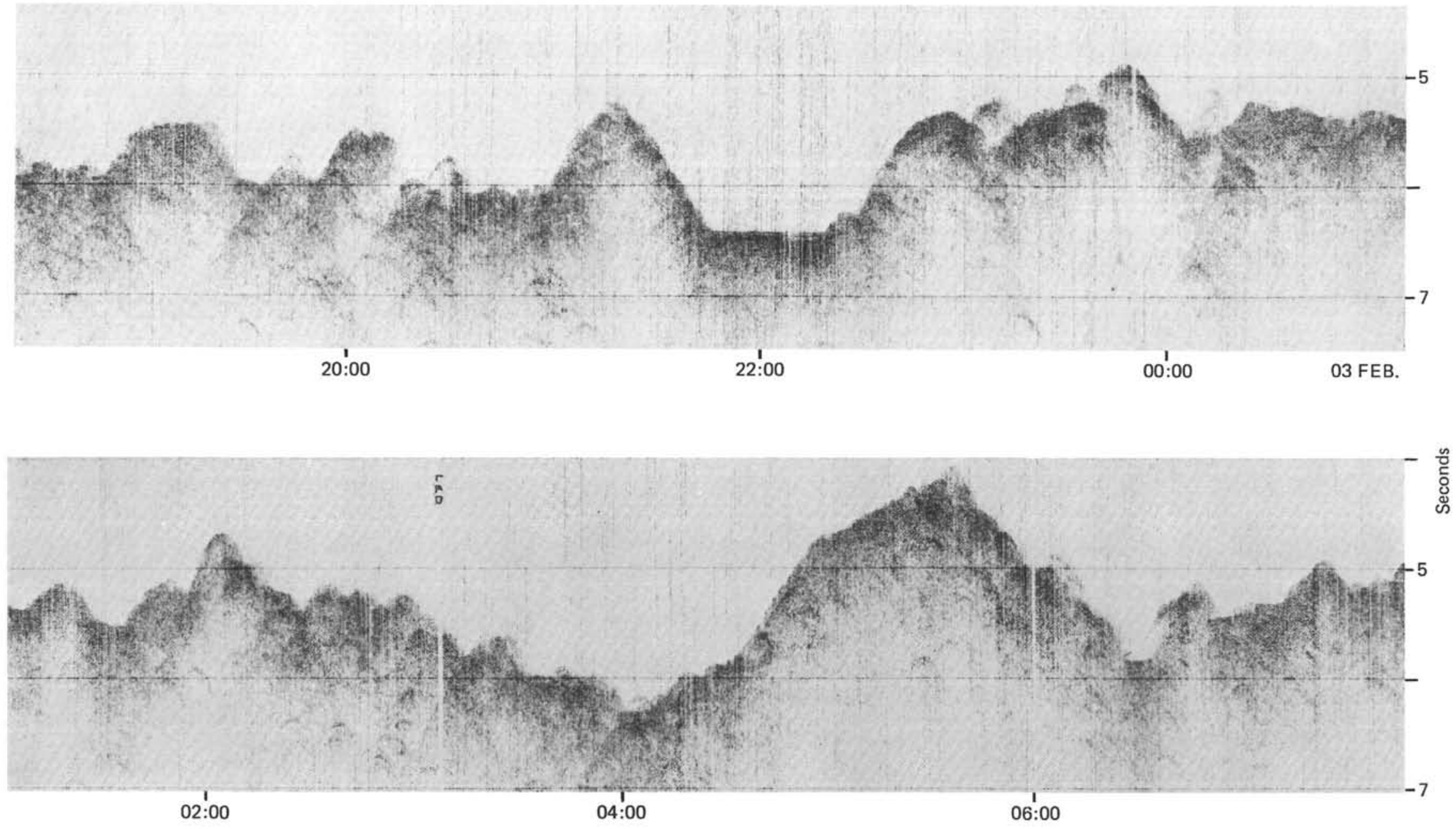

Figure 9. (Continued). 

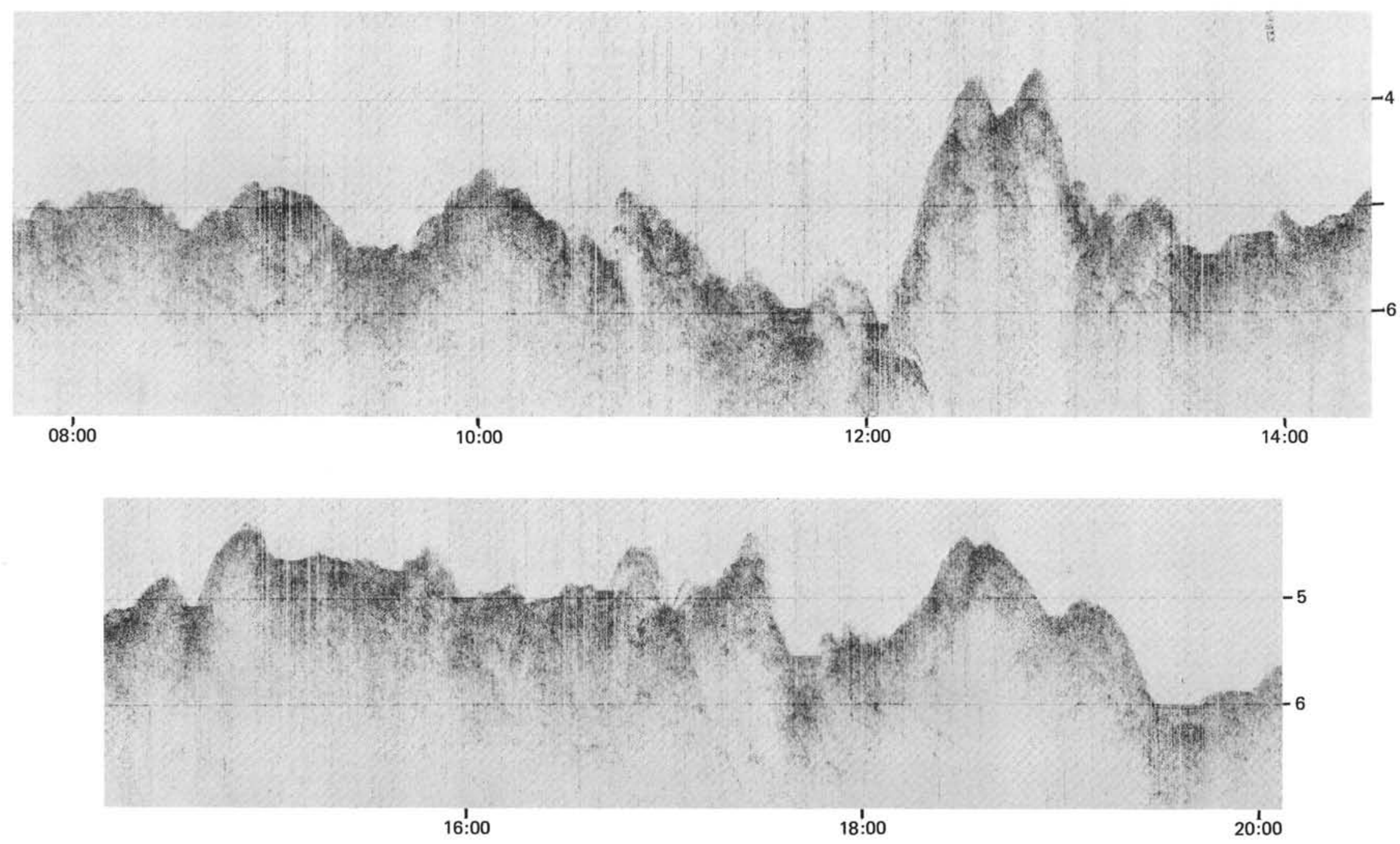

Figure 9. (Continued). 

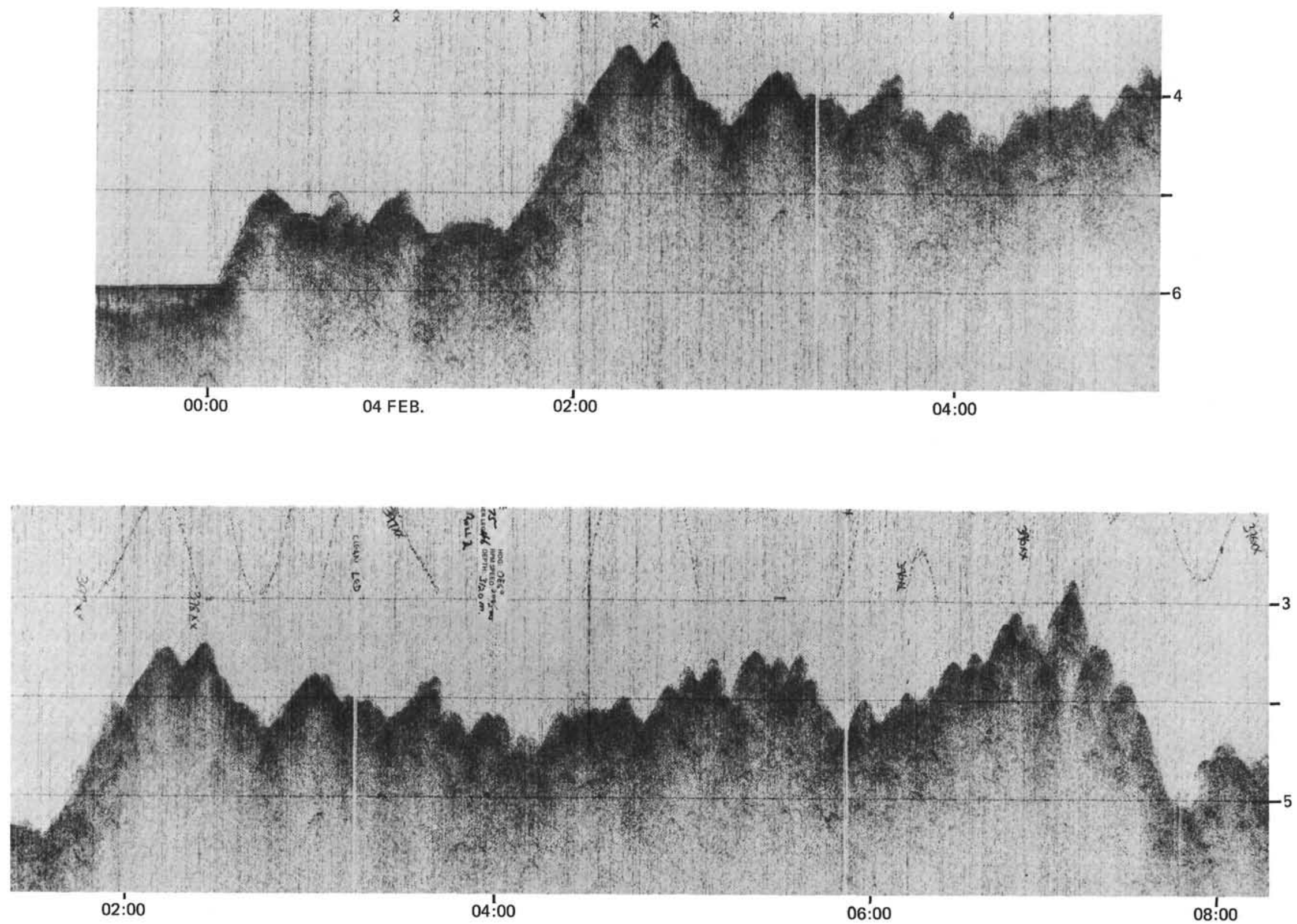

Figure 9. (Continued). 


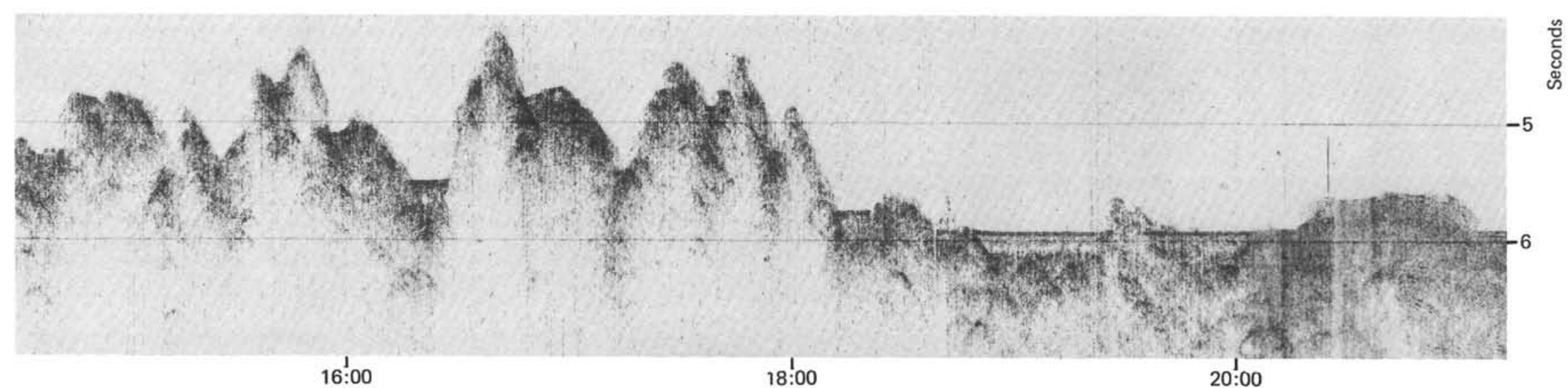

Figure 9. (Continued). 


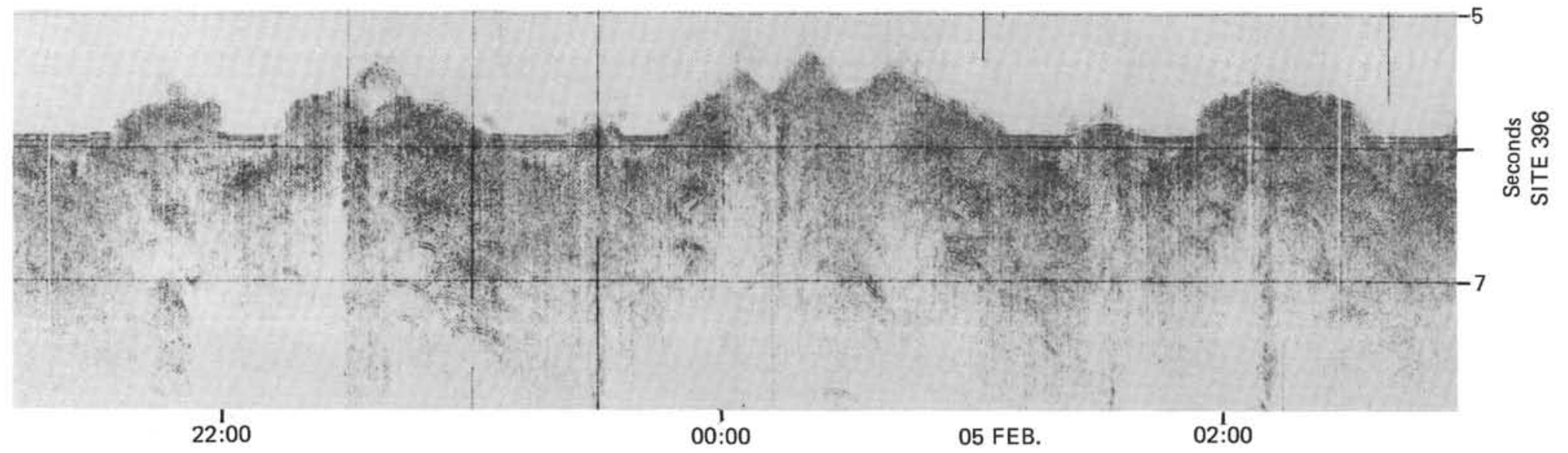

Figure 9. (Continued). 

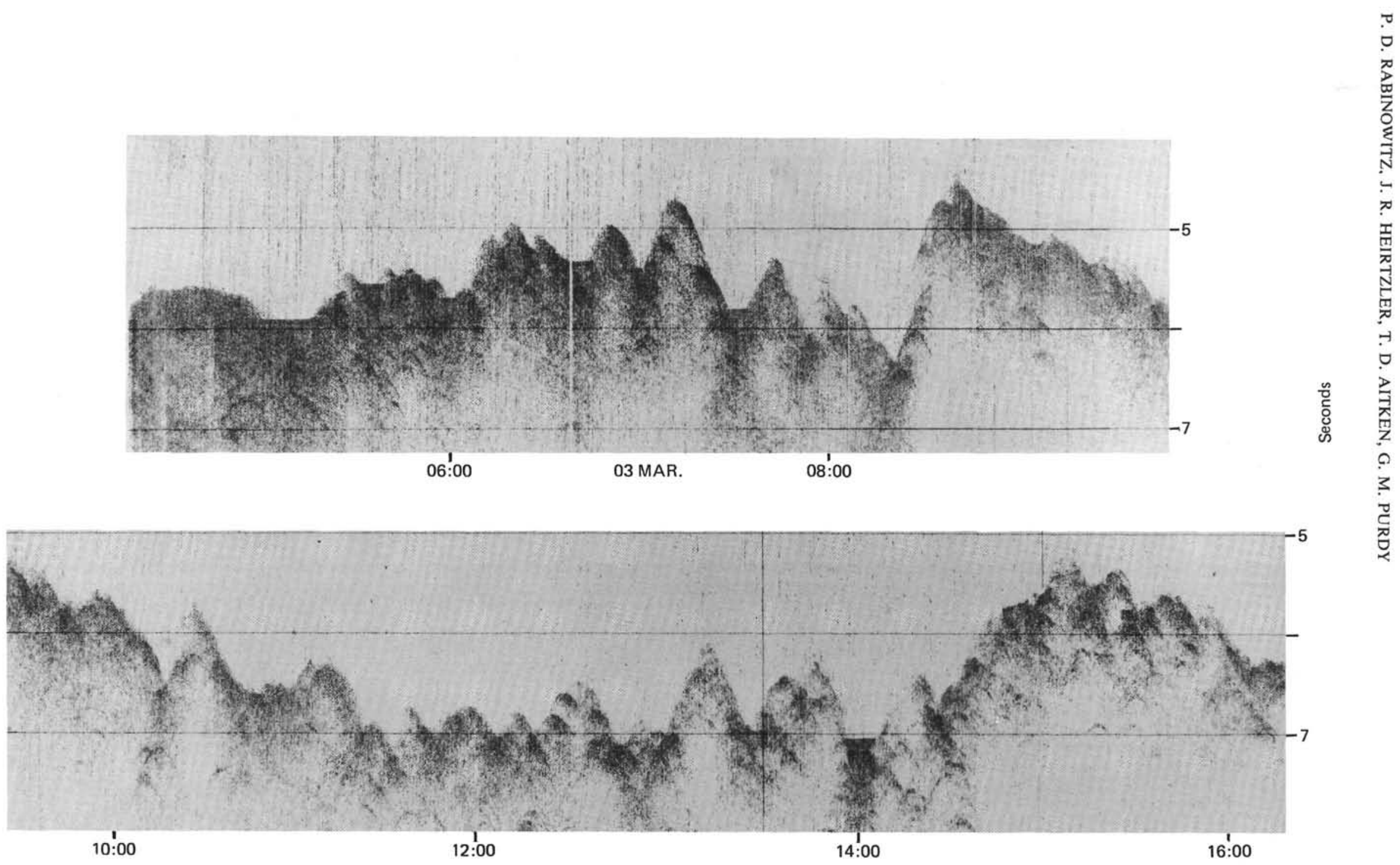

Figure 9. (Continued). 

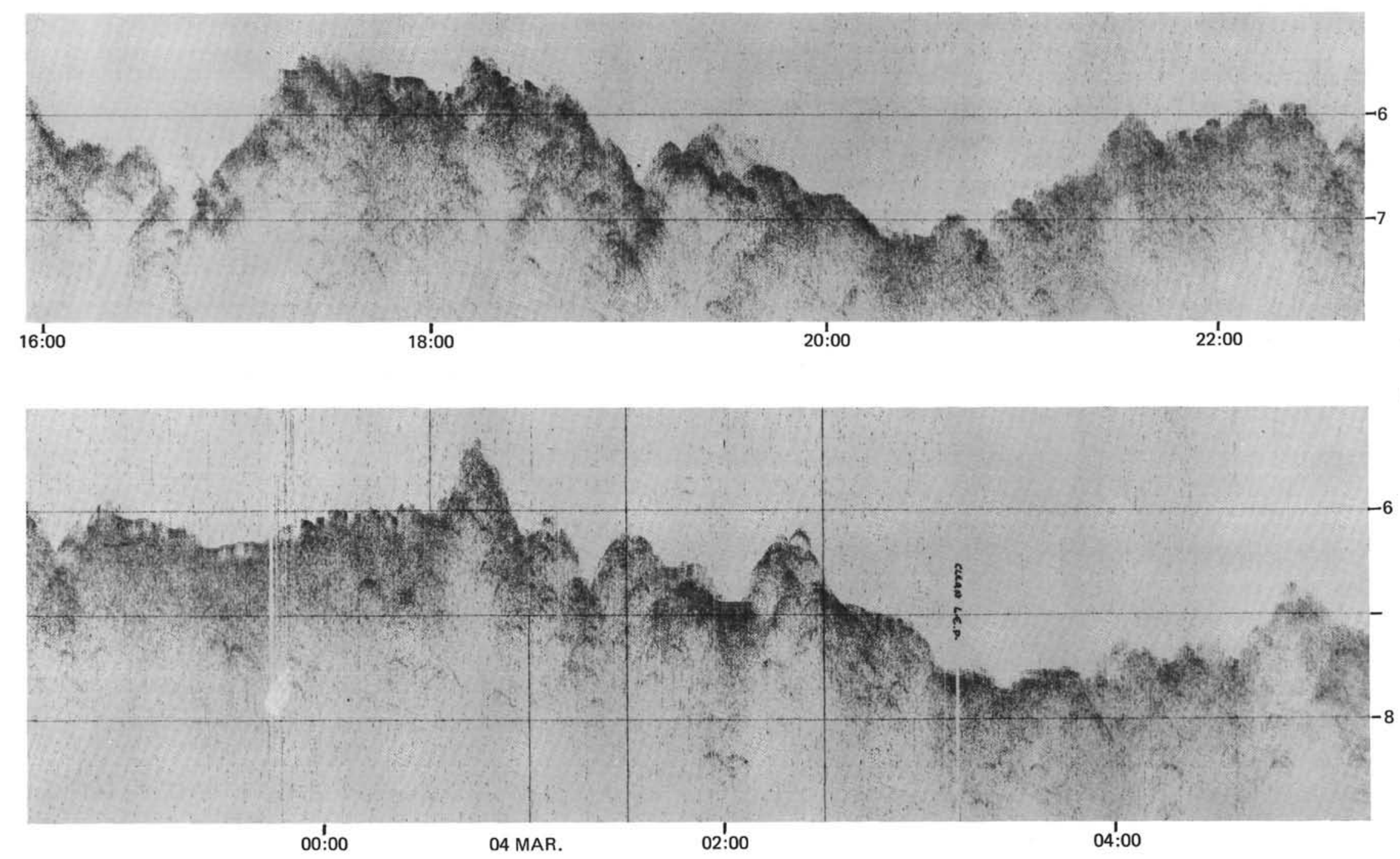

Figure 9. (Continued). 

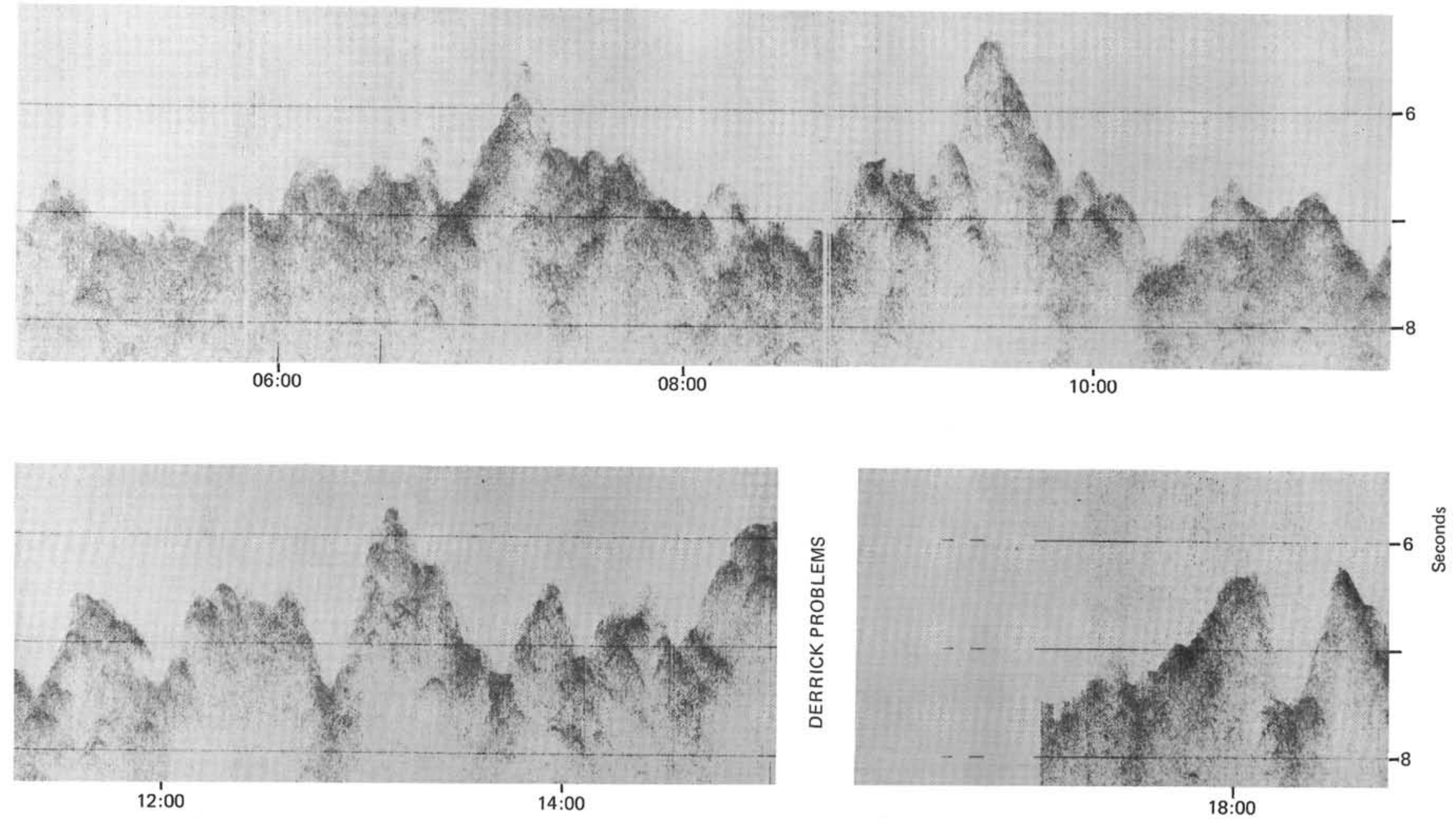

Figure 9. (Continued). 

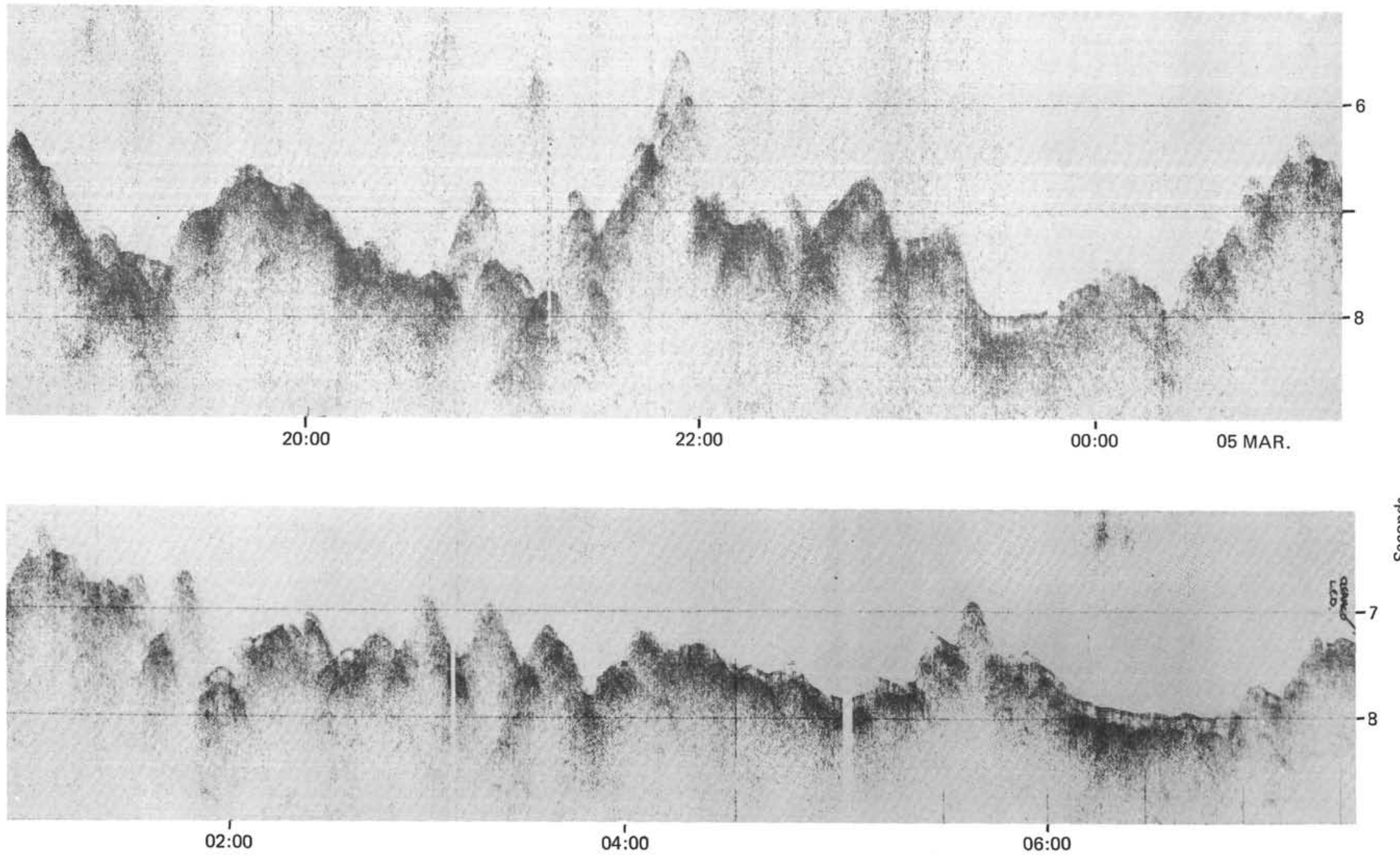

Figure 9. (Continued). 

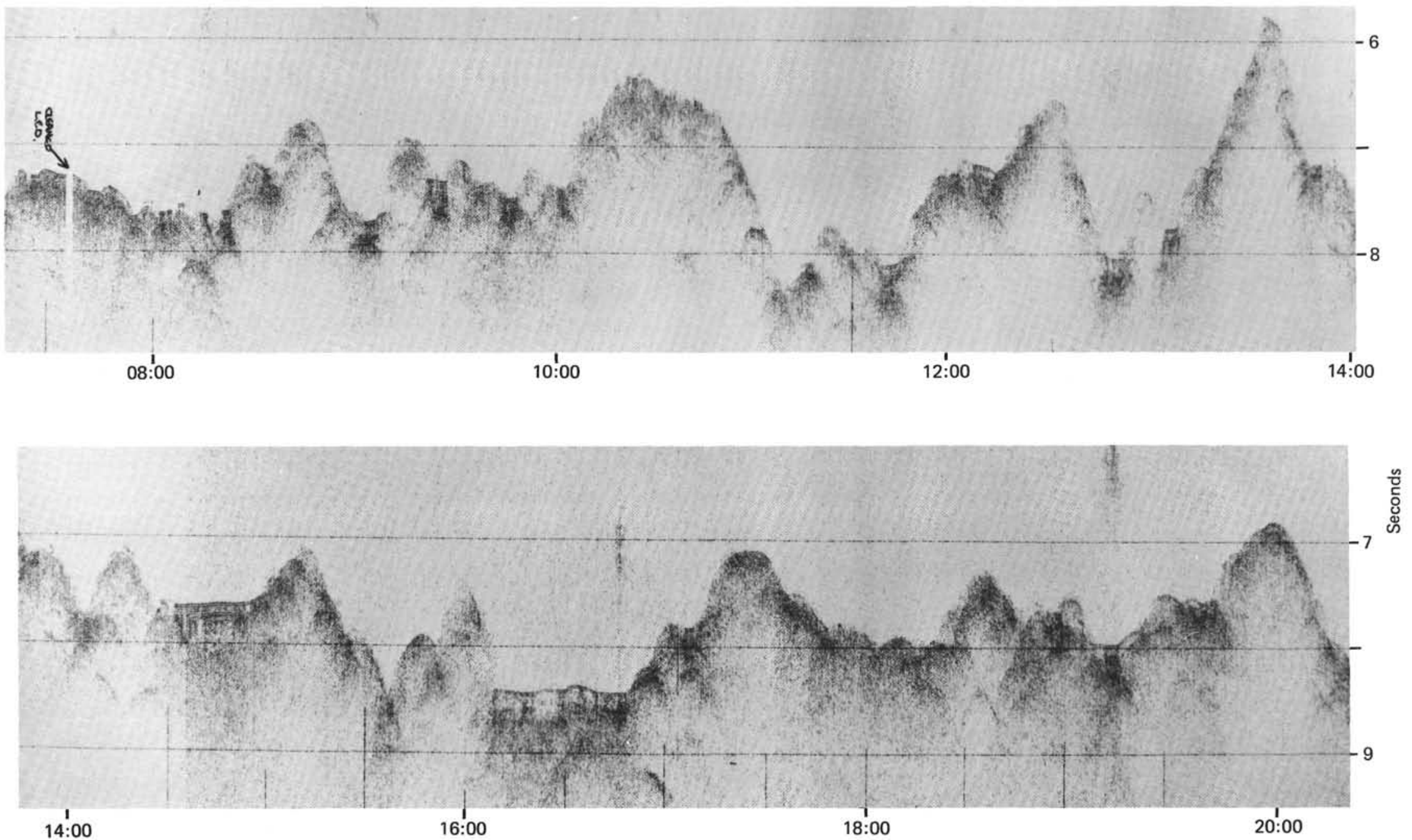

Figure 9. (Continued). 

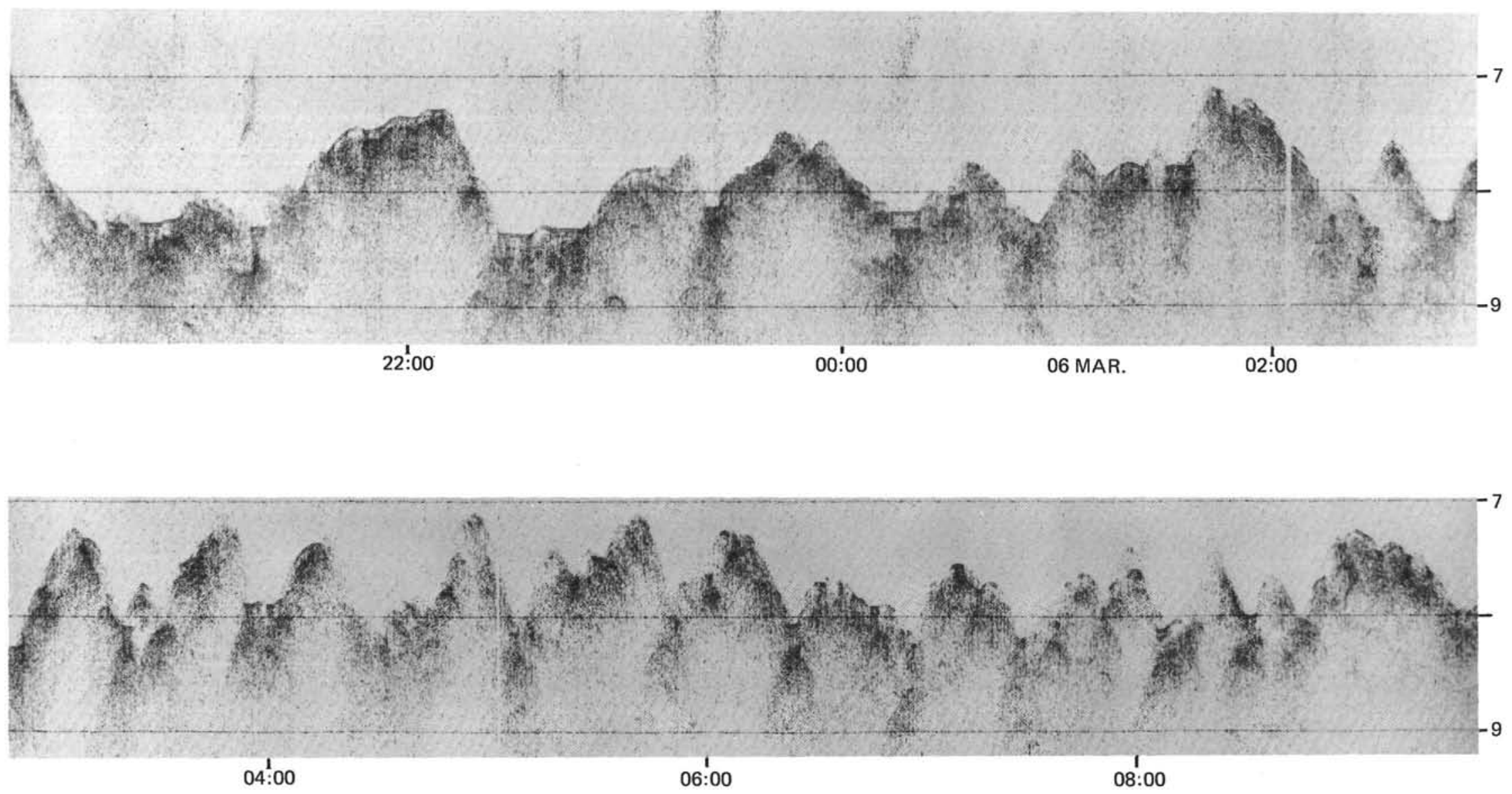

Figure 9. (Continued). 

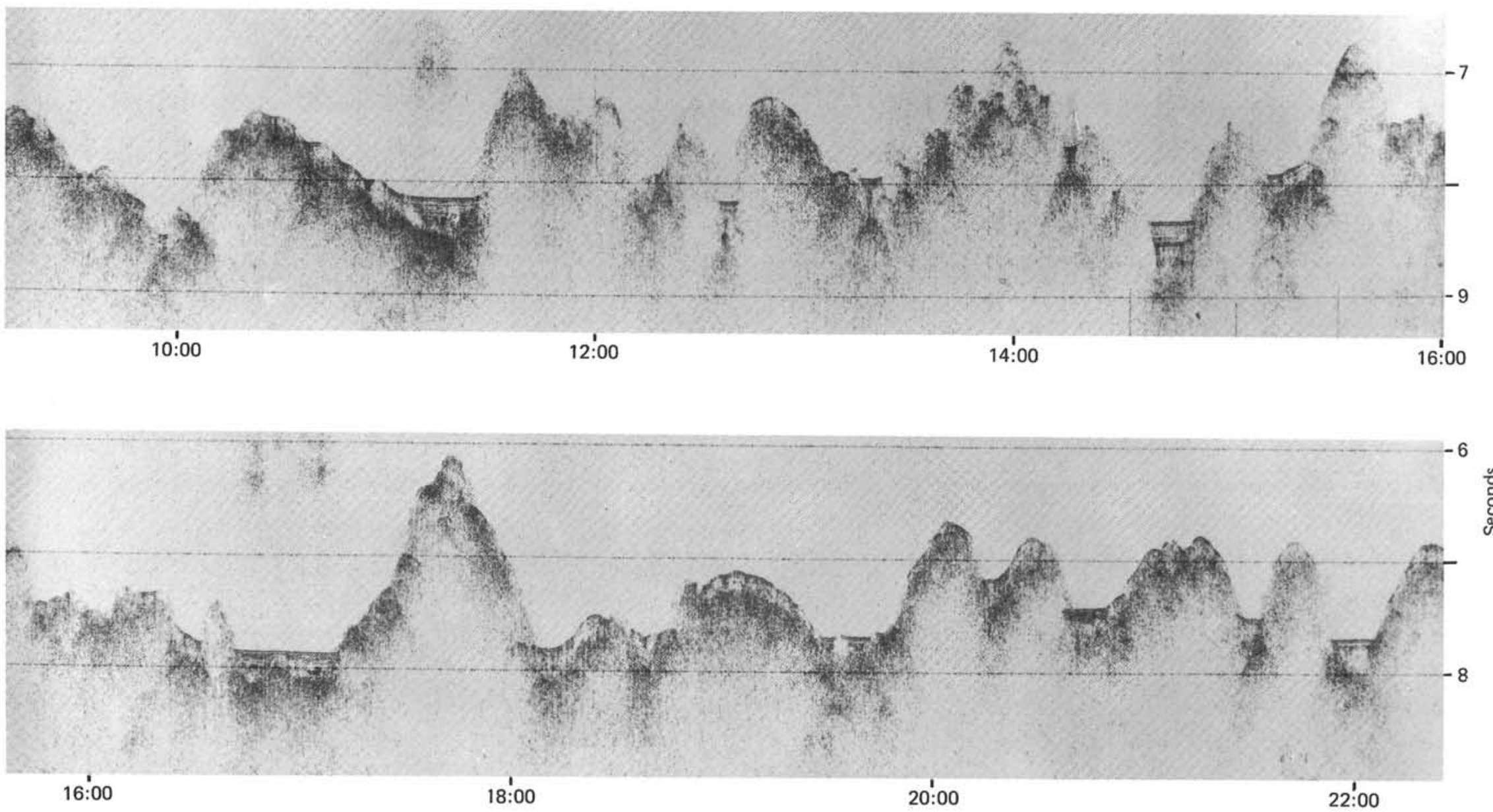

Figure 9. (Continued). 

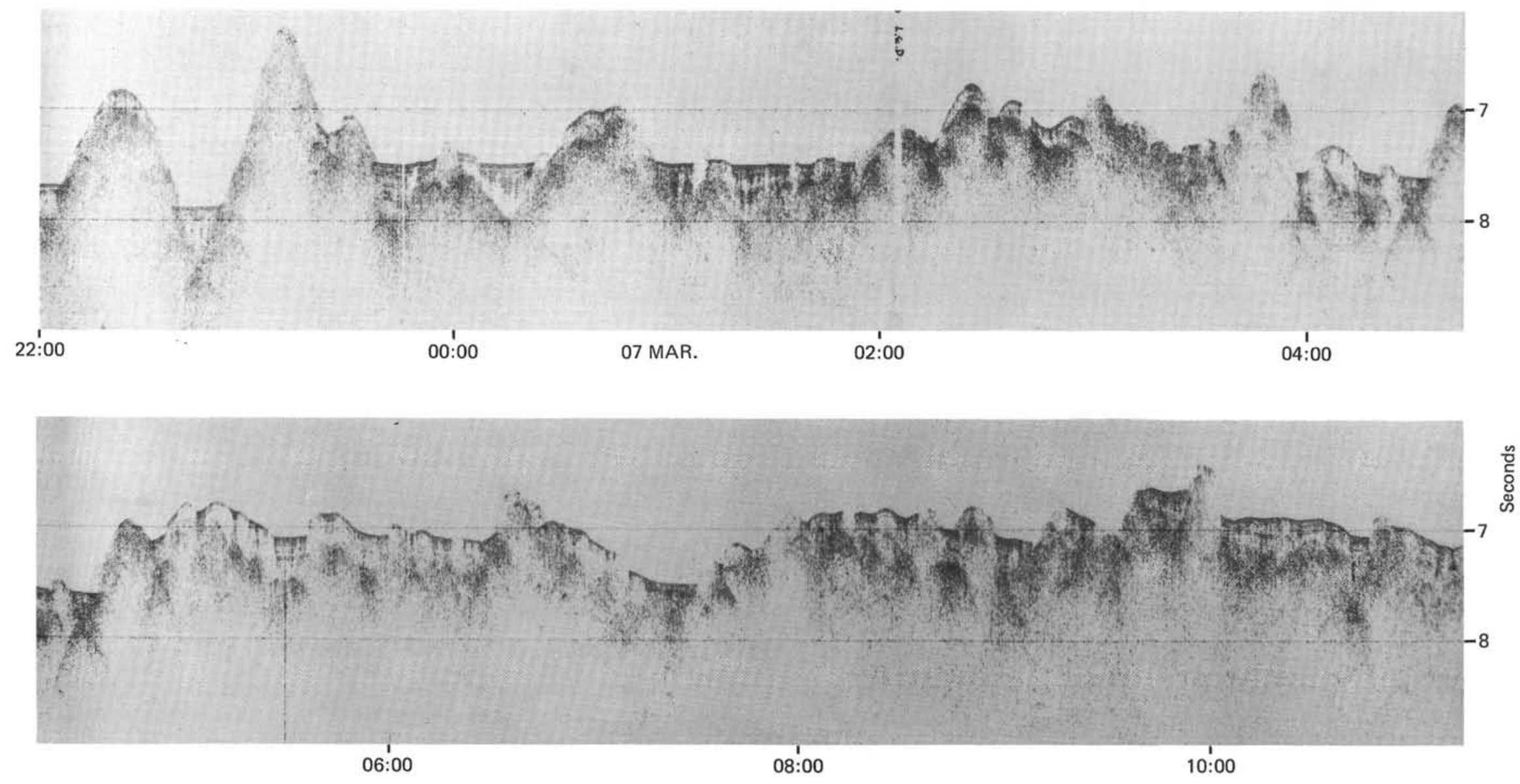

Figure 9. (Continued). 

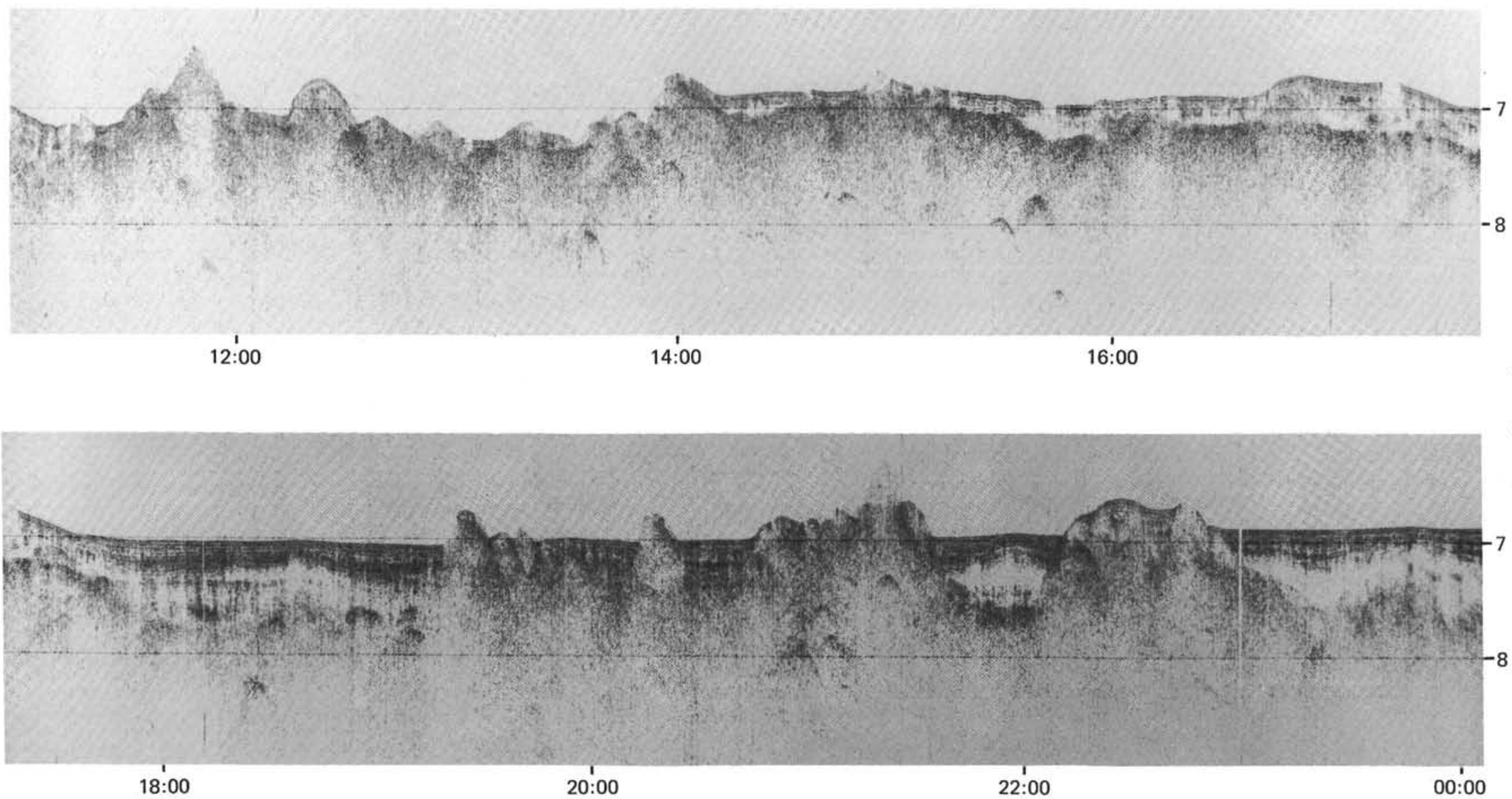

Figure 9. (Continued). 

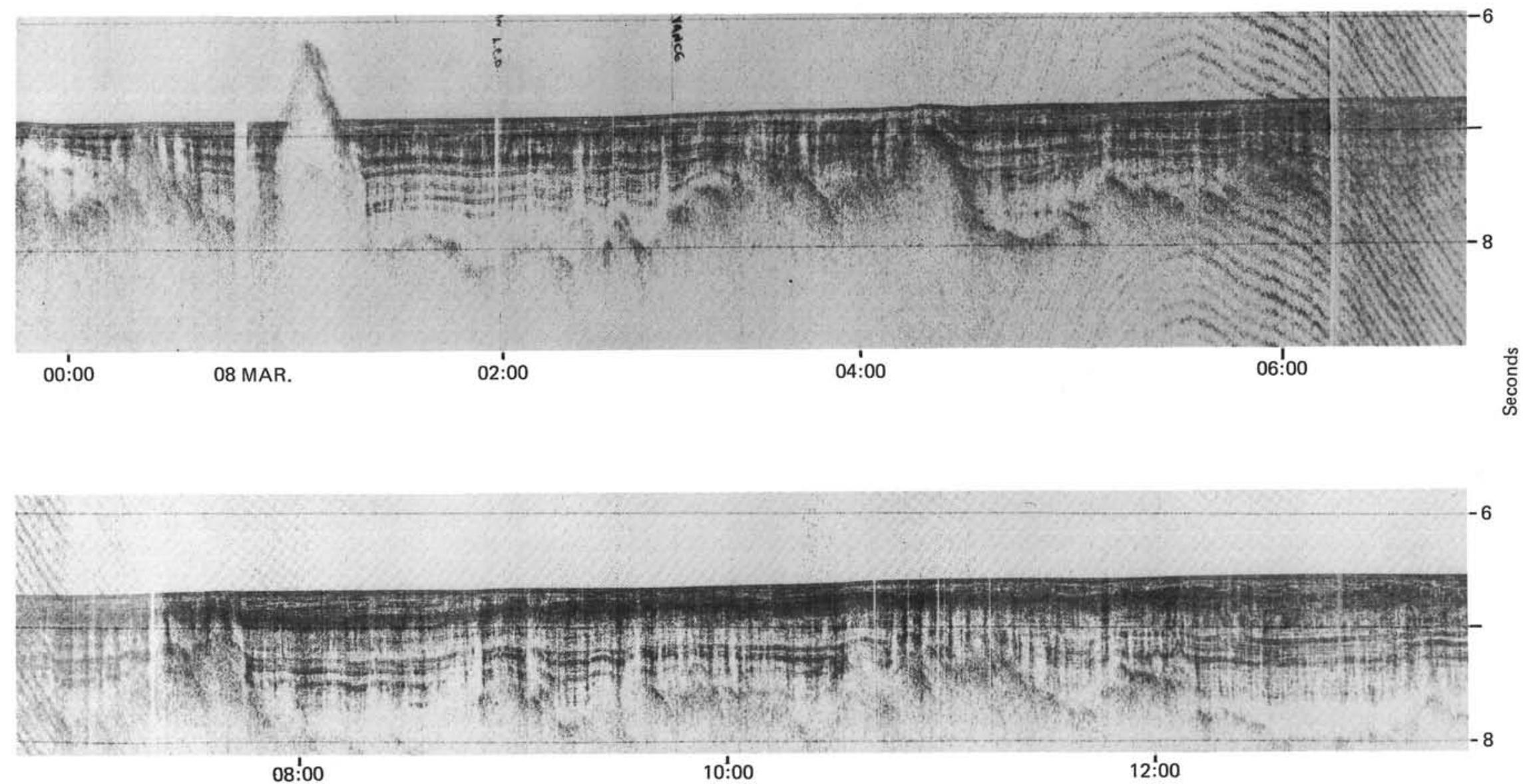

Figure 9. (Continued). 

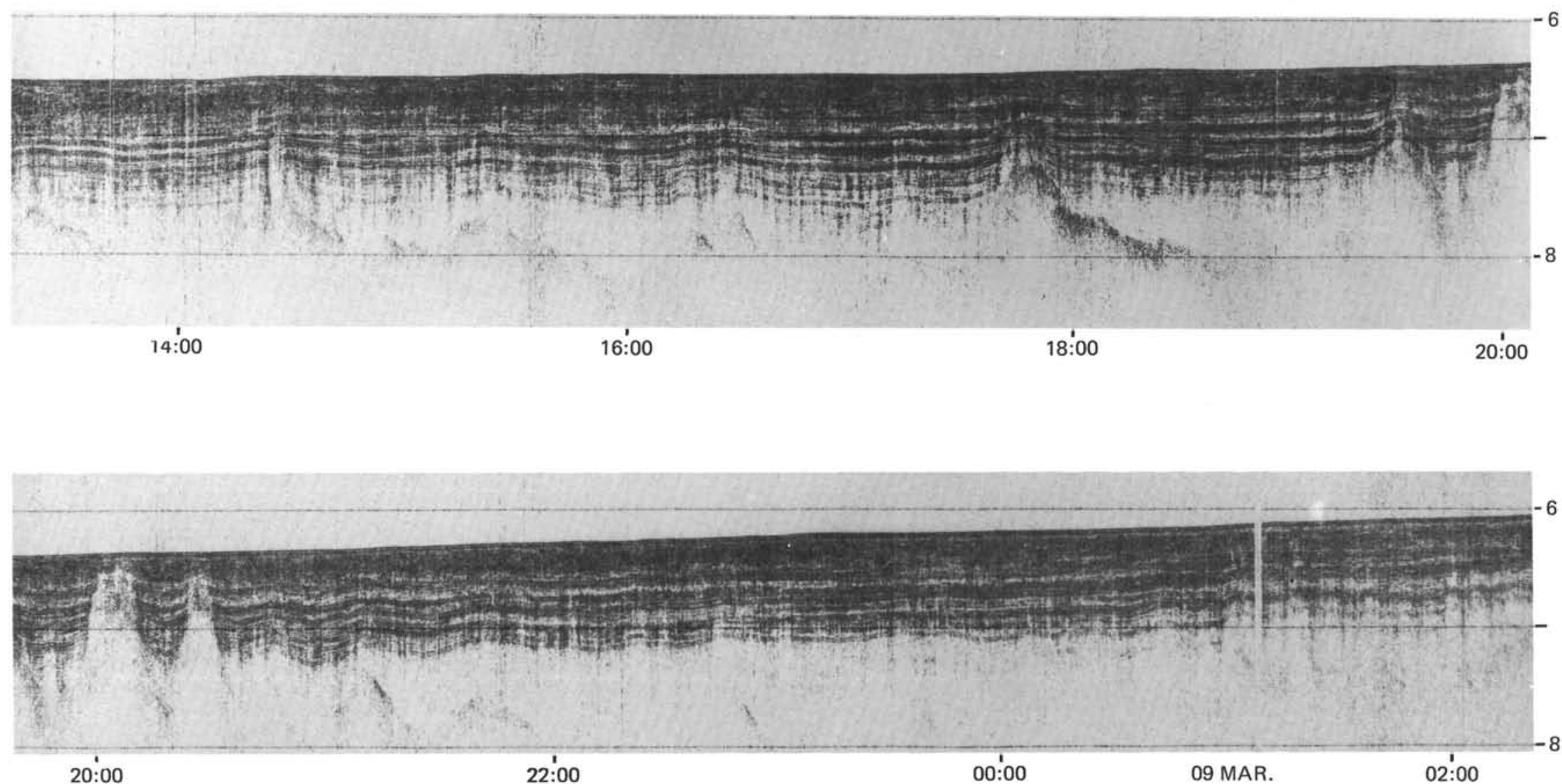

Figure 9. (Continued). 

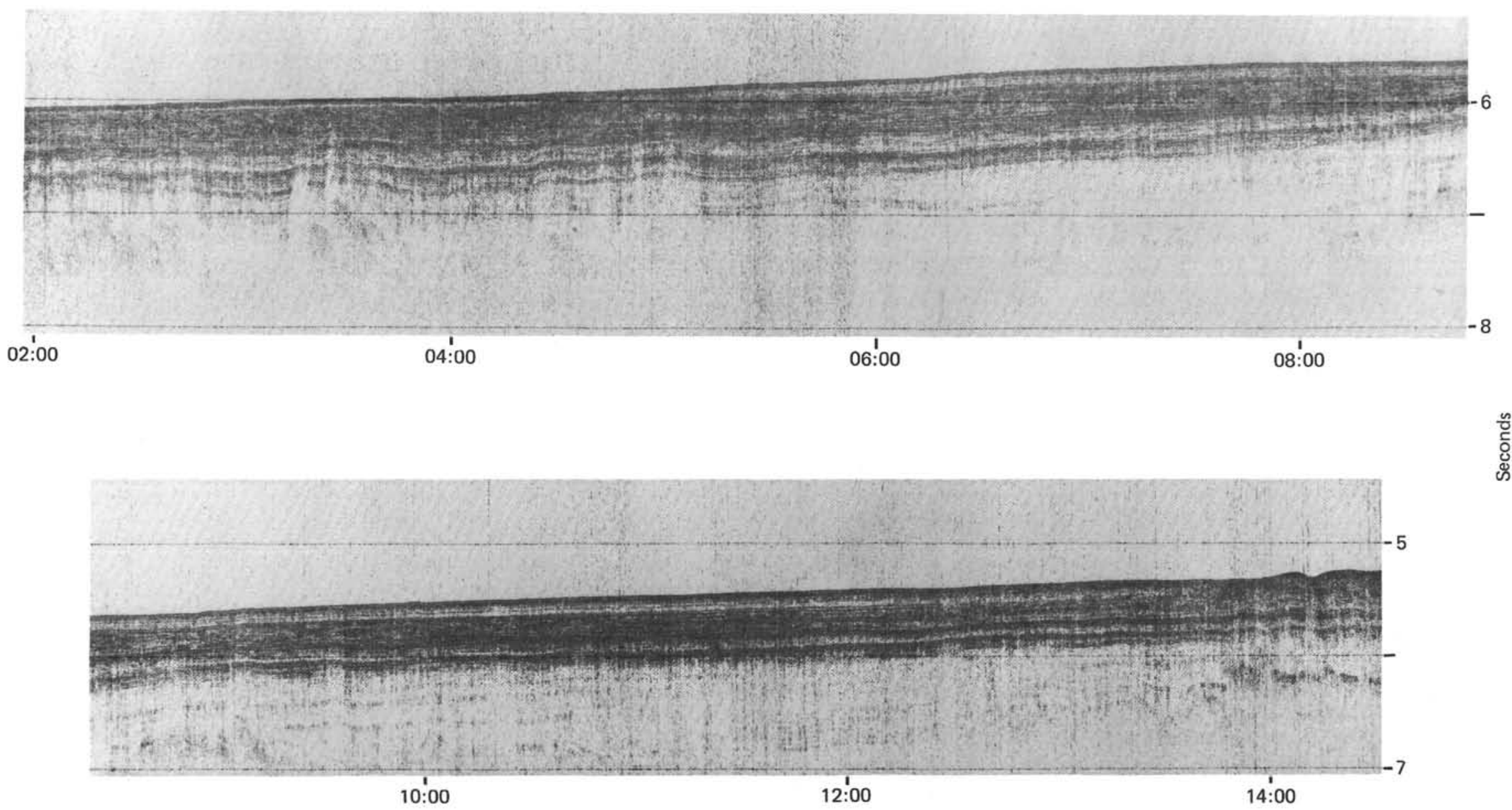

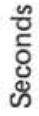

Figure 9. (Continued). 

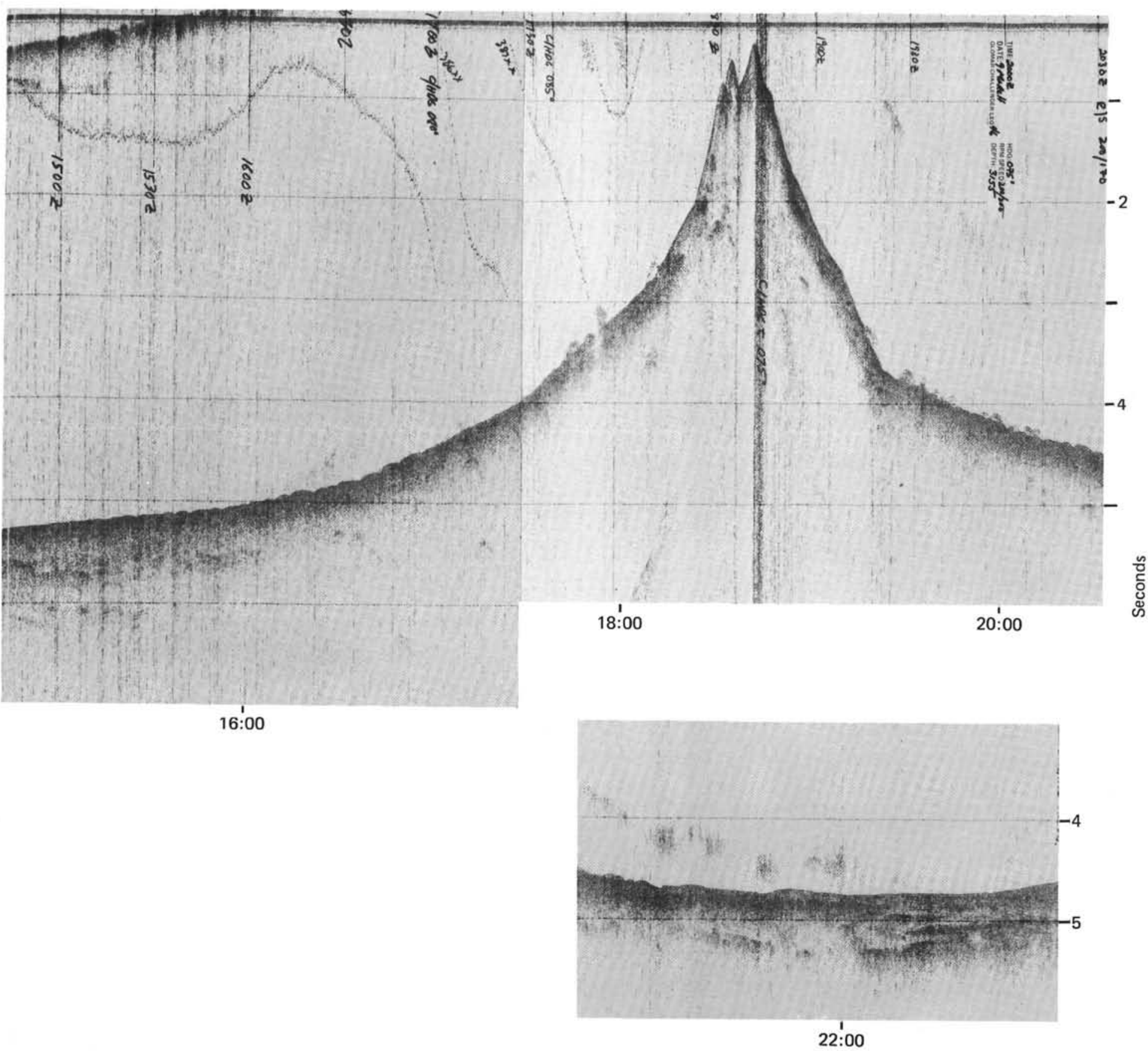